\title{
SEX DIFFERENCES IN COLLATERAL REMODELING FOLLOWING HINDLIMB ARTERIAL OCCLUSION
}

\author{
A Thesis \\ presented to \\ the Faculty of California Polytechnic State University, \\ San Luis Obispo
}

\author{
In Partial Fulfillment \\ of the Requirements for the Degree \\ Master of Science in Biomedical Engineering
}

by

Laura Lenae Burckhardt

December 2017 
(C) 2017

Laura Lenae Burckhardt

ALL RIGHTS RESERVED 
COMMITTEE MEMBERSHIP

TITLE:

Sex Differences in Collateral Remodeling Following Hindlimb Arterial Occlusion

AUTHOR: $\quad$ Laura Burckhardt

DATE SUBMITTED: December 2017

COMMITTEE CHAIR: $\quad$ Trevor Cardinal, Ph.D.

Professor of Biomedical Engineering

COMMITTEE MEMBER: Lily Laiho, Ph.D.

Professor of Biomedical Engineering

COMMITTEE MEMBER: Kristen O'Halloran Cardinal, Ph.D.

Professor of Biomedical Engineering 


\begin{abstract}
Sex Differences in Collateral Remodeling Following Hindlimb Arterial Occlusion

Laura Lenae Burckhardt
\end{abstract}

Clinical evidence indicates a higher incidence of peripheral arterial occlusive disease and associated likelihood of critical limb ischemia in women, as well as worse prognosis and decreased survival post myocardial infarction. Therefore, understanding the possible differences in underlying vascular compensation mechanisms is crucial. With arterial occlusions, necrosis and tissue injury can be naturally mitigated by the collateral circulation, improving patient prognosis. Previous sex-comparison studies describing differences in vascular remodeling are inconsistent. Therefore, the aim of this study was to describe the effect of arterial occlusion on collateral remodeling in healthy male and healthy reproductive-stage female mice. At 7 days following femoral artery ligation in $\mathrm{C} 57 \mathrm{Bl} / 6$ and $\mathrm{BALB} / \mathrm{c}$ mice, there were no sex-related differences in functional ambulatory recovery. There were no sex-related differences in mechanoadaptation indicators in the collateral stem- vascular smooth muscle cell (VSMC) length and overlap, with the exception of longer smooth muscle cells in male C57B1/6 mice, VSMC lengths $329 \pm 19$ verses $288 \pm 13 \mu \mathrm{m}$, male and female. Collateral midzone luminal and abluminal diameters, as well as wall thicknesses were not different between sexes. As comprehensive sex-specific differences were not captured in our specific investigation of arteriogenesis, an evaluation of microvascular remodeling in the ischemic zone and collateral vasodilation would be of interest, as would evaluating arteriogenesis following oophorectomy with estrogen depletion. The determination of any underlying mechanistic sex-specific differences could be the foundation for which targeted therapeutics are developed, which will be crucial for closing the prognosis gap between men and women in the global treatment of peripheral arterial occlusive disease.

Keywords: arteriogenesis, mechanoadaptation, collateral circulation, hindlimb, mouse 


\section{ACKNOWLEDGMENTS}

I would first like to thank Dr. Cardinal for his time and care in helping me to develop as a researcher and an individual. You have trusted me and positively pushed me while caring for my emotional wellbeing, and for that I am very thankful.

Secondly, this could not have been done without the MaVR lab, both present and past members. This is a unique and special club to belong to, and I am thankful for the past members who mentored me, answered my questions even though they were no longer at Cal Poly, or even assisted in furthering my professional career. Thank you to the members who made long days and nights in the research lab much more fun.

Finally, thank you to my family for their love and care. You have worked hard to give me every possible opportunity, and any current successes are because you invested in and helped to shape me, both intellectually and emotionally. Love you always.

"If I have seen further, it is by standing on the shoulders of giants."

-Sir Isaac Newton 


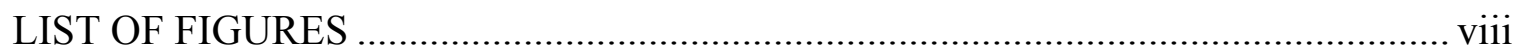

\section{CHAPTER}

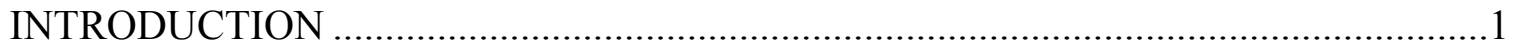

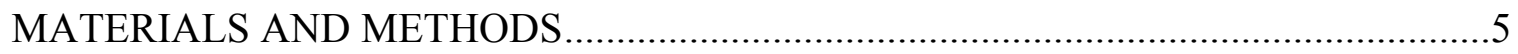

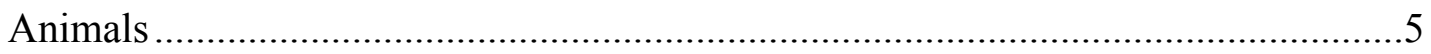

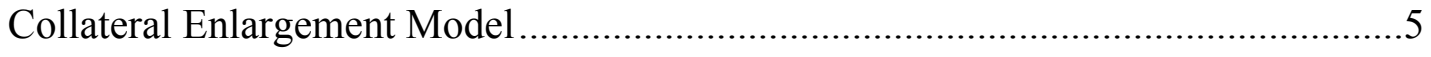

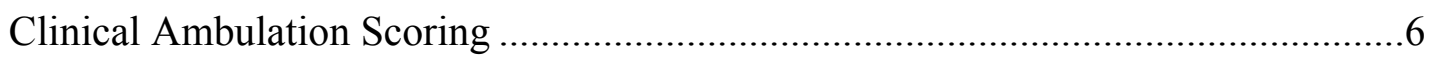

Perfusion Fixation and Microfil Infusion ...................................................

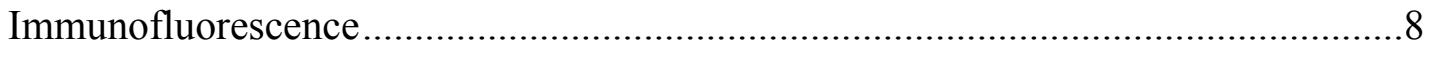

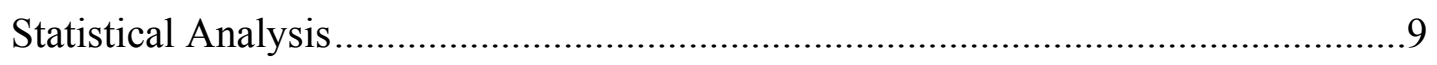

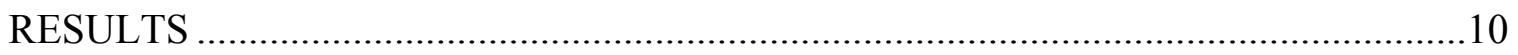

Functional Impairment Following Femoral Artery Ligation ................................10

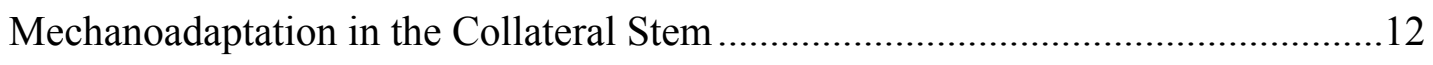

Anterior Gracilis Collateral Remodeling Post-Femoral Artery Ligation ..................14

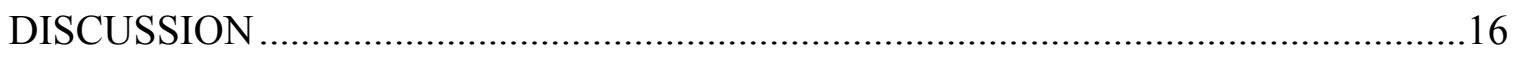

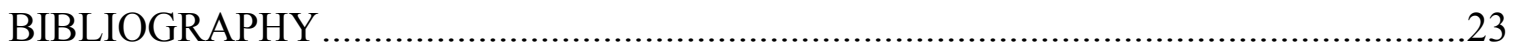

\section{APPENDICES}

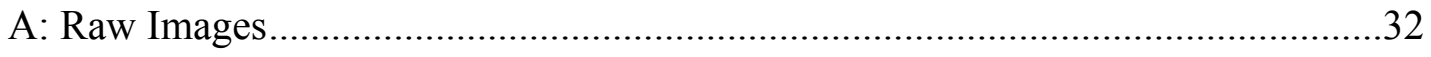

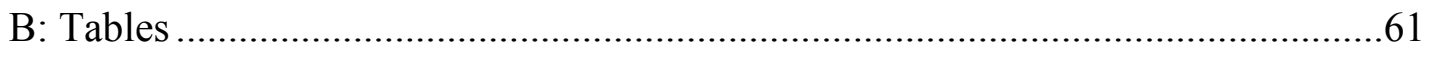




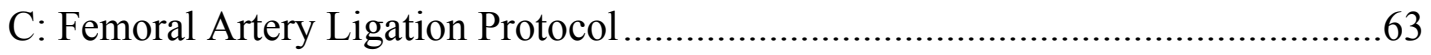

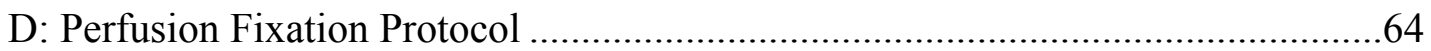

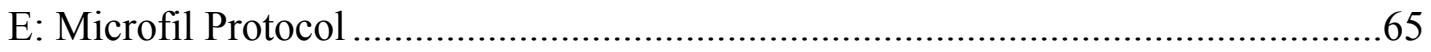

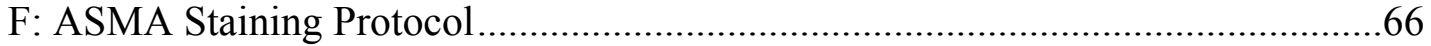

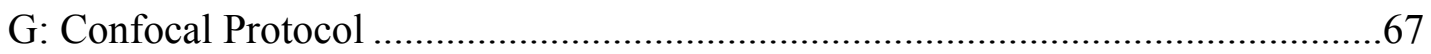

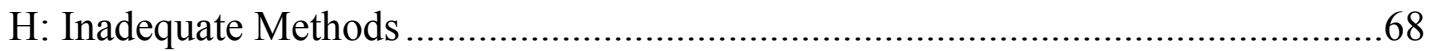

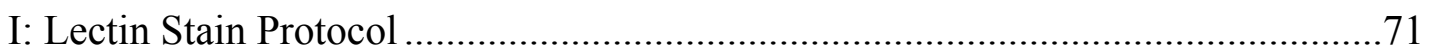




\section{LIST OF FIGURES}

Figure 1. Arteriogenesis....................................................

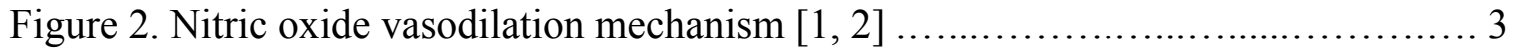

Figure 3. Perfusion fixation and Microfil injection methods..........................

Figure 4. Hindlimb ambulation scoring following femoral artery ligation in BALB/c and $\mathrm{C} 57 \mathrm{Bl} / 6$ mice............................................... 11

Figure 5. Indicators of mechanoadaptation in $\mathrm{BALB} / \mathrm{c}$ and $\mathrm{C} 57 \mathrm{~B} 1 / 6$ mice.............. 13

Figure 6. Anterior gracilis collateral remodeling in $\mathrm{C} 57 \mathrm{Bl} / 6$ and $\mathrm{BALB} / \mathrm{c}$ mice following femoral artery ligation......................................... 15 


\section{INTRODUCTION}

Peripheral arterial occlusive disease (PAOD), an atherosclerotic narrowing of the arteries distal to the aortic bifurcation, affects an estimated 10 percent of the global population, including 27 million patients in the United States and Europe [4-7]. Critical limb ischemia (CLI), the most severe manifestation of PAOD, has 500 to 1000 new cases diagnosed yearly per million of the population, with an estimated annual cost of 40-66 billion dollars [8]. CLI can lead to amputation or death without proper treatment, with four-year survival rates as low as 40 percent [9]. Recent clinical evidence suggests a higher incidence of PAOD in females, and an associated higher likelihood of critical limb ischemia [10-15]. Women are also less likely to survive, and exhibit worse prognosis following a myocardial infarction (MI) [16, 17]. Within women, ovariectomy before age 35 increases the risk of a nonfatal MI by 7.2 times that of premenopausal women [18]. In patients with severe coronary artery lesions, the male sex was associated with increased collateralization [19], therefore, these differences in outcomes could be due to underlying molecular and cellular sex-related differences in vascular compensation methods [20, 21].

With arterial occlusions, necrosis and tissue injury can be naturally mitigated by the collateral circulation, improving patient prognosis [22-24]. When a hemodynamicallyrelevant stenosis occurs in a main feeding artery, blood is redirected to downstream tissues through the collateral vessel(s), which connects the high-pressure region upstream of the stenosis to the low-pressure region downstream. The increased blood velocity and shear stress through the collaterals initiates outward remodeling through arteriogenesis, 
allowing the collateral to improve patient prognosis by maintaining tissue perfusion $[3$, $25]$.

During this outward remodeling, vessel caliber increases in a process involving monocyte extravasation and transformation into cytokine-, growth factor-, and enzyme-secreting macrophages. Specific secreted agents, such as vascular endothelial growth factor A (VEGF-A) and fibroblast growth factor 2 (FGF-2), promote proliferation of endothelial

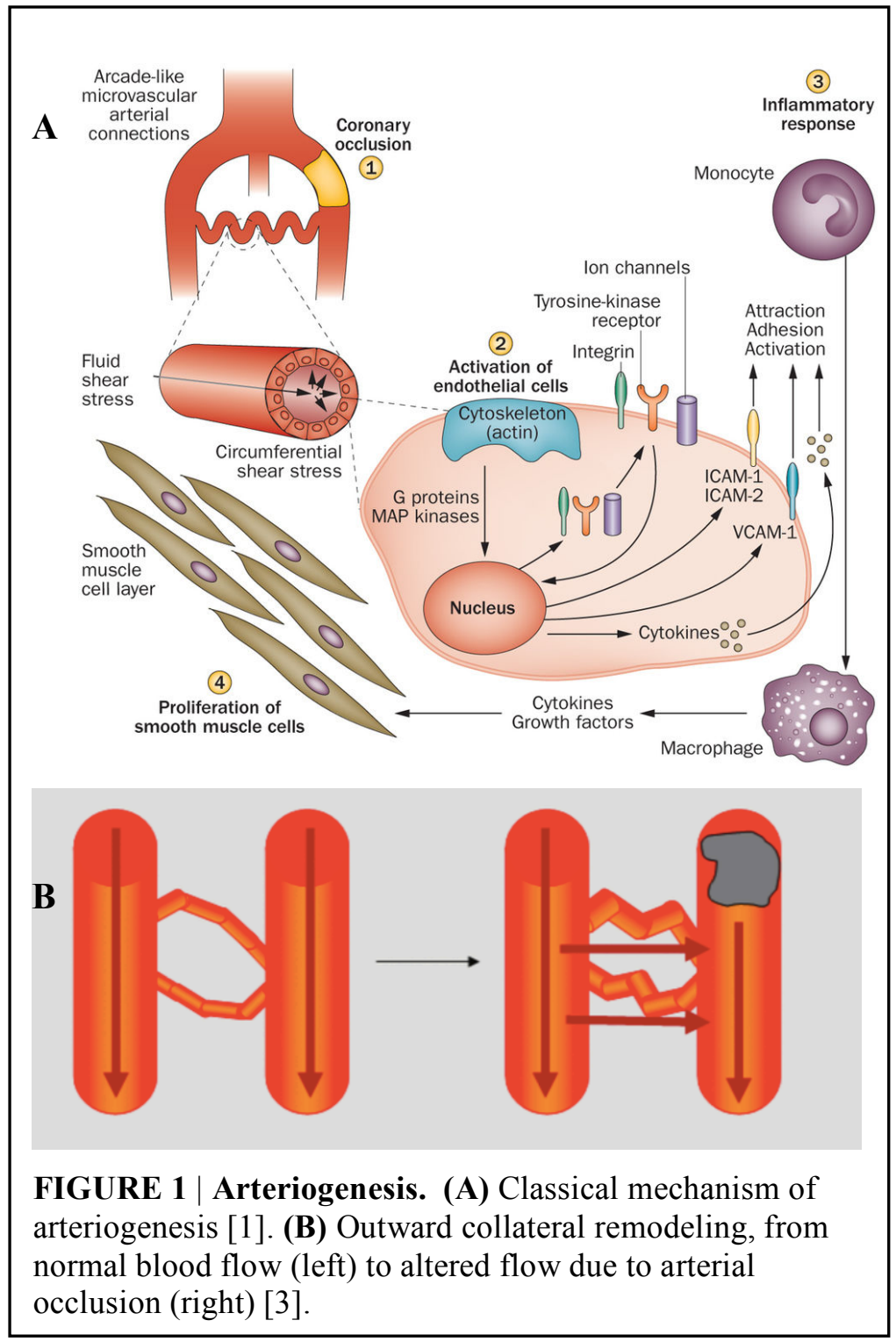

and vascular smooth muscle cells (VSMCs) in classical arteriogenesis, Figure 1 [2632]. Although outward remodeling usually involves VSMC proliferation, inward remodeling can involve both VSMC apoptosis [33-37] and changes in VSMC length, increasing cellular overlap through a process described as mechanoadaptation [38]. As inward remodeling involves a continuum from changes in apoptosis to VSMC 
morphology, outward remodeling may also involve a continuum from proliferation to changes in VSMC morphology.

In addition to VSMC proliferation, outward remodeling also requires a transient inflammatory response, moderate oxidative stress, and activation of the nitric oxide (NO) pathway, Figure 2, with all three processes partially modulated by estrogens [39-42]. Estradiol levels in men and postmenopausal women are lower than levels in non-

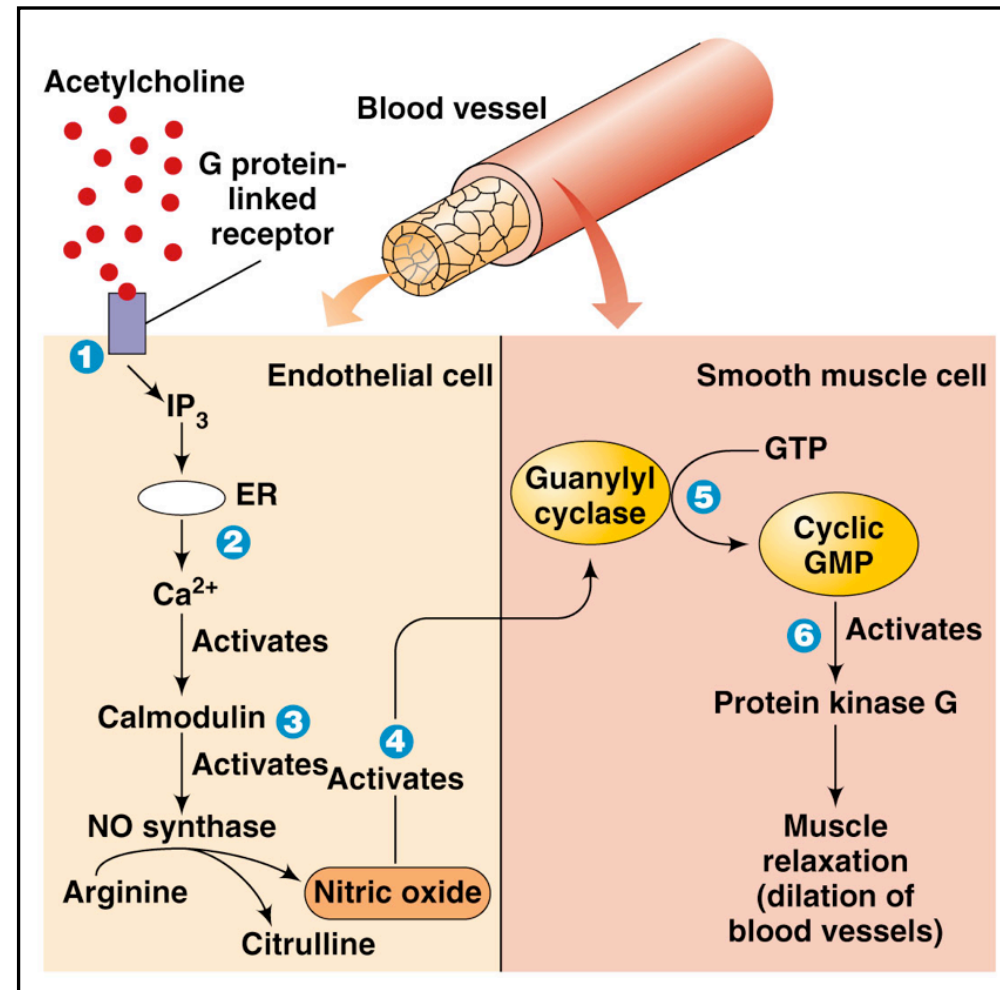

FIGURE 2 | Nitric oxide vasodilation mechanism [1, 2]. pregnant women, possibly explaining the differences in outward remodeling [43-45]. 17$\beta$-estradiol increases the endothelial production of nitric oxide and flow-mediated outward remodeling following oophorectomy is rescued by $17-\beta$-estradiol $[42,46]$. Oophorectomy also increases blood pressure and decreases vessel densities in rabbits, indicators of angiogenesis and arteriogenesis [47].

However, sex comparison of arteriogenesis without female estrogen depletion is of value due to female hormonal cycle variation in the general population, as well as the presence of PAOD in females prior to the average age of natural menopause [11, 43, 48, 49]. Following femoral excision, similar blood pressure and vessel densities were observed in 
male and non-oophorectomized female rabbits, although collateral number was not examined [47]. Furthermore, female mice without oophorectomy exhibit higher hindlimb vascular resistance, less responsiveness to vasodilators, and more sensitivity to vasoconstrictors following arterial occlusion [50].

The inconsistency in female flow-recovery impairment following femoral artery occlusion or excision within a small body of literature necessitates further study [21, 47, 50]. Increased vascular resistance in female mice is suggestive of impaired collateral enlargement, therefore we evaluated the extent and mechanisms of collateral enlargement throughout the gracilis collateral circuit in male and female mice. The aim of this study was test the hypothesis that healthy male mice exhibit superior collateral remodeling to healthy reproductive-stage female mice following femoral artery ligation. This was performed by evaluating daily hindlimb use, mechanoadaptation in the gracilis collateral stem, and collateral enlargement in the gracilis collateral midzone. 


\section{MATERIALS AND METHODS}

\section{Animals}

All experimental procedures were performed according to the protocols approved by the Institutional Animal Care and Use Committee (IACUC) of California Polytechnic State University. Female and male eight-week old $\mathrm{C} 57 \mathrm{Bl} / 6$ and $\mathrm{BALB} / \mathrm{c}$ mice were obtained from Taconic Farms, Jackson Laboratories, or Charles River Laboratories. Eight female and eight male $\mathrm{C} 57 \mathrm{~B} 1 / 6$, and six female and six male $\mathrm{BALB} / \mathrm{c}$ mice were used for the mechanoadaptation and collateral remodeling studies. All mice were maintained on a 12:12 hour light:dark cycle in a temperature controlled room in the University Vivarium. Mice were housed by sex with littermates in micro-isolator cages, supplied with feed, water, and enrichment ('houses', nesting material, and tubes), and inspected daily.

\section{Collateral Enlargement Model}

Collateral enlargement was induced in the superficial gracilis collaterals by ligating the femoral artery between the profunda femoris and popliteal branches of the left hindlimb, as described previously [51]. Briefly, mice were anesthetized using 1-3\% isoflourane gas at an oxygen flow rate of $0.8-1.21 \cdot \mathrm{min}^{-1}$, administered through a 'nose-cone', and given pre-operative analgesic (buprenorphine, $0.075 \mathrm{mg} \cdot \mathrm{kg}^{-1}$ subcutaneous). Hair on the medial hindlimb was depilated and the surgical area was disinfected with chlorohexidine diacetate. Mice were placed supine on a heated surgical stage, adjusted to maintain a core body temperature of $35^{\circ} \mathrm{C}$. Ophthalmic ointment was applied to the eyes to avoid corneal desiccation. 
A small skin incision $(1-2 \mathrm{~cm})$ was made on the middle, medial aspect of the left thigh, with subcutaneous connective tissue blunt dissected to maximize surgical exposure. Throughout the procedure, the incision site was irrigated with sterile phosphate buffered saline (PBS) to prevent tissue desiccation. To expose the ligation site, the epigastric fat pad was reflected medially, and the femoral artery was blunt dissected from the neurovascular bundle before ligation with 6.0 silk suture distal to the epigastric branch and proximal to the popliteal branch [51]. The skin was closed using 7.0 polypropylene suture. For control, the surgical procedure outlined above was performed on the contralateral hindlimb, with the exception of ligating the femoral artery. Animals were given post-operative buprenorphine $\left(0.075 \mathrm{mg} \cdot \mathrm{kg}^{-1}\right)$, and supplied with buprenorphine water $\left(0.01 \mathrm{mg} \cdot \mathrm{ml}^{-1}\right)$ for approximately 2-3 days.

\section{Clinical Ambulation Scoring}

Following surgery, animals were observed daily for ambulation, and scored from 0-3 based on hindpaw range of motion, as described previously [52]. A dragging hindpaw was scored as a 3, no plantar flexion and constant dorsiflexion a 2, some plantar flexion a 1, and normal use a 0 . Animals were monitored until normal ambulation was observed on two consecutive days, or until day-7 post ligation.

\section{Perfusion Fixation and Microfil Infusion}

In preparation for vascular casting and immunofluorescence, mice were perfusion fixed with paraformaldehyde. Through a thoracotomy, an incision was made in the apex of the heart into the left ventricle, and a catheter was inserted and secured with a vascular 
clamp, Figure 3A. A cycle of $40 \mathrm{ml}$ vasodilator cocktail heated to $37^{\circ} \mathrm{C}\left(5 \mathrm{U} \cdot \mu \mathrm{L}^{-1}\right.$ heparin, $10^{-3} \mathrm{M}$ sodium nitroprusside, $10^{-4} \mathrm{M}$ adenosine, in PBS), followed by $5 \mathrm{ml} 4 \%$ paraformaldehyde (PFA), was injected through the catheter with a syringe pump (5 $\mathrm{ml} \cdot \mathrm{min}^{-1}$ ), Figure 3B. Following fixation, microfil agents were combined, and $1 \mathrm{ml}$ was injected $\left(0.5 \mathrm{ml} \cdot \mathrm{min}^{-1}\right)$. Once the Microfil perfused distal to the knee, both ankles were ligated with silk suture to prevent entry into venous circulation through ankle A-V shunts, Figure 3C. Microfil infusion continued until the casting agent reached the anterior gracilis collateral (approximately $3 \mathrm{ml}$ of additional solution). Post infusion, the exposed tissue was covered with plastic wrap and Microfil polymer cured overnight at room temperature. The anterior gracilis muscle and profunda femoris artery were resected and post fixed in 4\% PFA for approximately 24 hours before rinsing and storing in PBS at 4 ${ }^{\circ} \mathrm{C}$.

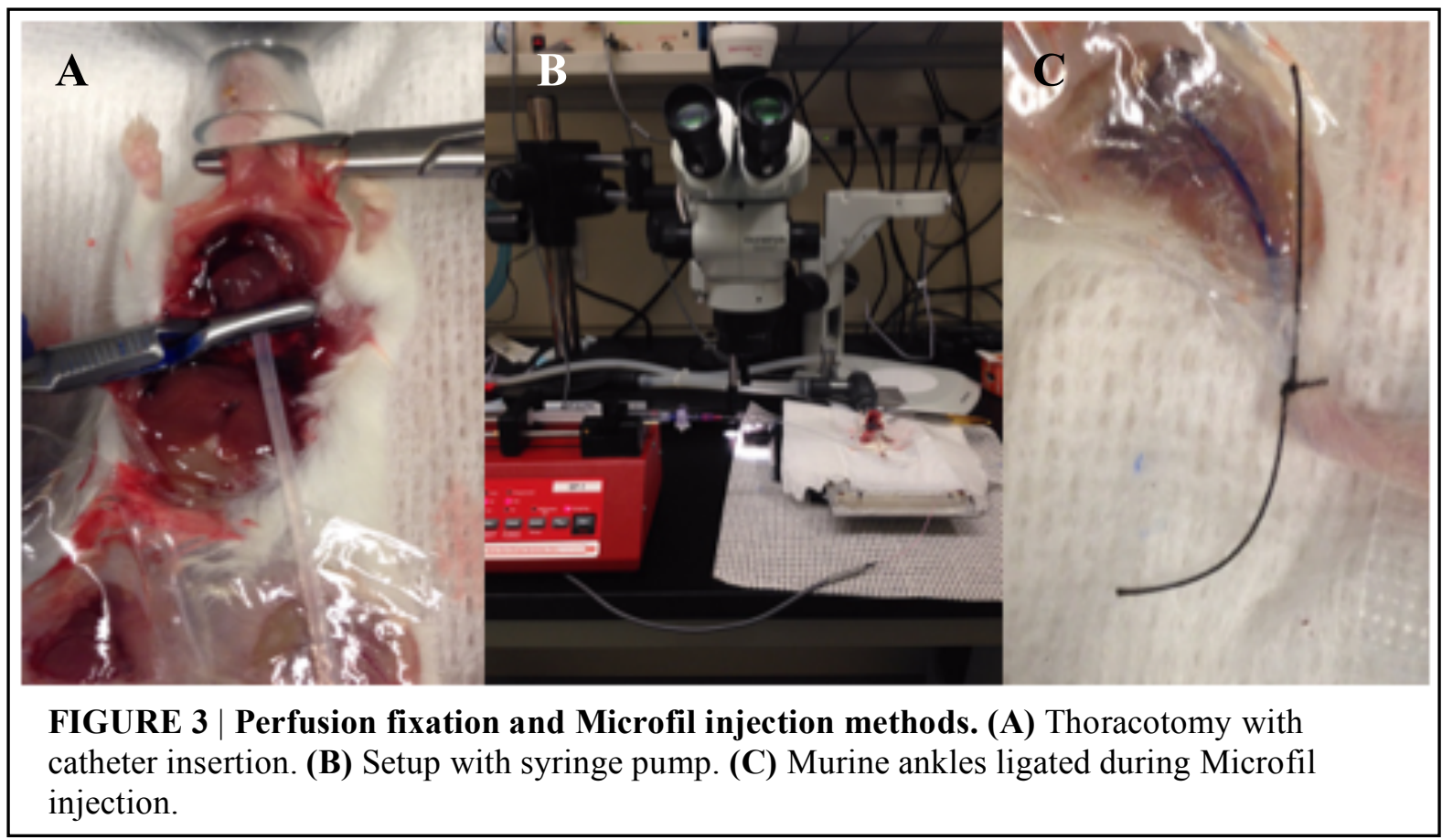




\section{Immunofluorescence}

Immunofluorescence was used to determine collateral vessel diameters and smooth muscle cell mechanoadaptation. Whole gracilis anterior muscles were stained with $\alpha$ smooth muscle actin (Sigma Aldrich Anti-Actin $\alpha$-Smooth Muscle Cy $3^{\mathrm{TM}}$ Antibody, C6198) in a solution with $0.1 \%$ saponin and $2 \%$ BSA in PBS for 3 days at $4^{\circ} \mathrm{C}$. After staining, muscles were washed in $0.1 \%$ saponin in PBS $3 \mathrm{x}$ for 20 minutes at room temperature, and PBS for 30 minutes. The samples were mounted onto depression slides with 50:50 PBS:glycerol to clear.

The midzone of the anterior gracilis collateral was captured with widefield fluorescence microscopy ( $\alpha$-smooth muscle actin) and widefield microscopy (Microfil cast). All anterior gracilis collateral inner and outer diameters were measured at the collateral midzone in three locations using ImageJ.

Confocal microscopy was used to visualize smooth muscle cells around each artery to assess smooth muscle cell overlap and length (mechanoadaptation indicators). Utilizing a 40x oil immersion objective, images of the collateral stem region of the profunda femoris artery were captured with Fluoview Viewer software (Olympus, FV10-ASW 4.1). Image stacks in the z-direction were captured with 1-micron slices for approximately half the diameter for each artery. To assess mechanoadaptation in the collateral stem, the z-stacks of the profunda femoris were merged into single, 3-D reconstructions, and smooth muscle cell overlap between the individual cells and smooth muscle cell length were measured using ImageJ software, as described previously $[38,53]$. Briefly, a $100 \mu \mathrm{m}$ length of 
artery was delineated from each 3D reconstruction, and average VSMC length for each vessel, $\mathrm{L}_{\mathrm{v}}$, was determined using Equation 1 below [38, 53]:'

$$
L_{v}=4 \pi R_{v} F\left(S_{w}+S_{t}\right) / T_{v}
$$

In equation $1, \mathrm{~L}_{\mathrm{v}}$ is the average VSMC length, $\mathrm{R}_{\mathrm{v}}$ the radius of the artery, $\mathrm{F}$ the fraction of vessel circumference in which measurements were made, $S_{w}$ the number of wrap cells, $S_{t}$ the length of all tapered cells divided by the length of one wrap cell, and $T_{v}$ the number of taper cells.

\section{Statistical Analysis}

Differences in daily ambulation scores were determined using a repeated measures analysis of variance (ANOVA). Differences in intersex or interstrain ambulation scores, collateral stem VSMC lengths and overlaps, collateral midzone inner and outer diameters, and collateral midzone wall thicknesses were determined using independent ttests. All values are expressed as mean \pm standard error of the mean. 


\section{RESULTS}

\section{Functional Impairment Following Femoral Artery Ligation}

Previous investigations of male-female differences in response to arterial occlusion suggested that deficits observed in female mice were likely attributable to reduced collateral remodeling or fewer collateral number [50]. However, because recovery from femoral artery resection involves both collateral enlargement in the thigh along with angiogenesis and capillary arterialization in the leg $[54,55]$, we sought to evaluate the impact of female sex in an arterial occlusion model that involves primarily collateral enlargement [56]. Surprisingly, there was no difference in hindlimb use between male and female $\mathrm{C} 57 \mathrm{Bl} / 6$, which was normalized by $3.9 \pm 0.4$ days for both, Figure 4 . If anything, C57B1/6 female mice may have recovered normal hindlimb use before the males, but this was only statistically different at the day-5 time point. Female C57Bl/6 mice were statistically different at days 1,2, and 5 from the rest of the days scored for that group, and male $\mathrm{C} 57 \mathrm{Bl} / 6$ were different at days 1 and 6 . Female BALB/c mice were different at days 4 and 6 from the rest of the days scored for that group, and male $\mathrm{BALB} / \mathrm{c}$ mice were different at days 4, 5, and 6 . As expected, BALB/c mice regained normal hindlimb function more slowly, but there was no difference between males and females, $5.8 \pm 0.2$ and $6.0 \pm 0$ days, respectively. As ambulation was only scored up to 6 days, these data suggest that $\mathrm{BALB} / \mathrm{c}$ mice hindlimb function did not return to normal use during the experiment.

Although no difference in hindlimb use suggests a similar degree of collateral enlargement between male and female mice, hindlimb use is a sufficiently coarse 
assessment that depends upon more than collateral flow. Therefore, we specifically

evaluated collateral remodeling between male and female mice following femoral artery ligation.

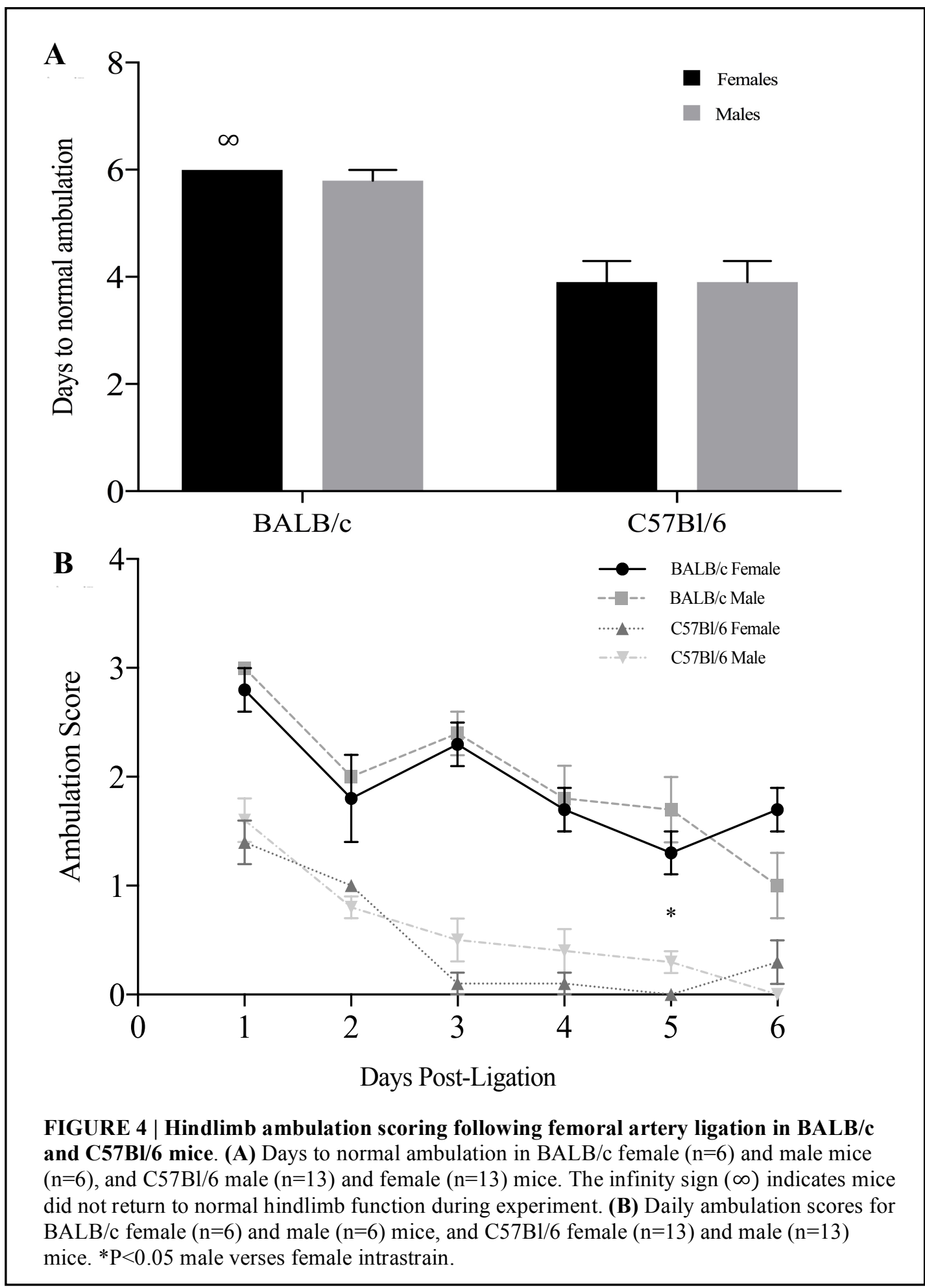




\section{Mechanoadaptation in the Collateral Stem}

Although the collateral stem enlarges following femoral artery ligation, the absence of smooth muscle cell proliferation suggests the enlargement is not due to typical arteriogenesis $[57,58]$. To test the hypothesis that enlargement in the collateral stem occurs via mechanoadaptation, change in vascular diameter by the modification of VSMC length and overlap, and to determine if female mice are deficient in this process, we assessed smooth muscle cell length and overlap utilizing confocal microscopy at day 7 in both sham-operated and ligated profunda femoris arteries in male and female $\mathrm{C} 57 \mathrm{Bl} / 6$ mice. Although the native anatomy of smooth muscle cells in the collateral stem of $\mathrm{C} 57 \mathrm{Bl} / 6$ male and female mice was not different, VSMCs were longer in males following remodeling, and VSMC lengths in both sexes were greater than the contralateral controls, Figure 5C. Consistent with mechanoadaptation, smooth muscle cell overlap decreased at day-7 post ligation in both sexes, but there was no difference between male and female mice Figure 5D.

As BALB/c mice have lower collateral density and decreased collateral remodeling when compared to $\mathrm{C} 57 \mathrm{Bl} / 6$ mice at day-21 following ligation, we examined enlargement in this model $[52,56]$. There was no difference in VSMC lengths of male and female collateral stems in BALB/c mice, and remodeling was consistent, with all VSMC lengths greater in both male and female mice following ligation than the contralateral controls.

Smooth muscle cell overlap decreased at day-7 post ligation in both male and female BALB/c mice, consistent with mechanoadaptation, Figure 5D. Despite the native anatomy of the BALB/c mice differing with VSMC overlap shorter in male than female mice in the non-ligated group, there was no difference in remodeled collateral stem 
VSMC overlaps between male and female BALB/c mice.

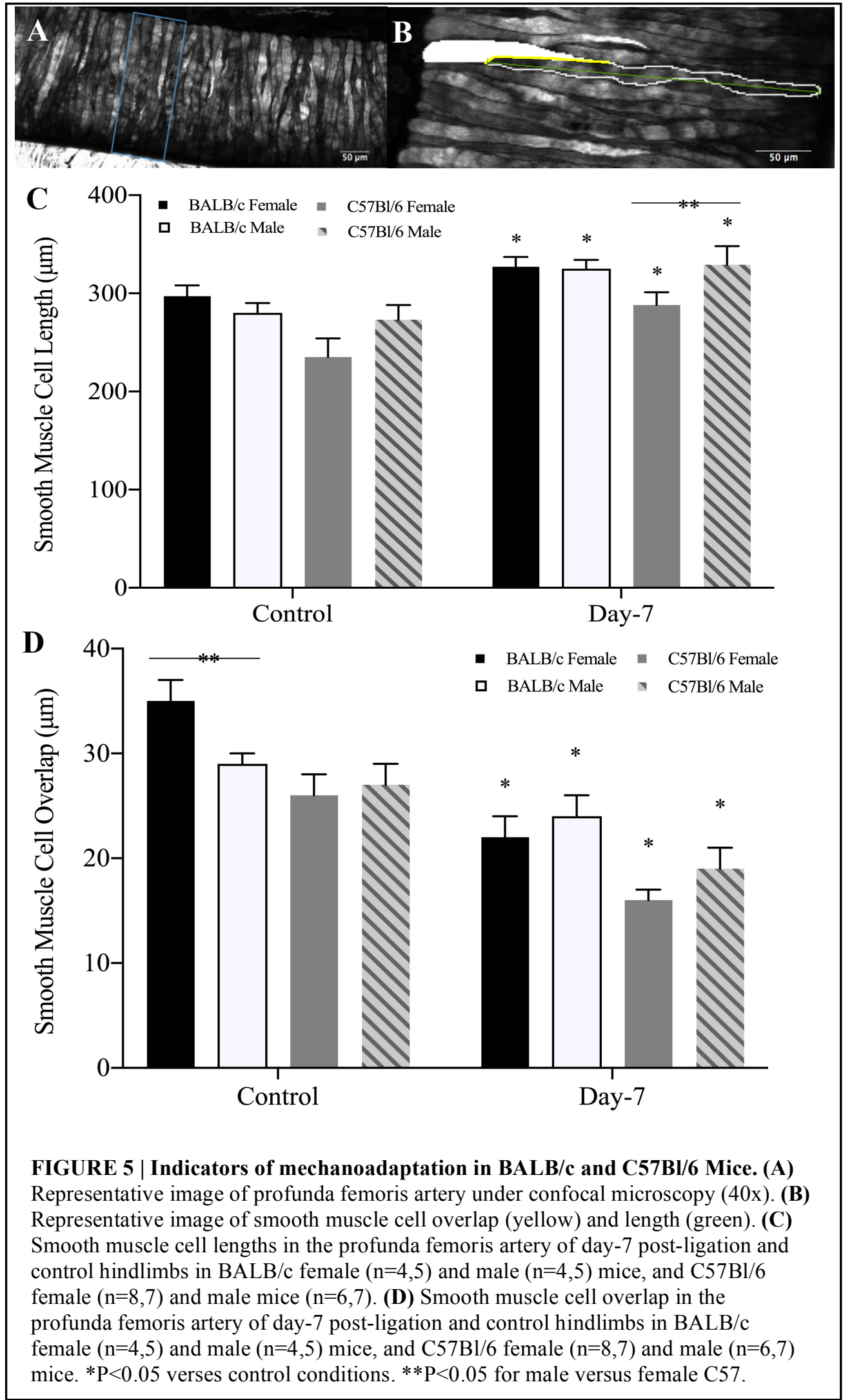




\section{Anterior Gracilis Collateral Remodeling Post-Femoral Artery Ligation}

Having compared the mechanoadaptation events between males and females, we next evaluated the arteriogenesis response in the collateral midzone within the anterior gracilis muscle [56]. To determine if female mice exhibit impaired arteriogenesis, we measured outward remodeling (based on luminal diameter) and measured abluminal diameter so that we could calculate wall thicknesses and identify any differences in the type of remodeling that occurred (i.e. hypertrophic, eutrophic, or hypotrophic), Figure 6, in male and female $\mathrm{C} 57 \mathrm{Bl} / 6$ and $\mathrm{BALB} / \mathrm{c}$ mice. As expected, robust outward remodeling occurred, as the luminal diameter was larger for all ligated gracilis collaterals compared to the respective contralateral control, for both male and female C57Bl/6 mice, Figure 6E. The abluminal diameter was also larger for both male and female C57B1/6 mice, and even larger than expected based on the increase in luminal diameter, suggesting a hypertrophic outward remodeling. Figure 6F. Indeed, measurements of wall thickness confirmed a hypertrophic outward remodeling, which was not different between male and female C57B1/6 mice. Figure 6G. There was no difference between male and female $\mathrm{C} 57 \mathrm{Bl} / 6$ mice for luminal diameter, abluminal diameter, or wall thickness in the remodeled collateral.

With no evidence of intersex differences in collateral midzone outward remodeling in $\mathrm{C} 57 \mathrm{Bl} / 6$ mice, we examined if there was an impairment in collateral remodeling for $\mathrm{BALB} / \mathrm{c}$ female mice. Like the $\mathrm{C} 57 \mathrm{Bl} / 6$ mice, the lumen was larger for all ligated gracilis collaterals compared to the respective contralateral control, within both males and females, Figure 6E. The abluminal diameter was also greater for both male and female 
mice, comparing the ligated gracilis collaterals to the contralateral control, Figure $6 \mathbf{F}$.

Both males and females exhibited larger wall thicknesses for the day-7 remodeled

collaterals compared to the contralateral control, Figure 6G. There was no difference

between male and female $\mathrm{BALB} / \mathrm{c}$ mice for luminal diameter, abluminal diameter, or

wall thickness in the remodeled or control collaterals.
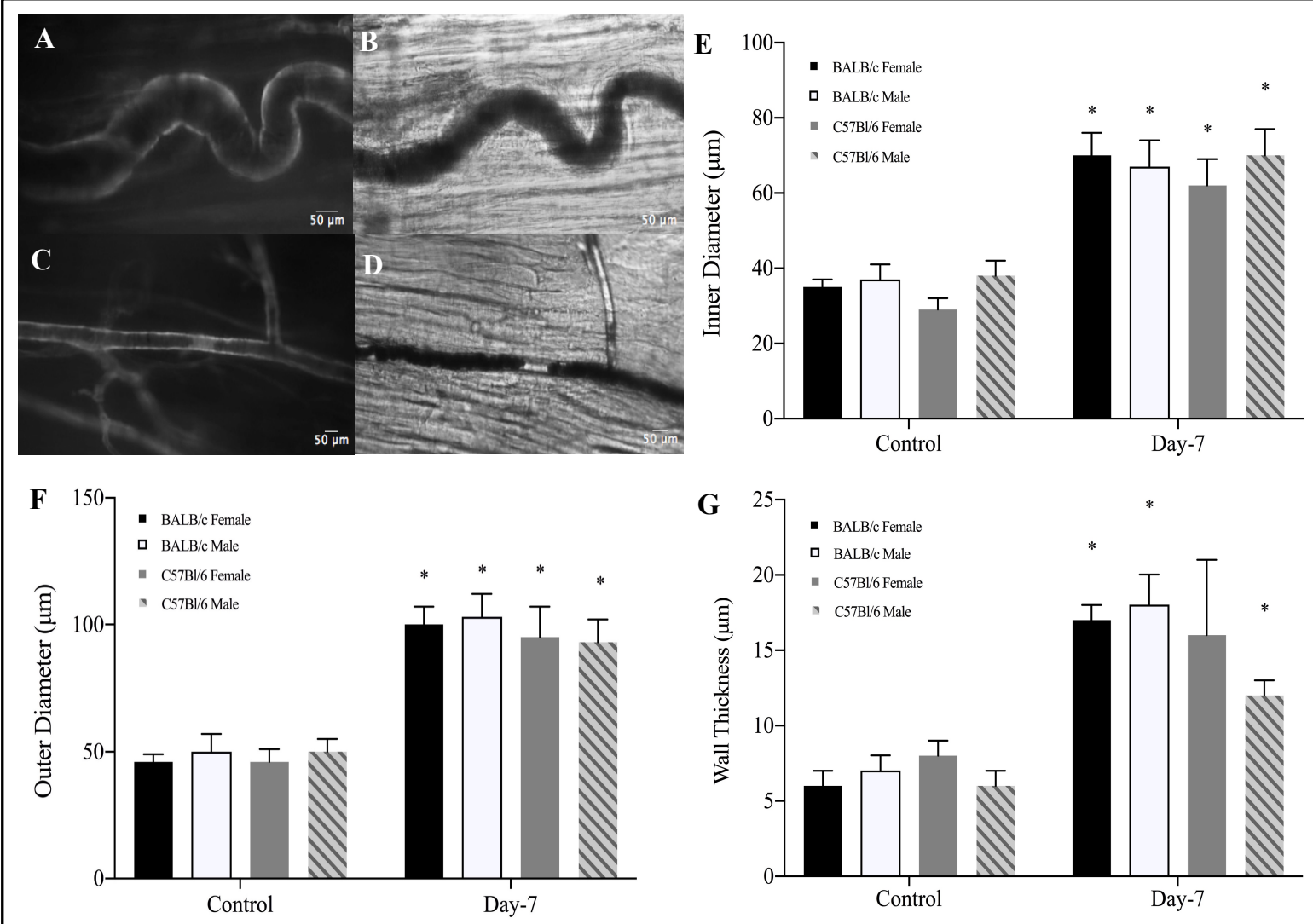

FIGURE 6 | Anterior gracilis collateral remodeling in C57BI/6 and BALB/c mice following femoral artery ligation. (A) Representative day-7 post ligation collateral abluminal diameter alpha-VSMC stained (10x). (B) Representative day-7 post ligation collateral luminal-diameter polymer perfused (10x). (C) Representative alpha-SMA control anterior gracilis collateral (10x). (D) Representative control collateral luminal-diameter polymer perfused (10x). (E) Luminal diameter of the anterior gracilis collateral of day-7 post-ligation and control hindlimbs in BALB/c female $(n=6,5)$ and male $(n=6,6)$ mice, and C57B1/6 female $(n=4,5)$ and male $(n=4,5)$ mice. $(\mathbf{F})$ Abluminal diameter of the anterior gracilis collateral of day-7 post-ligation and control hindlimbs in BALB/c female $(n=6,5)$ and male $(n=6,6)$ mice, and C57BL/6 female $(n=4,5)$ and male $(n=4,5)$ mice. (G) Wall thickness of the anterior gracilis collateral of day-7 post-ligation and control hindlimbs in BALB/c female $(n=6,5)$ and male $(n=6,6)$ mice, and C57B1/6 female $(n=4,5)$ and male $(\mathrm{n}=4,5)$ mice. ${ }^{*} \mathrm{P}<0.05$ male verses female control conditions. 


\section{DISCUSSION}

Contemporary clinical evidence indicates a higher incidence of PAOD and associated likelihood of critical limb ischemia in women [10-15, 59]. Women are also less likely to survive, and exhibit worse prognosis following myocardial infarction $[16,17]$. With these differences possibly due to discrepancies in vascular compensation, developing effective therapeutics necessitates understanding the mechanisms underlying these potential differences [20,21]. Previous work is inconsistent on the impact of female sex on flow recovery following arterial occlusion, but suggested an impairment in collateral growth $[21,47,50]$. Therefore, we described the effect of arterial occlusion on collateral remodeling in healthy male and healthy reproductive-stage female mice.

In functional ambulatory recovery evaluation, both male and female C57Bl/6 mice regained normal hindlimb function more quickly than BALB/c mice post-ligation, Figure 4. The inter-strain findings are consistent with previous observations that $\mathrm{BALB} / \mathrm{c}$ mice have greater hindlimb use impairment at days 3 and 7 when compared to $\mathrm{C} 57 \mathrm{Bl} / 6$ models [52]. Furthermore, BALB/c mice had greater myofiber atrophy, greater myocyte apoptosis, and attenuated myogenic regulatory gene expression and stress-response signaling following hindlimb ischemia, with evidence in functional impairment [60]. No difference existed in days to normal ambulation between male and female mice with normal estrous cycles in either strain.

In exploring the outward vascular remodeling mechanisms underlying the ambulatory recovery, it is known that the collateral stem outwardly remodels following an upstream 
occlusion in male mice [57]. Although the collateral stem enlarges, the lack of VSMC proliferation in this area suggests the enlargement was due to other processes [58, 61-63]. Repositioning of VSMCs due to an altered mechanical environment is established, as physical alignment and reorientation of isolated cultured VSMCs in a position perpendicular to the stretch vector occurs due to cyclic stretch, and arteriolar inward remodeling in response to norepinephrine and angiotensin [64-66]. As such, we tested the hypothesis that enlargement in the collateral stem occurs via VSMC mechanoadaptation, and that female mice are deficient in this process. Although all smooth muscle cell lengths increased relative to their contralateral control, surprisingly, the only sex difference in remodeling was longer VSMCs in $\mathrm{C} 57 \mathrm{Bl} / 6$ males compared to females. As the native VSMC lengths between $\mathrm{C} 57 \mathrm{Bl} / 6$ mice were not different, these males may exhibit the ability to elongate VSMCs greater than females of the same strain, although this did not affect the diameter of the vessel in a measurable way. VSMC shape and migration are altered by many different stimuli, including humoral factors (ANGII, $\mathrm{TGF}_{\mathrm{b} 1}$, ET-1, etc.), neuronal contributors, intercellular VSMC paracrine factors, endothelial cell influences (NO, etc.), and mechanical forces such as active stress and strain [67]. Estrogen levels in men and postmenopausal women are lower than levels in non-pregnant women [41-43], and estrogen has been shown to cause an increase in norepinephrine levels [68]. Norepinephrine exposure has resulted in shortening of VSMCs [38]. Therefore, it is possible that if the females had higher baseline levels of norepinephrine, their VSMCs lengths may not lengthen as robustly, resulting in the sexual dimorphism seen. In examining an additional aspect of mechanoadaptation, all 
VSMC overlaps decreased relative to their contralateral control, but there were no sexrelated remodeling differences among BALB/c or C57B1/6 strains, Figure 5.

As the anterior gracilis collateral exhibits smooth muscle cell proliferation, evidence of typical arteriogenesis $[56,58]$, we tested the hypothesis that female mice exhibit impaired arteriogenesis in this vessel. No differences were found between C57B1/6 and BALB/c mice, consistent with prior day-7 collateral arteriole remodeling results, in which male BALB/c collateral outward remodeling was impaired at day-3 post arterial occlusion, but showed no difference at day-7 [56]. Vessel diameters and wall thickness were larger in the remodeled vessel than the control vessel in all sexes and strains. The only exception was the wall thickness of $\mathrm{C} 57 \mathrm{Bl} / 6$ female mice. This measurement had a large amount of variability, which may be due to variations in the mice estrous cycles. 17- $\beta$-estradiol levels are variable during the cycle [69], and 17- $\beta$-estradiol increases the endothelial production of nitric oxide [46], which is an endothelial-derived vasodilator [70]. Nitric oxide diffuses into VSMCs, initiating a cascade that activates protein kinase G. This then regulates calcium concentrations and sensitization, and causes actin and myosin dynamic alterations that result in cellular relaxation, possibly altering wall thickness [71]. However, no difference existed between male and female C57Bl/6 mice for inner diameter, outer diameter, or wall thickness in the remodeled or control collaterals, Figure 6. Therefore, this lack of difference in diameters may suggest the lack of increase in wall thickness to be artifact. As this finding suggests no obvious anatomical remodeling differences in the anterior gracilis collateral midzone of male and female mice, there may 
be other factors accounting for any flow recovery differences previously observed, such as increased vascular resistance in the ischemic zone in females [50].

Fewer preexisting collaterals in females with unimpaired remodeling, or dysregulated capillary arterialization and angiogenesis may explain increased vascular resistance in females, with collaterals remodeling to the same extent. However, no difference between male and female C57Bl/6 mice in number of $\alpha$-smooth muscle actin-positive vessels was found at baseline in the midpoint of the semimembranosus muscle [50]. Despite this lack of difference, the small sample size of no more than 5 mice in each group leaves this possibility to be considered [50]. Furthermore, the collateral distribution between male and females may be different, so although there was no difference at the midpoint of the semimembranosus muscle, there may be fewer preexisting collaterals in other areas of the hindlimb. Despite no difference at day-7 post ligation in $\alpha$-smooth muscle actin-positive vessels compared to baseline for females, there was an increase in males. This increase is suggestive of preexisting capillaries being transformed into collaterals, possibly due to pericyte recruitment, known as capillary arterialization [72, 73]. In a basic examination of angiogenesis, female C57Bl/6 mice had less fewer red blood cell-containing vessels in a Matrigel Plug Assay compared to males after 5 days, indicating dysregulation [50]. An increased ability in either of these mechanisms would explain lower vascular resistance in males.

Alternatively, higher vascular resistance in female mice [46] may be due to impaired vasodilation in the ischemic zone, even without vessel growth impairment or difference 
in baseline collateral density $[50,74]$. Because reports concerning the impact of arterial occlusion on smooth muscle-dependent and endothelium-dependent vasodilation are inconsistent, it is unclear what component of the remodeling process may be affected. Vasodilation is impaired in response to endothelium-dependent agents in immature collaterals in animal models [75-79], but upon maturation is either restored [78] or continually impaired [79]. This may be explained by endothelial dysfunction induced by inflammatory conditions during remodeling [80], or an increase in collateral flow [81]. Hypercholesterolemia and ovariectomy in female mice each lead to impaired endothelialdependent vasodilation in resistance vessels [102], so it is possible that additional comorbidities or estrogen deficiency may precipitate sex-dependent causal effects on vasodilation impairment, possibly leading to higher female vascular resistance depending on female mice position in the estrous cycle [82].

Impaired vasodilation may be partially contributed to smooth muscle cell dysfunction [83]. This dysfunction is suggested by diminished endothelium-dependent and independent dilation responses in immature feed arteries that are restored after maturation [83]. Although feed arteries and collaterals remodel differently, endothelium-independent vasodilation is also impaired in collateral vessels $[79,84,85]$. This impairment could be due to smooth muscle dysfunction caused by the smooth muscle cell phenotype change during proliferation in immature collaterals [86, 87]. Although there is conflicting evidence that vasodilation responses to sodium nitroprusside are intact at day-14 following the induction of chronic ischemia [79], nitric oxide-induced, smooth muscledependent dilation is impaired in intramuscular arterioles at 5-weeks post chronic 
ischemia induction $[79,85]$. Although the mechanism of the impairment is unknown in these reports, there is a possible relation to oxidative stress. This stress increases with chronic ischemia [88], impairing dilation response in the obese Zucker rat to sodium nitroprusside [89]. Impaired dilation may have increased vascular resistance in female C57B1/6 mice, as they were less responsive to vasodilators at day-7 following femoral artery excision [50].

This research had several limitations regarding its interpretation. One of the potential limitations of this study is the non-standardization of the estrus cycle. This cycle in mice is approximately 4-5 days in length, consisting of the four phases: proestrus, estrus, metestrus and diestrus [90]. Through the duration of the study, the female mice were randomly cycling through these phases, undergoing several cycles. Although this nonstandardization is not optimal in determining correlative mechanisms, it more accurately reflects the healthy female general population hormonal cycle variation. Another limitation is the variation in ambulation scorers throughout the week. A different lab member is in charge of determining an ambulation score for the mice every day, which may have led to variation in the data due to the subjective nature of the measure. To mitigate this potential variation, it may be best to have one individual assign scores throughout the duration of the experiment, possibly limiting the data collection to days 1 , 3 , and 6 post ligation to ease workload and still capture a comprehensive view of recovery. In addition, training videos or sessions could be created to minimize variation between scorers within the lab. Another possible limitation is the variation in time of day 
in which the ambulation data was collected, so moving forward it would be recommended to score the mice at a similar time each day for consistency.

In summary, the aim of these studies was to describe the effect of arterial occlusion on collateral remodeling in male and healthy reproductive stage female mice. The collateral stem enlarged seemingly due to mechanoadaptation in both $\mathrm{BALB} / \mathrm{c}$ and $\mathrm{C} 57 \mathrm{Bl} / 6$ mice. There were no major sex-related differences in the gracilis collateral stem or midzone remodeling or resultant functional ambulation, with the exception of longer VSMCs in male C57B1/6 mice, at day-7 post femoral artery ligation in the collateral stem. As clinical evidence indicates a higher incidence of PAOD and associated likelihood of critical limb ischemia in women, as well as worse prognosis and decreased survival post myocardial infarction, understanding the possible differences in underlying vascular compensation mechanisms is crucial [10-17, 59]. As these differences were not captured in our specific investigation of arteriogenesis, an evaluation of microvascular remodeling in the ischemic zone and collateral vasodilation would be of interest. Furthermore, as oophorectomy reduces flow-mediated outward remodeling and decreased vessel densities in mice [46], arteriogenesis should be evaluated in the hindlimb following oophorectomy with estrogen depletion. 17- $\beta$-estradiol increases the endothelial production of nitric oxide, and flow-mediated outward remodeling following oophorectomy is rescued by 17 $\beta$-estradiol, with increased age a risk factor for PAOD development $[11,42,46]$. The determination of any underlying mechanistic sex-specific differences could be the foundation in which targeted therapeutics are developed, crucial for closing the prognosis gap between men and women in the global treatment of PAOD. 


\section{BIBLIOGRAPHY}

[1] M. Zimarino, M. D'Andreamatteo, R. Waksman, S. E. Epstein, and R. D. Caterina, "The dynamics of the coronary collateral circulation," (in En), Nature Reviews Cardiology, Reviews vol. 11, no. 4, p. 191, 2014-01-07 2014.

[2] (2017). Nitric oxide. Available:

http://lookfordiagnosis.com/mesh_info.php?term=nitric+oxide $/=1$

[3] M. Heil, I. Eitenmüller, T. Schmitz-Rixen, and W. Schaper, "Arteriogenesis versus angiogenesis: similarities and differences," (in eng), J Cell Mol Med, vol. 10, no. 1, pp. 45-55, Jan 2006.

[4] M. H. Criqui, R.D. Langer, A. Fronek, H.S. Feigelson, M.R. Klauber, T.J. McCann, D. Browner, "Mortality over a period of 10 years in patients with peripheral arterial disease," (in Eng), $N$ Engl J Med, vol. 326, no. 6, pp. 381-6, Feb 61992.

[5] W. R. Hiatt, S. Hoag, and R. F. Hamman, "Effect of Diagnostic Criteria on the Prevalence of Peripheral Arterial Disease," (in en), 1995-03-01 1995.

[6] E. Selvin and T. P. Erlinger, "Prevalence of and Risk Factors for Peripheral Arterial Disease in the United States," (in en), 2004-08-10 2004.

[7] A. T. Hirsch, M.H. Criqui, D. Treat-Jacobson, J.G. Regensteiner, M.A. Creager, J.W. Olin, S.H. Krook, D.B. Hunninghake, A.J. Comerota, M.E. Walsh, M.M. McDermott, W.R. Hiatt , "Peripheral arterial disease detection, awareness, and treatment in primary care," (in Eng), Jama, vol. 286, no. 11, pp. 1317-24, Sep 19 2001.

[8] M. Yost, "The real cost of peripheral artery disease.," THE SAGE GROUP.2011, Available:

https://www.m3meetevents.com/ncvh/Documents/Material/NCVH16/2243_EA_0 840_Mary_Yost_16by9_BB.pdf.

[9] J. D. Santilli and S. M. Santilli, "Chronic Critical Limb Ischemia: Diagnosis, Treatment and Prognosis - American Family Physician," 1999.

[10] G. Peach, M. Griffin, K. G. Jones, M. M. Thompson, and R. J. Hinchliffe, "Diagnosis and management of peripheral arterial disease," (in en), 2012-08-14 2012.

[11] J. Hooi, A. Kester, S. Henri, M. Overdijk, J. van Ree, A. Knottnerus, "Incidence of and Risk Factors for Asymptomatic Peripheral Arterial Occlusive Disease: A Longitudinal Study," American Journal of Epidemiology, vol. 153, no. 7, 2001. 
[12] B. Sigvant, K. Wiberg-Hedman, D. Bergqvist, O. Rolandsson, B. Andersson, E. Persson, E. Wahlberg, "A population-based study of peripheral arterial disease prevalence with special focus on critical limb ischemia and sex differences," (in ENG), J Vasc Surg, vol. 45, no. 6, pp. 1185-91, Jun 2007.

[13] G. Brevetti, R. Bucur, A. Balbarini, E. Melillo, S. Novo, I. Muratori, M. Chiariello, "Women and peripheral arterial disease: same disease, different issues," (in Eng), J Cardiovasc Med (Hagerstown), vol. 9, no. 4, pp. 382-8, Apr 2008.

[14] Y. He, Y. Jiang, J. Wang, L. Fan, X. Li, and F. Hu, "Prevalence of peripheral arterial disease and its association with smoking in a population-based study in Beijing, China," vol. 44, no. 2, pp. 333-338, August 20062006.

[15] I. D. J. Moussa, Michael R. Gray, William. Dangas, George. Lazic, Zoran. Moses, Jeffery W., "Prevalence and prediction of previously unrecognized peripheral arterial disease in patients with coronary artery disease: The peripheral arterial disease in Interventional Patients Study," (in en), Catheterization and Cardiovascular Interventions, vol. 73, no. 6, pp. 719-724, 2017.

[16] P. Greenland, H. Reicher-Reiss, U. Goldbourt, and S. Behar, "In-hospital and 1year mortality in 1,524 women after myocardial infarction. Comparison with 4,315 men.," (in en), 1991-02-01 1991.

[17] N. H. Fiebach, C. M. Viscoli, and R. I. Horwitz, "Differences Between Women and Men in Survival After Myocardial Infarction: Biology or Methodology?," $J A M A$, vol. 263, no. 8, pp. 1092-1096, 1990.

[18] L. Rosenberg, C. H. Hennekens, B. Rosner, C. Belanger, K. J. Rothman, and F. E. Speizer, "Early menopause and the risk of myocardial infarction," (in eng), Am J Obstet Gynecol, vol. 139, no. 1, pp. 47-51, Jan 1981.

[19] A. Abac1, A. Oguzhan, S. Kahraman, N. Eryol, S. Unal, H. Arinic, A. Ergin, "Effect of Diabetes Mellitus on Formation of Coronary Collateral Vessels," (in en), Circulation., no. 99, pp. 2239-2242, 1999-05-04 1999.

[20] M. E. Mendelsohn and R. H. Karas, "Molecular and cellular basis of cardiovascular gender differences," (in Eng), Science, vol. 308, no. 5728, pp. 1583-7, Jun 102005.

[21] D. P. Sieveking, P. Lim, R. Chow, L. Dunn, S. Bao, K. McGrath, A. Heather, D. Celermajer, M. Ng. "A sex-specific role for androgens in angiogenesis," (in en), 2010-02-15 2010.

[22] P. Meier, S. Gloekler, R. Zbinden, S. Beckh, S. de Marchi, S. Zbinden, K. Wustmann, M. Billinger, R. Vogel, S. Cook, P. Wenaweser, M. Togni, S. 
Windecker, B. Meier, C. Seiler, "Beneficial effect of recruitable collaterals: a 10year follow-up study in patients with stable coronary artery disease undergoing quantitative collateral measurements," (in Eng), Circulation, vol. 116, no. 9, pp. 975-83, Aug 282007.

[23] H. M. Nathoe, "Determinants and prognostic significance of collaterals in patients undergoing coronary revascularization," (in Eng), Am J Cardiol, vol. 98, no. 1, pp. 31-5, Jul 12006.

[24] H. M. Nathoe, J. Koerselman, E. Buskens, D. van Dijk, P. Stella, T. Plokker, P. Doevendans, D. Grobbee, P. de Jaegere, "Role of coronary collaterals in off-pump and on-pump coronary bypass surgery," (in Eng), Circulation, vol. 110, no. 13, pp. 1738-42, Sep 282004.

[25] I. Buschmann and W. Schaper, "Arteriogenesis Versus Angiogenesis: Two Mechanisms of Vessel Growth," (in en), 1999-06-01 1999.

[26] E. Fung and A. Helisch, "Macrophages in Collateral Arteriogenesis," (in English), Frontiers in Physiology, vol. 3, 20122012.

[27] A. Helisch and W. Schaper, "Arteriogenesis The Development and Growth of Collateral Arteries," (in en), Microcirculation, vol. 10, no. 1, pp. 83-97, 2003.

[28] M. Arras, W. D. Ito, D. Scholz, B. Winkler, J. Schaper, and W. Schaper, "Monocyte activation in angiogenesis and collateral growth in the rabbit hindlimb.," (in en), 1998-01-01 1998.

[29] T. Ziegelhoeffer, B. Fernandez, S. Kostin, M. Heil, R. Voswinckel, A. Helisch, W. Schaper, "Bone Marrow-Derived Cells Do Not Incorporate Into the Adult Growing Vasculature," (in en), 2004-02-06 2004.

[30] K. L. Sato, Roger J. Pearlman, Justin. Novicki, Deborah. Sellke, Frank. Simons, Michael. Post, Mark., "Efficacy of intracoronary versus intravenous FGF-2 in a pig model of chronic myocardial ischemia," (in English), The Annals of Thoracic Surgery, vol. 70, no. 6, pp. 2113-2118, 2000/12/01 2000.

[31] W. Schaper, "Collateral circulation," Basic Research in Cardiology, vol. 104, no. 1, pp. 5-21, 2009.

[32] J. Pöling, M. Szibor, S. Schimanski, M. Ingelmann, W. Rees, P. Gajawada, Z. Kochfar, H. Lorchner, I. Salwig, J. Shin, K. Wiebe, T. Kubin, H. Warnecke, T. Braun. "Induction of Smooth Muscle Cell Migration During Arteriogenesis Is Mediated by Rap2," (in en), 2011-10-01 2011.

[33] A. Cho, D. W. Courtman, and B. L. Langille, "Apoptosis (Programmed Cell Death) in Arteries of the Neonatal Lamb," (in en), 1995-02-01 1995. 
[34] P. Hamet, D. de Blois, T. Dam, L. Richard, E. Teiger, B. Tea, S. Orlov, J. Tremblay, "Apoptosis and vascular wall remodeling in hypertension," (in eng), Can J Physiol Pharmacol, vol. 74, no. 7, pp. 850-61, Jul 1996.

[35] A. M. Devlin, J. S. Clark, J. L. Reid, and A. F. Dominiczak, "DNA Synthesis and Apoptosis in Smooth Muscle Cells From a Model of Genetic Hypertension," (in en), 2000-07-01 2000.

[36] H. D. Intengan and E. L. Schiffrin, "Vascular Remodeling in Hypertension," (in en), 2001-09-01 2001.

[37] R. M. Lee, G. K. Owens, T. Scott-Burden, R. J. Head, M. J. Mulvany, and E. L. Schiffrin, "Pathophysiology of smooth muscle in hypertension," (in eng), Can $J$ Physiol Pharmacol, vol. 73, no. 5, pp. 574-84, May 1995.

[38] L. A. Martinez-Lemus, M. A. Hill, S. S. Bolz, U. Pohl, and G. A. Meininger, "Acute mechanoadaptation of vascular smooth muscle cells in response to continuous arteriolar vasoconstriction: implications for functional remodeling," (in Eng), Faseb j, vol. 18, no. 6, pp. 708-10, Apr 2004.

[39] E. N. T. P. M. Bakker, Hanke. Bonta, Peter. van Rooijen, Nico. VanBavel, Ed., "Blood flow-dependent arterial remodelling is facilitated by inflammation but directed by vascular tone," Cardiovascular Research, vol. 78, no. 2, pp. 341-348, 2017.

[40] E. J. Belin de Chantemele, E. Vessieres, O. Dumont, A. Guihot, B. Toutain, L. Loufrani, D. Henrion, "Reactive oxygen species are necessary for high flow (shear stress)-induced diameter enlargement of rat resistance arteries," (in eng), Microcirculation, vol. 16, no. 5, pp. 391-402, Jul 2009.

[41] D. Godin, E. Ivan, C. Johnson, R. Magid, and Z. S. Galis, "Remodeling of Carotid Artery Is Associated With Increased Expression of Matrix Metalloproteinases in Mouse Blood Flow Cessation Model," (in en), 2000-12-05 2000.

[42] J.-F. Arnal, C. Fontaine, A. Billion-Gales, J. Favre, H. Laurell, F. Lenfant, P. Gourdy, "Estrogen Receptors and Endothelium," (in en), 2010-08-01 2010.

[43] M. W. Elmlinger, W. Kuhnel, and M. B. Ranke, "Reference ranges for serum concentrations of lutropin (LH), follitropin (FSH), estradiol (E2), prolactin, progesterone, sex hormone-binding globulin (SHBG), dehydroepiandrosterone sulfate (DHEAS), cortisol and ferritin in neonates, children and young adults," (in eng), Clin Chem Lab Med, vol. 40, no. 11, pp. 1151-60, Nov 2002.

[44] S. R. Cummings, W. Browner, D. Bauer, K. Stone, K. Ensrud, S. Jamal, B. Ettinger, "Endogenous Hormones and the Risk of Hip and Vertebral Fractures among Older Women," (in EN), 
http://dx.doi.org/10.1056/NEJM199809103391104, research-article 2009-07-15 2009.

[45] D. S. Celermajer, K. E. Sorensen, D. J. Spiegelhalter, D. Georgakopoulos, J. Robinson, and J. E. Deanfield, "Aging is associated with endothelial dysfunction in healthy men years before the age-related decline in women," (in eng), $\mathrm{J} \mathrm{Am}$ Coll Cardiol, vol. 24, no. 2, pp. 471-6, Aug 1994.

[46] K. Tarhouni, A. Guihot, M. Fridja, B. Toutain, B. Henrion, C. Baufreton, F. Pinaud, V. Procaccio, L. Grimaud, A. Ayer, L. Loufrani, F. Lenfant, J. Arnal, D. Henrion, "Key Role of Estrogens and Endothelial Estrogen Receptor $\alpha$ in Blood Flow-Mediated Remodeling of Resistance Arteries," (in en), 2013-03-01 2013.

[47] Z. S. Kyriakides, P. Petinakis, T. Lyras, E. Sbarouni, P. Karayannakos, D. Iliopoulos, D. Kremastinos, "Gender does not influence angiogenesis and arteriogenesis in a rabbit model of chronic hind limb ischemia," (in Eng), Int $J$ Cardiol, vol. 92, no. 1, pp. 83-91, Nov 2003.

[48] D. W. Cramer and H. Xu, "Predicting age at menopause," (in eng), Maturitas, vol. 23, no. 3, pp. 319-26, Apr 1996.

[49] G. S. Cooper, D. D. Baird, and F. R. Darden, "Measures of menopausal status in relation to demographic, reproductive, and behavioral characteristics in a population-based study of women aged 35-49 years," (in eng), Am J Epidemiol, vol. 153, no. 12, pp. 1159-65, Jun 152001.

[50] X. Peng, J. Wang, R. Lassance-Soares, A. Najafi, S. Sood, N. Aghili, L. Alderman, J. Panza, J. Faber, S. Wang, S. Epstein, M. Burnett, "Gender differences affect blood flow recovery in a mouse model of hindlimb ischemia," (in ENG), Am J Physiol Heart Circ Physiol, vol. 300, no. 6, pp. H2027-34, Jun 2011.

[51] A. Limbourg, T. Korff, L. C. Napp, W. Schaper, H. Drexler, and F. P. Limbourg, "Evaluation of postnatal arteriogenesis and angiogenesis in a mouse model of hind-limb ischemia," (in en), Nature Protocols, vol. 4, no. 12, pp. 1737-1748, 2009-11-05 2009.

[52] D. Chalothorn, J. A. Clayton, H. Zhang, D. Pomp, and J. E. Faber, "Collateral density, remodeling, and VEGF-A expression differ widely between mouse strains," (in en), 2007-07-01 2007.

[53] B. G. Miller, V. H. Gattone, 2nd, J. M. Overhage, H. G. Bohlen, and A. P. Evan, "Morphological evaluation of vascular smooth muscle cell: length and width from a single scanning electron micrograph of microvessels," (in Eng), Anat Rec, vol. 216, no. 1, pp. 95-103, Sep 1986. 
[54] C. J. Sullivan, T. Doetschman, and J. B. Hoying, "Targeted disruption of the Fgf2 gene does not affect vascular growth in the mouse ischemic hindlimb," (in en), 2002-12-01 2002.

[55] G. Gruionu, J. B. Hoying, A. R. Pries, and T. W. Secomb, "Structural remodeling of mouse gracilis artery after chronic alteration in blood supply," (in en), 200505-01 2005.

[56] D. Scholz, T. Ziegelhoeffer, A. Helisch, S. Wagner, C. Friedrich, T. Podzuweit, W. Schaper, "Contribution of Arteriogenesis and Angiogenesis to Postocclusive Hindlimb Perfusion in Mice," (in English), Journal of Molecular and Cellular Cardiology, vol. 34, no. 7, pp. 775-787, 2002/07/01 2002.

[57] A. Krall, A. Nehzati, A. Bynum, L. Laiho, and T. Cardinal, "Smooth muscle cell organization in the stem region of the gracilis collateral circulation (670.1)," (in en), 2014-04-01 2014.

[58] A. Bynum, "Impact of Collateral Enlargement on Smooth Muscle Phenotype Semantic Scholar," Biomedical Engineering, @allenai_org, 2011.

[59] T. R. Cardinal, K. R. Struthers, T. J. Kesler, M. D. Yocum, D. T. Kurjiaka, and J. B. Hoying, "Chronic Hindlimb Ischemia Impairs Functional Vasodilation and Vascular Reactivity in Mouse Feed Arteries," (in eng), Front Physiol, vol. 2, 2011.

[60] J. M. McClung, T. McCord, S. Keum, S. Johnson, B. Annex, D. Marchuk, C. Kontos, "Skeletal Muscle-Specific Genetic Determinants Contribute to the Differential Strain-Dependent Effects of Hindlimb Ischemia in Mice," (in English), The American Journal of Pathology, vol. 180, no. 5, pp. 2156-2169, 2012/05/012012.

[61] D. I. Scholz, W.Fleming, I.Deindl, E.Sauer, A.Wiesnet, M. Busse, R. Schaper, J. Schaper, W., "Ultrastructure and molecular histology of rabbit hind-limb collateral artery growth (arteriogenesis) | Springer for Research \& Development," 2000 .

[62] C. Heilmann, F. Beyersdorf, and G. Lutter, "Collateral growth: cells arrive at the construction site," vol. 10, no. 6, pp. 570-578, December 20022002.

[63] F. Optiz, K. Schenke-Layland, T. Cohnert, and U. Stock. (2007). Phenotypical plasticity of vascular smooth muscle cells-effect of in vitro and in vivo shear stress for tissue engineering of blood vessels. Available:

http://www.medscape.com/medline/abstract/17685849

[64] I. Mills, C. Cohen, K. Kamal, G. Li, T. Shin, W. Du, B. Sumpio, "Strain activation of bovine aortic smooth muscle cell proliferation and alignment: Study 
of strain dependency and the role of protein kinase A and C signaling pathways," (in en), Journal of Cellular Physiology, vol. 170, no. 3, pp. 228-234, 1997.

[65] P. R. Standley, A. Camaratta, B. P. Nolan, C. T. Purgason, and M. A. Stanley, "Cyclic stretch induces vascular smooth muscle cell alignment via NO signaling," (in en), 2002-11-01 2002.

[66] L. A. Martinez-Lemus, G. Zhao, E. L. Galiñanes, and M. Boone, "Inward remodeling of resistance arteries requires reactive oxygen species-dependent activation of matrix metalloproteinases," (in en), 2011-06-01 2011.

[67] G. K. Owens, M. S. Kumar, and B. R. Wamhoff, "Molecular Regulation of Vascular Smooth Muscle Cell Differentiation in Development and Disease," (in en), 2004-07-01 2004.

[68] A. R. Genazzani, F. Bernardi, N. Pluchino, S. Begliuomini, E. Lenzi, E. Casarosa, M. Luisi, "Endocrinology of menopausal transition and its brain implications," (in eng), CNS Spectr, vol. 10, no. 6, pp. 449-57, Jun 2005.

[69] A. C. McLean, N. Valenzuela, S. Fai, and S. A. Bennett, "Performing Vaginal Lavage, Crystal Violet Staining, and Vaginal Cytological Evaluation for Mouse Estrous Cycle Staging Identification," in J Vis Expno. 67), 2012.

[70] F. Ichinose, J. D. Roberts, and W. M. Zapol, "Inhaled Nitric Oxide," (in en), 2004-06-29 2004.

[71] Y. Tanaka, G. Tang, K. Takizawa, K. Otsuka, M. Eghbali, M. Song, K. Nishimaru, K. Shigenobu, K. Kokie, E. Stefani, L. Toro, "Kv channels contribute to nitric oxide- and atrial natriuretic peptide-induced relaxation of a rat conduit artery," (in eng), J Pharmacol Exp Ther, vol. 317, no. 1, pp. 341-54, Apr 2006.

[72] F. Mac Gabhann and S. M. Peirce, "Collateral Capillary Arterialization following arteriolar ligation in murine skeletal muscle," (in eng), Microcirculation, vol. 17, no. 5, pp. 333-47, Jul 2010.

[73] H. Zhang, P. Prabhakar, R. Sealock, and J. E. Faber, "Wide genetic variation in the native pial collateral circulation is a major determinant of variation in severity of stroke," (in English (US)), Journal of Cerebral Blood Flow and Metabolism, vol. 30, no. 5, pp. 923-934, 2010.

[74] M. Chu, "The Impacts of Arterial Occlusion, Sex, and Exercise on Arteriogenesis and Functional Vasodilation," 2016.

[75] S. Takeshita, T. Isshiki, M. Ochiai, K. Eto, H. Mori, E. Tanaka, K. Umetani, T. Sato, "Endothelium-dependent relaxation of collateral microvessels after intramuscular gene transfer of vascular endothelial growth factor in a rat model of 
hindlimb ischemia," (in eng), Circulation, vol. 98, no. 13, pp. 1261-3, Sep 29 1998.

[76] C. Bauters, T. Asahara, L. Zheng, S. Takeshita, S. Bunting, N. Ferrara, J. Symes, J. Isner, "Recovery of Disturbed Endothelium-Dependent Flow in the CollateralPerfused Rabbit Ischemic Hindlimb After Administration of Vascular Endothelial Growth Factor," (in en), 1995-06-01 1995.

[77] C. Orlandi, J. L. Blackshear, and N. K. Hollenberg, "Specific increase in sensitivity to serotonin of the canine hindlimb collateral arterial tree via the 5hydroxytryptamine-2 receptor," (in eng), Microvasc Res, vol. 32, no. 1, pp. 12130, Jul 1986.

[78] J. A. Rapps, P. R. Myers, Q. Zhong, and J. L. Parker, "Development of Endothelium-Dependent Relaxation in Canine Coronary Collateral Arteries," (in en), 1998-10-20 1998.

[79] C. J. Kelsall, M. D. Brown, and O. Hudlicka, "Alterations in Reactivity of Small Arterioles in Rat Skeletal Muscle as a Result of Chronic Ischaemia," (in english), Journal of Vascular Research, vol. 38, no. 3, pp. 212-218, 2001.

[80] D. N. Granger and E. Senchenkova, "Impaired Vasomotor Responses," (in en), Text 20102010.

[81] F. W. Sellke, J. E. Quillen, L. A. Brooks, and D. G. Harrison, "Endothelial modulation of the coronary vasculature in vessels perfused via mature collaterals.," (in en), 1990-06-01 1990.

[82] M. S. Cola, A. L. Gava, S. S. Meyrelles, and E. C. Vasquez, "Endothelial dysfunction of resistance vessels in female apolipoprotein E-deficient mice," in Lipids Health Dis, vol. 9, 2010, p. 51.

[83] R. Gallagher, "The Impact of Outward Remodeling on Vasodilation in Skeletal Muscle Resistance Arteries - Semantic Scholar," Biomedical Engineering MS, @allenai_org, 2012.

[84] P. N. Colleran, Z. Li, H. T. Yang, M. H. Laughlin, and R. L. Terjung, "Vasoresponsiveness of collateral vessels in the rat hindlimb: influence of training," (in eng), J Physiol, vol. 588, no. Pt 8, pp. 1293-307, Apr 152010.

[85] S. Takeshita, T. Isshiki, H. Mori, E. Tanaka, A. Tanaka, K. Umetani, K. Eto, Y. Miyazawa, M. Ochiai, T. Sato, "Microangiographic assessment of collateral vessel formation following direct gene transfer of vascular endothelial growth factor in rats," Cardiovascular Research, vol. 35, no. 3, pp. 547-552, 1997. 
[86] "Regulation and characteristics of vascular smooth muscle cell phenotypic diversity | SpringerLink," 2007.

[87] P. S. Kumar, B. R. Wamhoff, and G. K. Owens, "Molecular regulation of vascular smooth muscle cell differentiation in development and disease.," Physiological reviews, 2004-06-29 2004.

[88] Pipinos, S. Swanson, Z. Zhu, A. Nella, D. Weiss, T. Gutti, R. McComb, B. Baxter, T. Lynch, G. Casale, "Chronically ischemic mouse skeletal muscle exhibits myopathy in association with mitochondrial dysfunction and oxidative damage," in Am J Physiol Regul Integr Comp Physiol, vol. 295no. 1), 2008, pp. R290-6.

[89] J. C. Frisbee and D. W. Stepp, "Impaired NO-dependent dilation of skeletal muscle arterioles in hypertensive diabetic obese Zucker rats," (in en), 2001-09-01 2001.

[90] G. Ekambaram, S. K. Sampath Kumar, and L. D. Joseph, "Comparative Study on the Estimation of Estrous Cycle in Mice by Visual and Vaginal Lavage Method," (in eng), J Clin Diagn Res, vol. 11, no. 1, pp. AC05-7, Jan 2017.

[91] S. Mazzetti, S. Frigerio, M. Gelati, A. Salmaggi, and L. Vitellaro-Zuccarello, "Lycopersicon esculentum lectin: an effective and versatile endothelial marker of normal and tumoral blood vessels in the central nervous system," (in eng), Eur J Histochem, vol. 48, no. 4, pp. 423-8, Oct-Dec 2004.

[92] R. M. Nidavani, A. Shalavadi, Mallappa., "Vascular permeability and Evans blue dye: a physiological and pharmacological approach (PDF Download Available)," 2014.

[93] S. Byers, M. V. Wiles, S. Dunn, and R. Taft, "Mouse Estrous Cycle Identification Tool and Images," 2012.

[94] M. E. Seaman, S. M. Peirce, and K. Kelly, "Rapid analysis of vessel elements (RAVE): a tool for studying physiologic, pathologic and tumor angiogenesis," (in eng), PLoS One, vol. 6, no. 6, p. e20807, 2011. 


\section{APPENDICES}

Appendix A: Raw Images

Wideview Microscopy (10x)

\section{C57Bl/6 Females:}

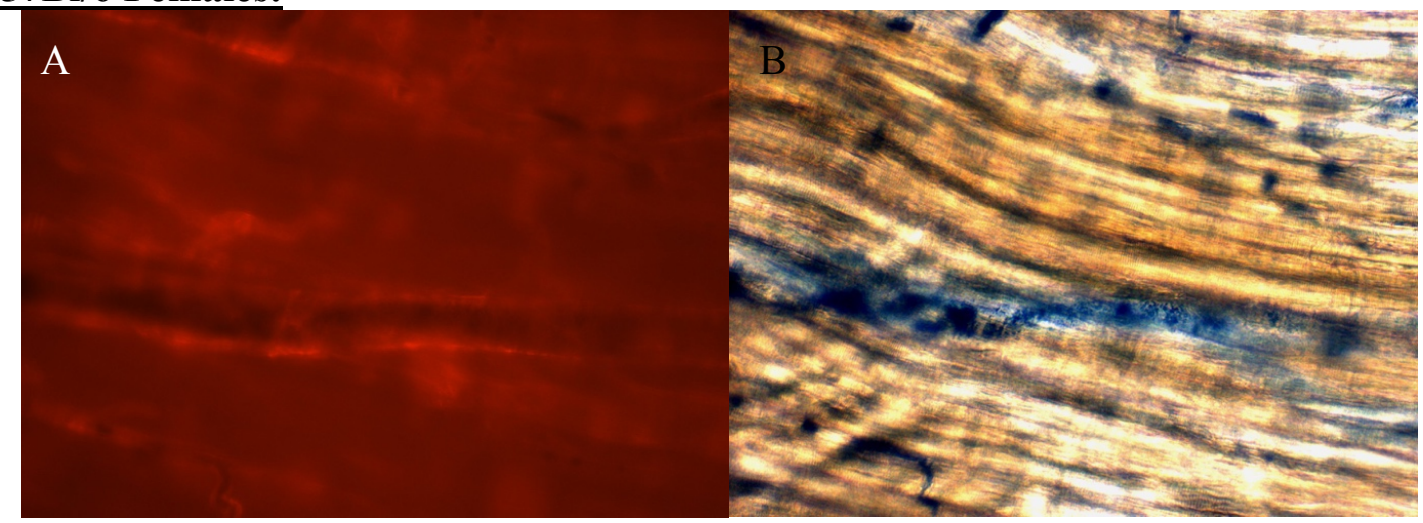

$\mathrm{N}=1$ Anterior Gracilis Collateral Day-7 Post-Femoral Artery Ligation A) Alpha-Smooth Muscle Actin B) Microfil

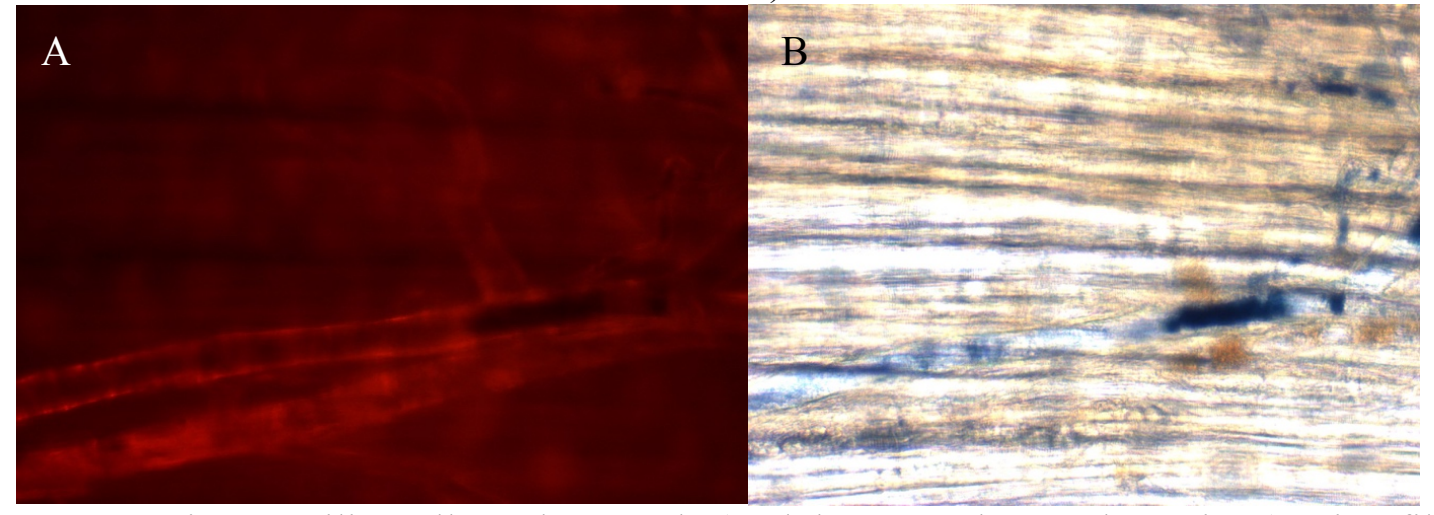

$\mathrm{N}=1$ Anterior Gracilis Collateral Control A) Alpha-Smooth Muscle Actin B) Microfil

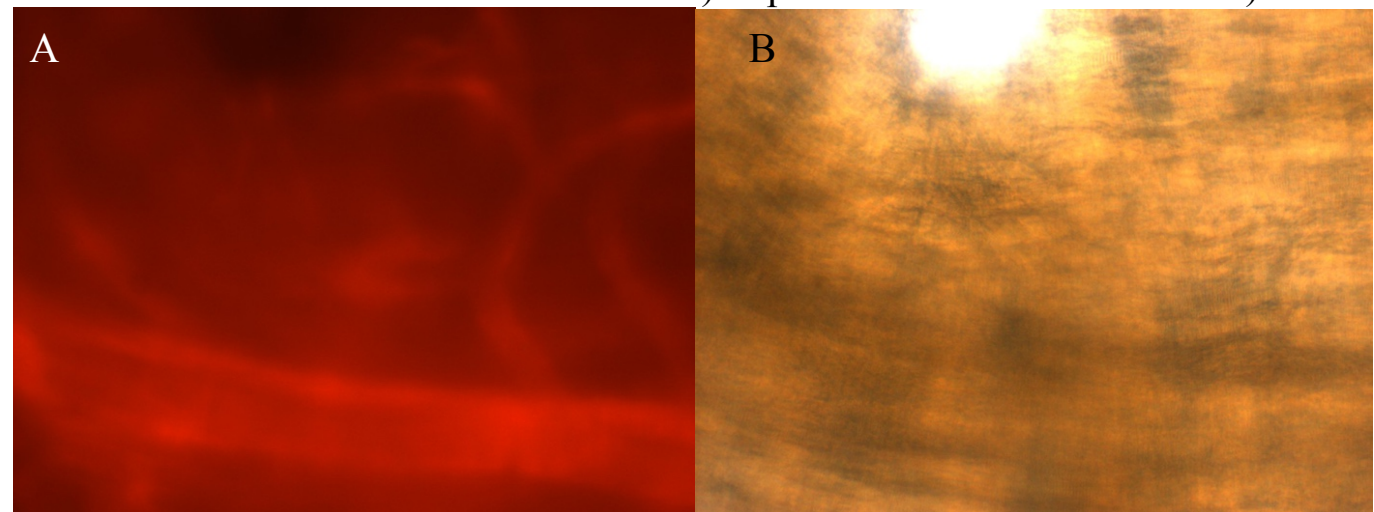

$\mathrm{N}=2$ Anterior Gracilis Collateral Day-7 Post-Femoral Artery Ligation A) Alpha-Smooth Muscle Actin B) Microfil (Did not use) 


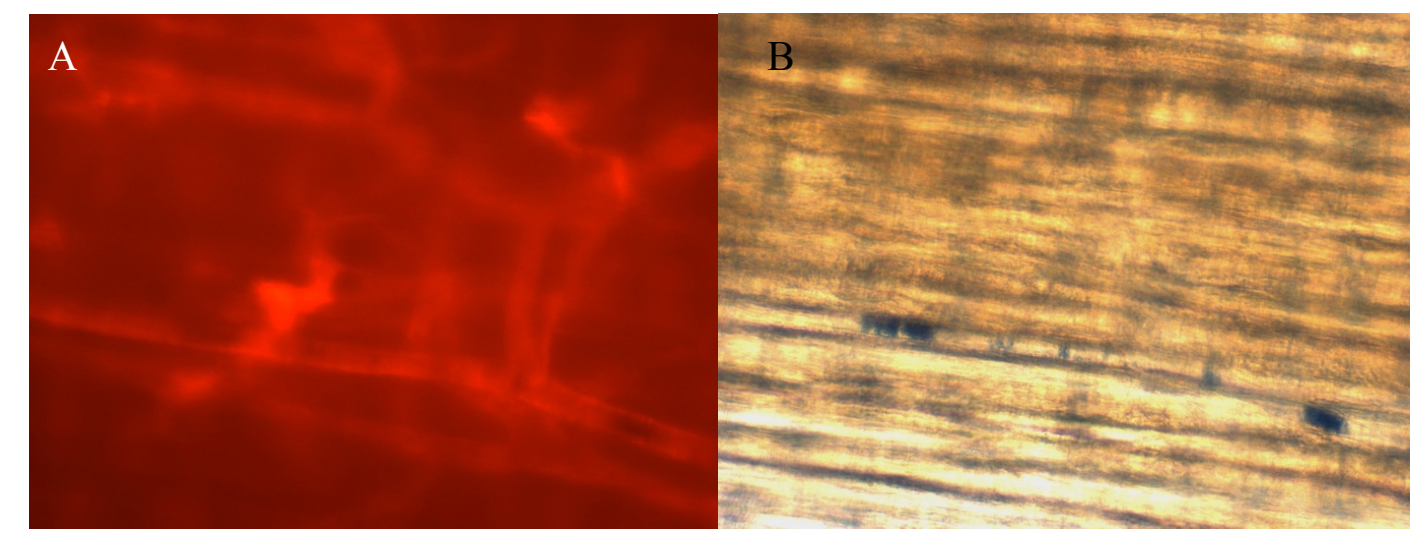

$\mathrm{N}=2$ Anterior Gracilis Collateral Control A) Alpha-Smooth Muscle Actin B) Microfil
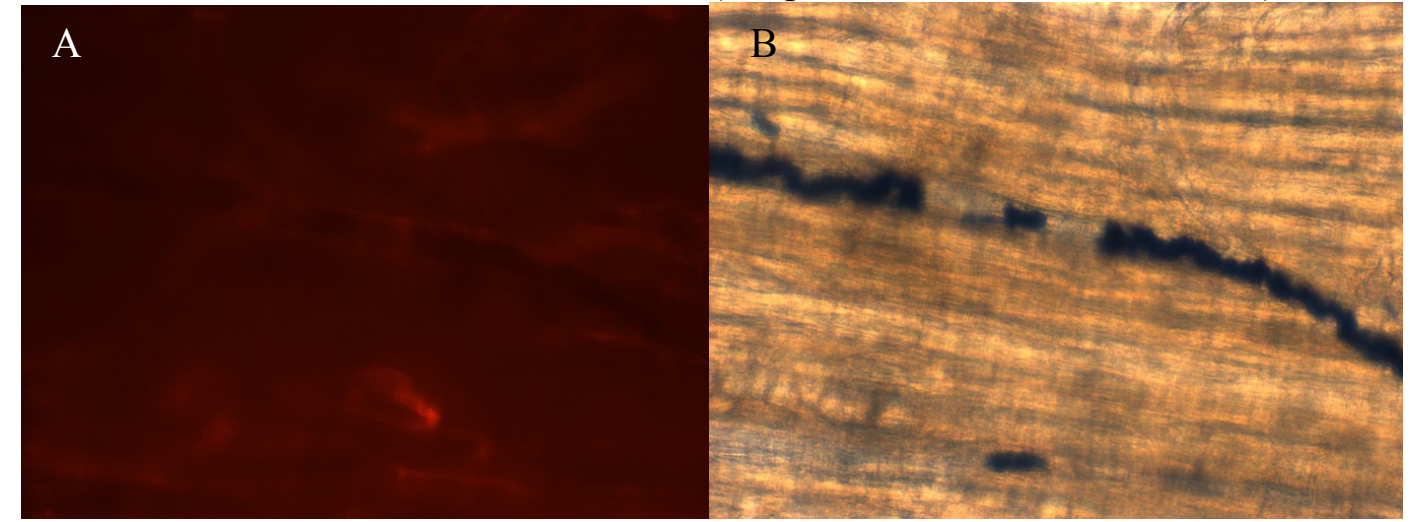

N=3 Anterior Gracilis Collateral Day-7 Post-Femoral Artery Ligation A) Alpha-Smooth Muscle Actin B) Microfil

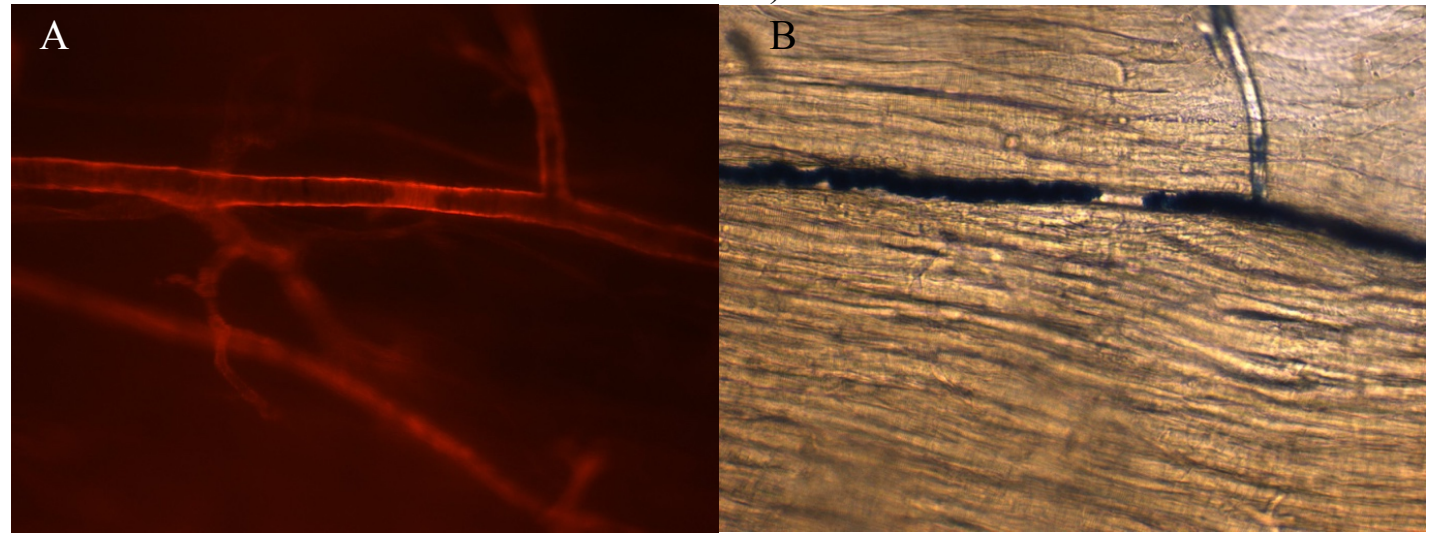

$\mathrm{N}=3$ Anterior Gracilis Collateral Control A) Alpha-Smooth Muscle Actin B) Microfil 


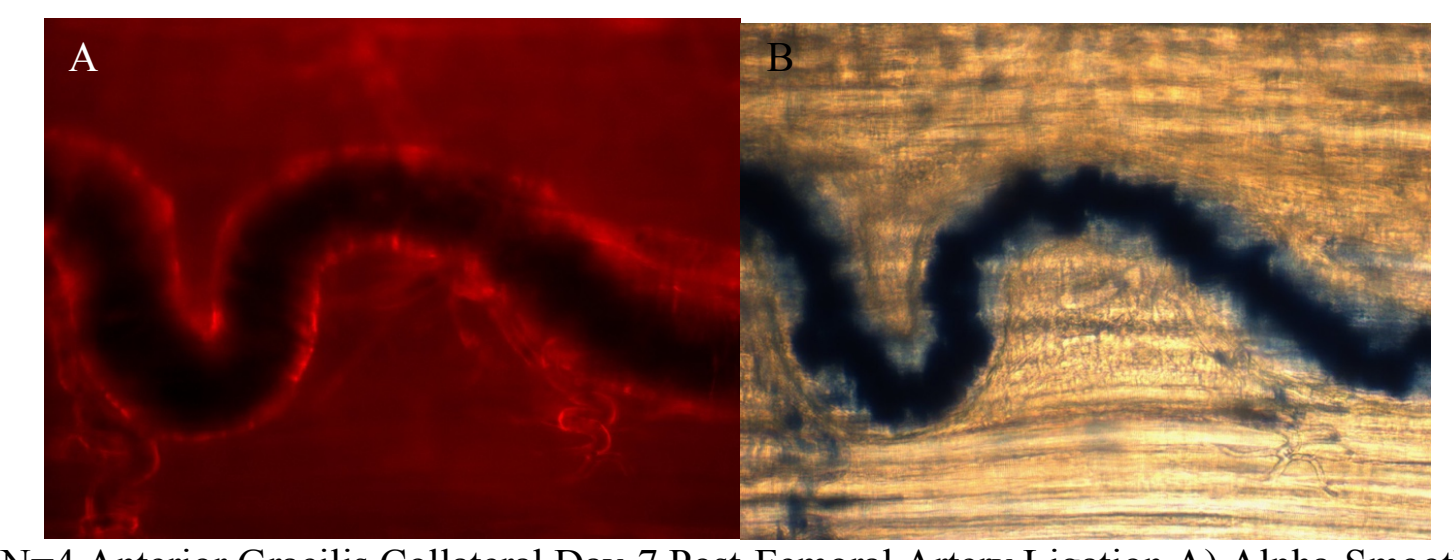

$\mathrm{N}=4$ Anterior Gracilis Collateral Day-7 Post-Femoral Artery Ligation A) Alpha-Smooth Muscle Actin B) Microfil

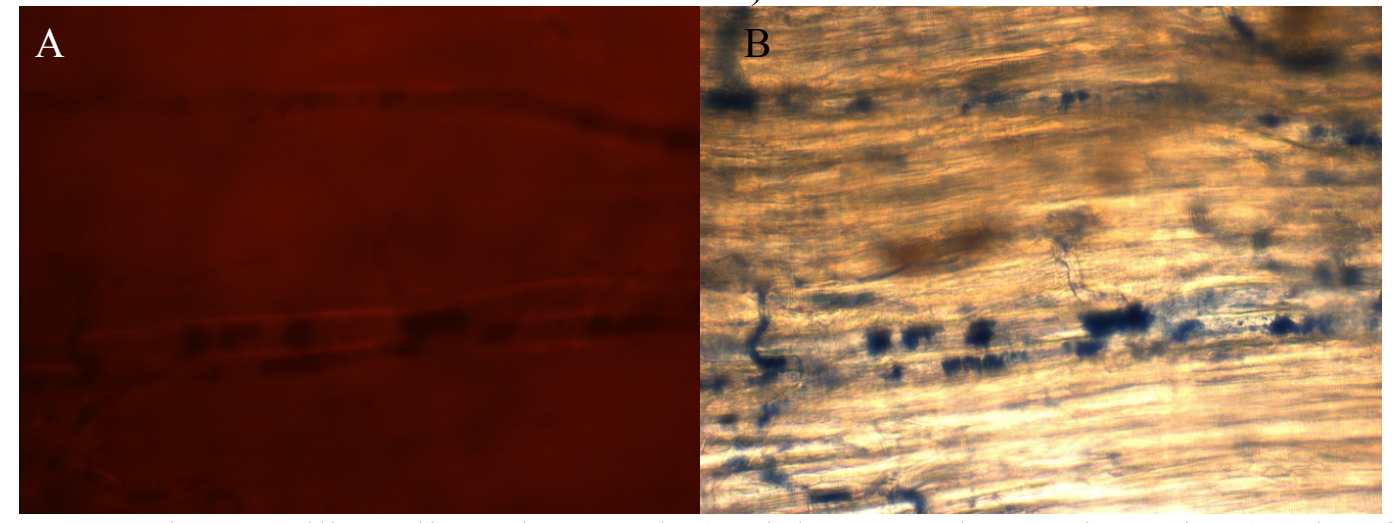

$\mathrm{N}=4$ Anterior Gracilis Collateral Control A) Alpha-Smooth Muscle Actin B) Microfil

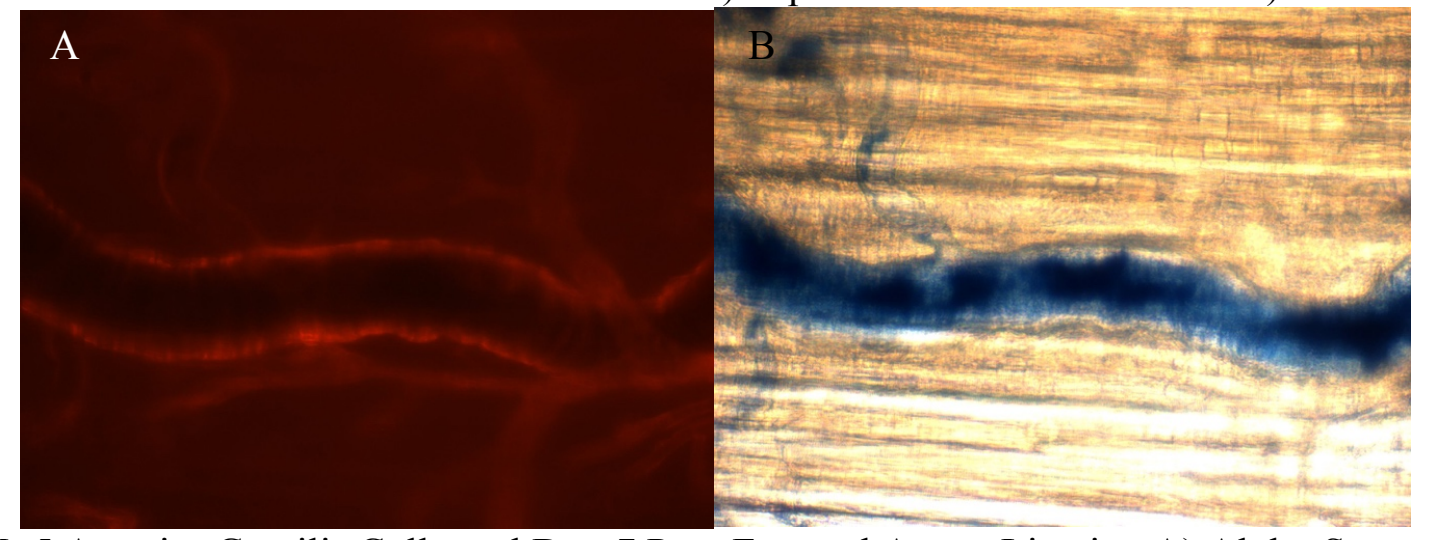

$\mathrm{N}=5$ Anterior Gracilis Collateral Day-7 Post-Femoral Artery Ligation A) Alpha-Smooth Muscle Actin B) Microfil 


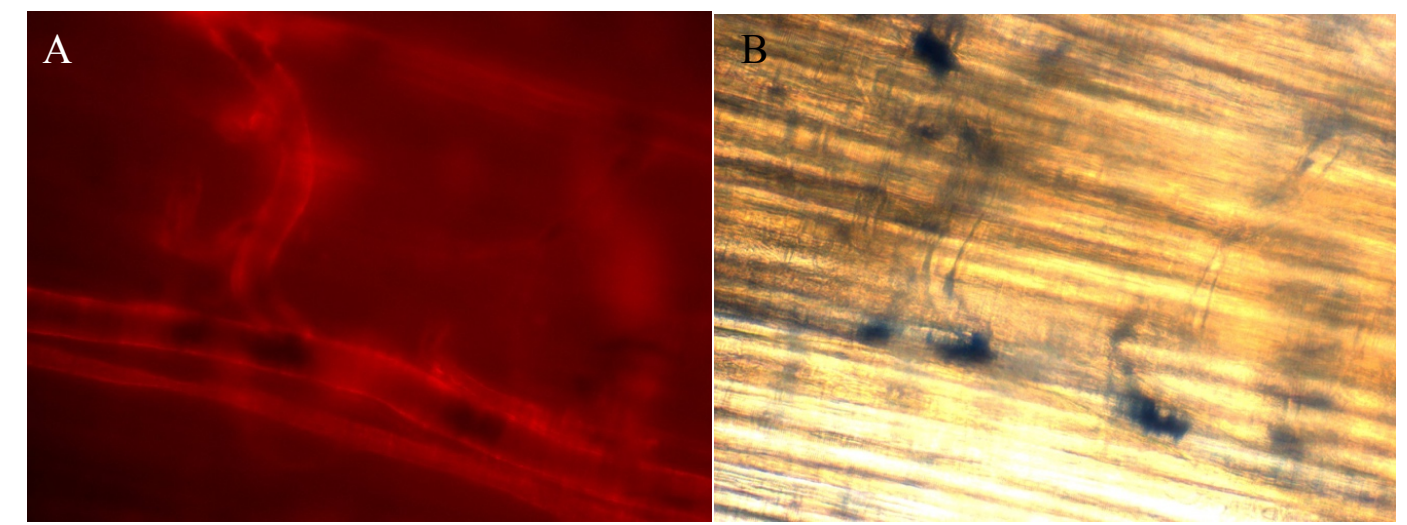

$\mathrm{N}=5$ Anterior Gracilis Collateral Control A) Alpha-Smooth Muscle Actin B) Microfil C57B1/6 Males:

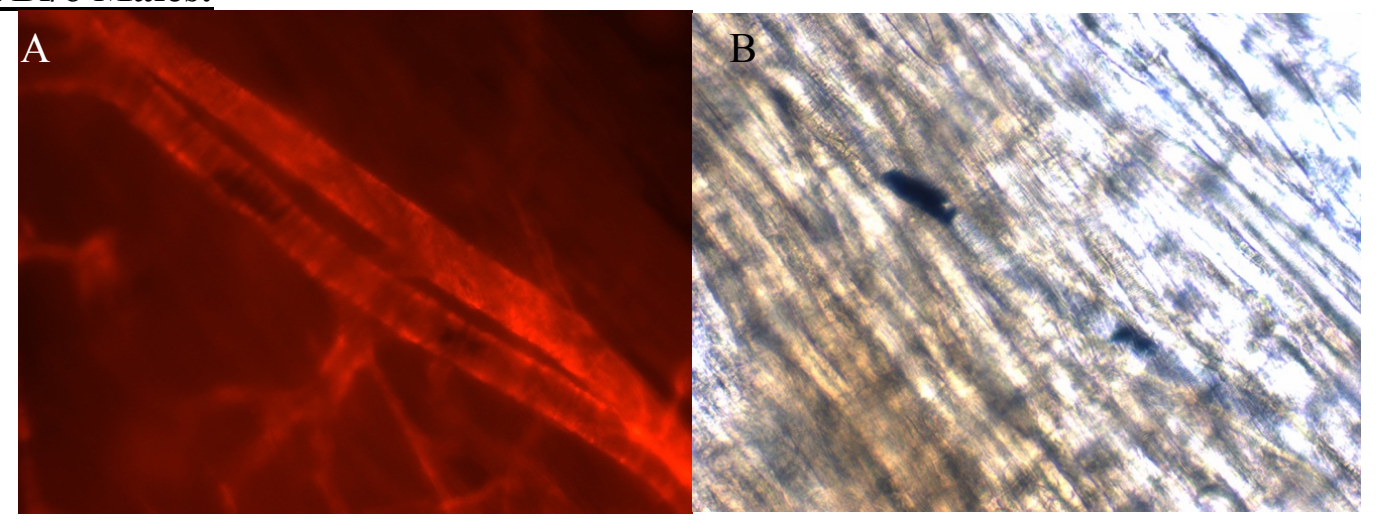

$\mathrm{N}=1$ Anterior Gracilis Collateral Day-7 Post-Femoral Artery Ligation A) Alpha-Smooth Muscle Actin B) Microfil

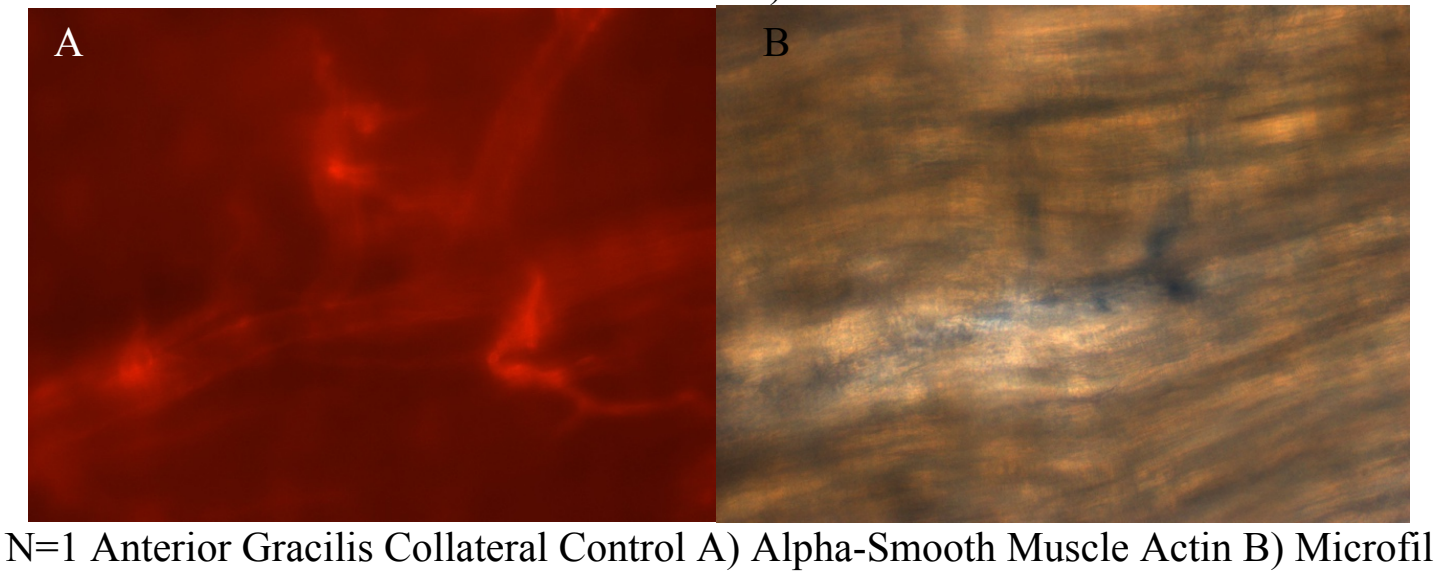




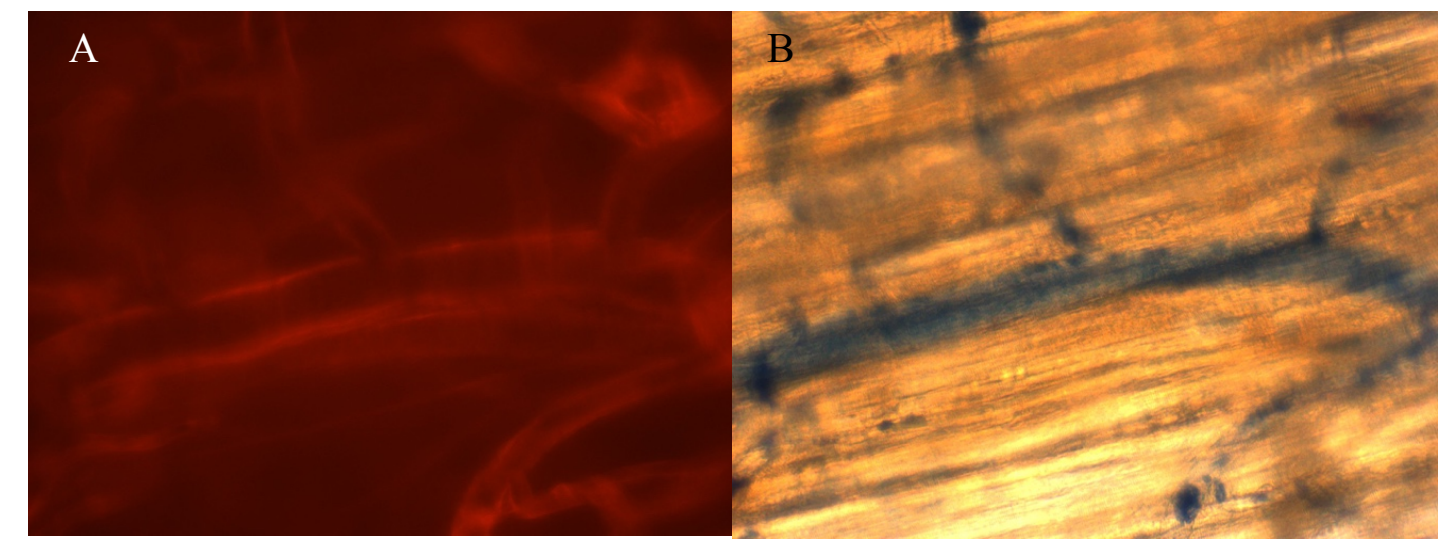

$\mathrm{N}=2$ Anterior Gracilis Collateral Day-7 Post-Femoral Artery Ligation A) Alpha-Smooth Muscle Actin B) Microfil

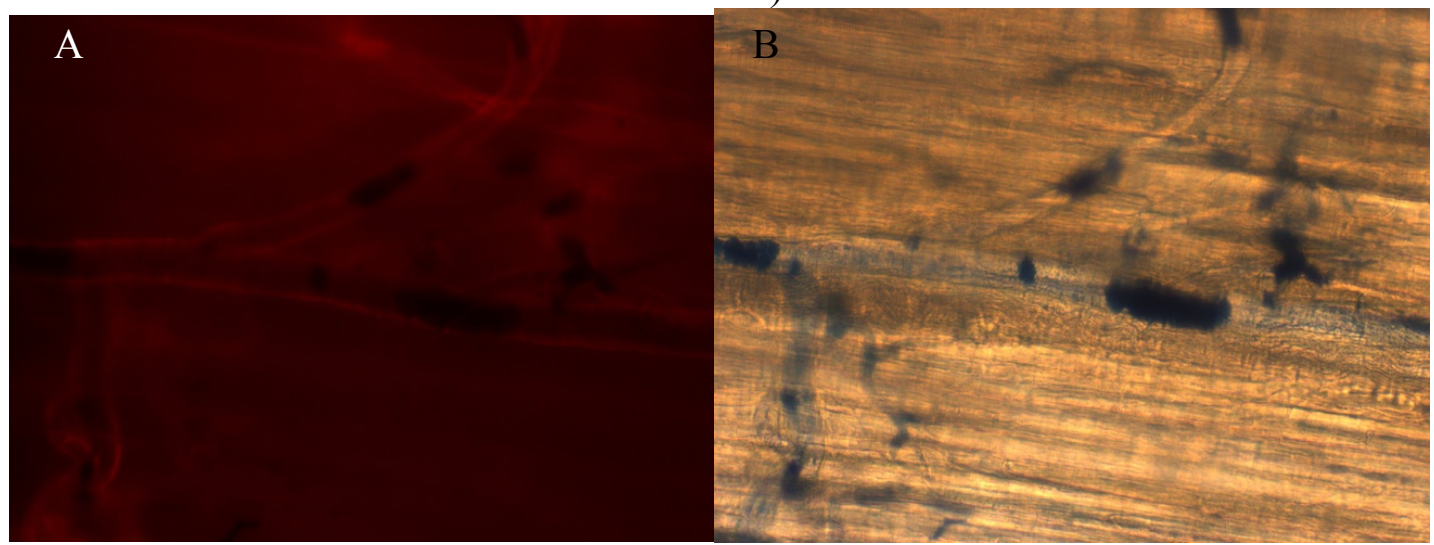

$\mathrm{N}=2$ Anterior Gracilis Collateral Control A) Alpha-Smooth Muscle Actin B) Microfil

A

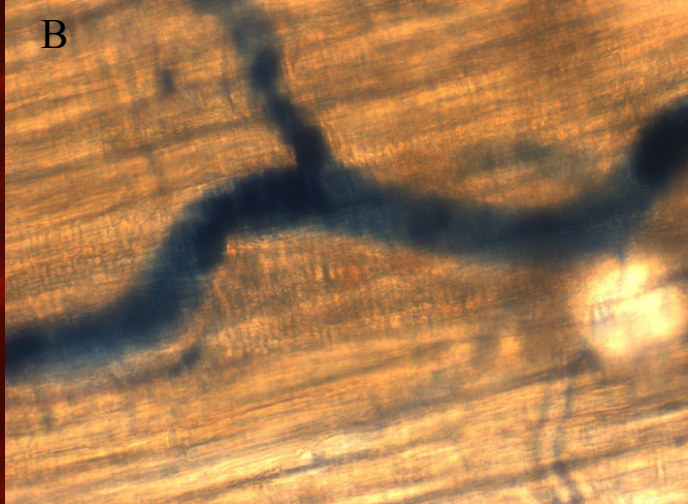

N=3 Anterior Gracilis Collateral Day-7 Post-Femoral Artery Ligation A) Alpha-Smooth Muscle Actin B) Microfil 


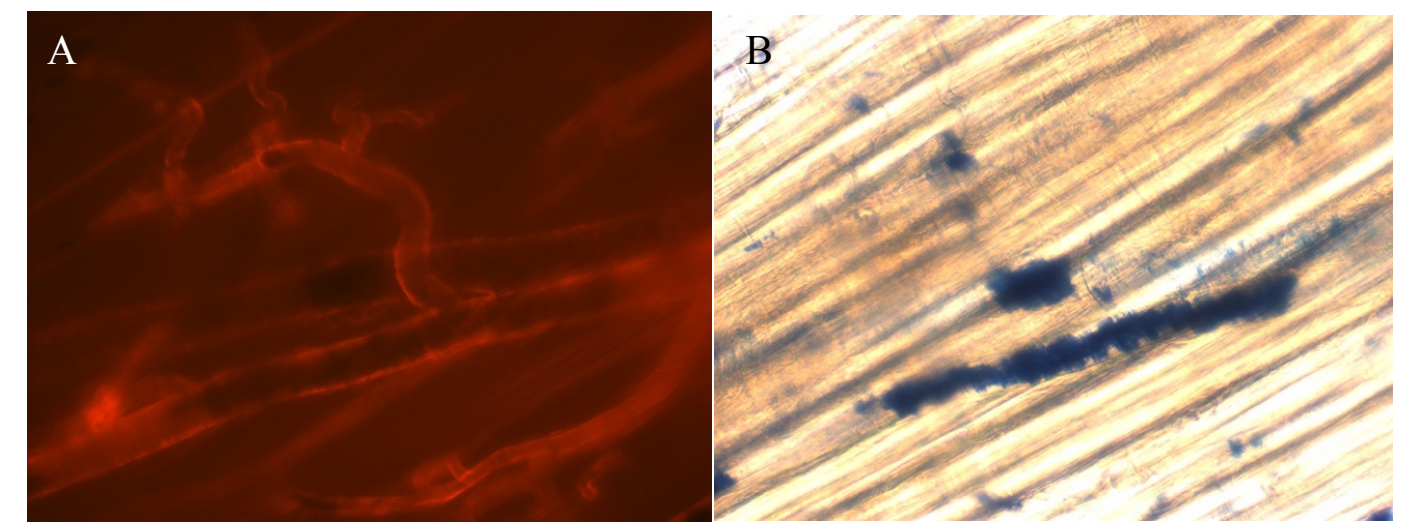

$\mathrm{N}=3$ Anterior Gracilis Collateral Control A) Alpha-Smooth Muscle Actin B) Microfil

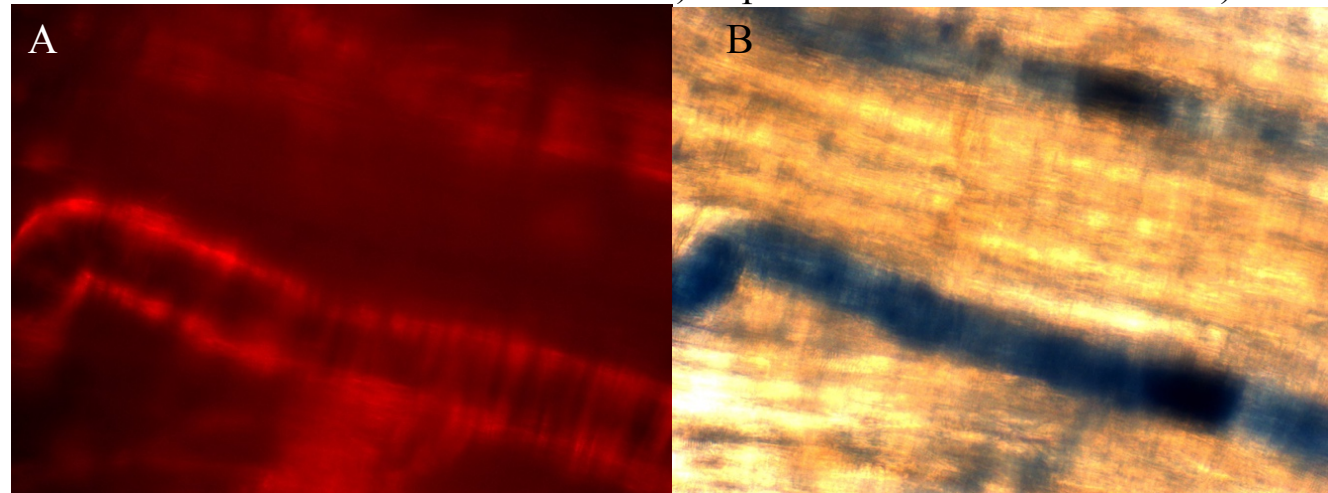

$\mathrm{N}=4$ Anterior Gracilis Collateral Day-7 Post-Femoral Artery Ligation A) Alpha-Smooth Muscle Actin B) Microfil
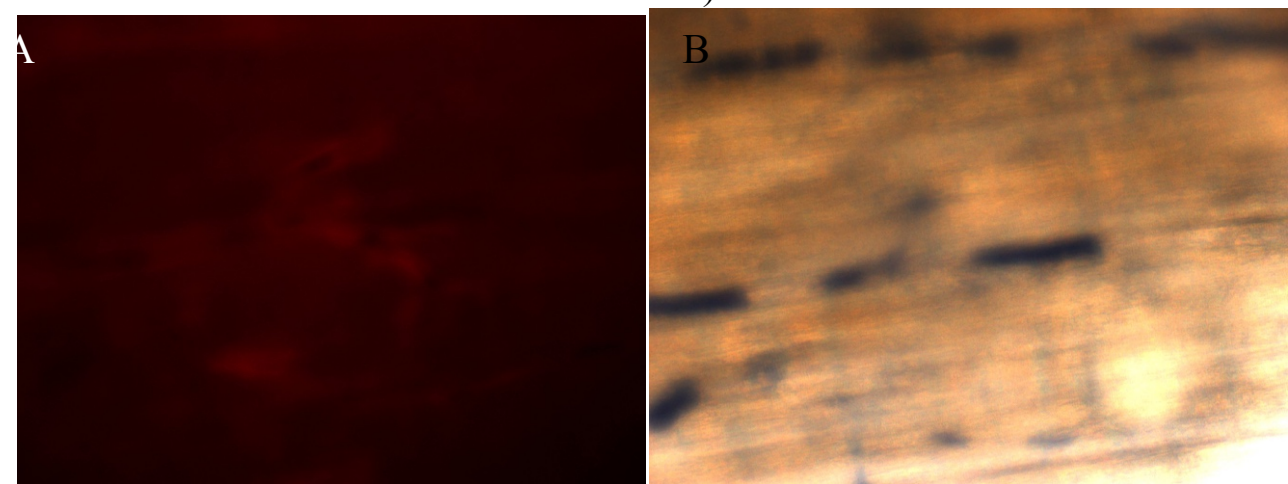

$\mathrm{N}=4$ Anterior Gracilis Collateral Control A) Alpha-Smooth Muscle Actin B) Microfil
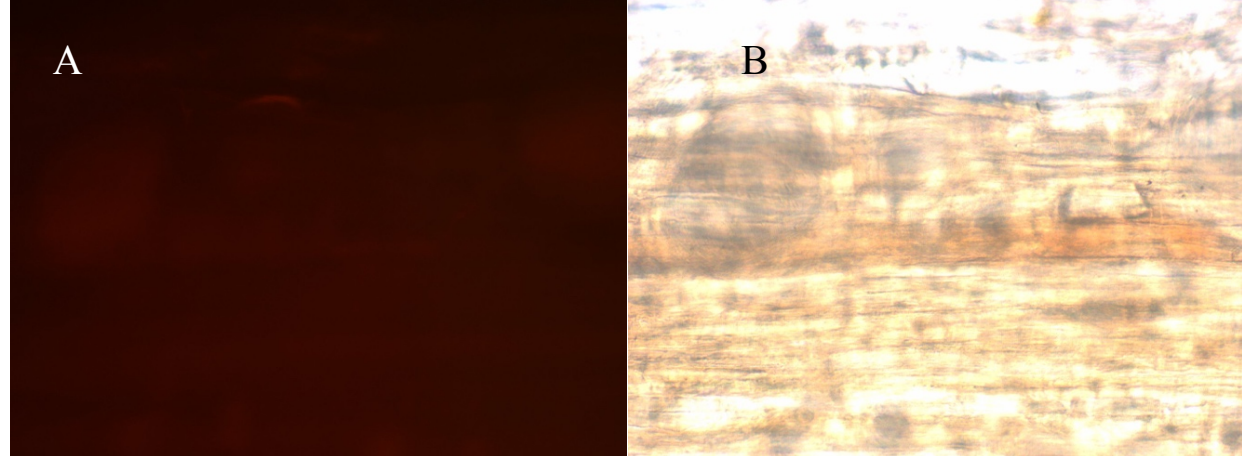

$\mathrm{N}=5$ Anterior Gracilis Collateral Day-7 Post-Femoral Artery Ligation A) Alpha-Smooth Muscle Actin B) Microfil (Did not use) 


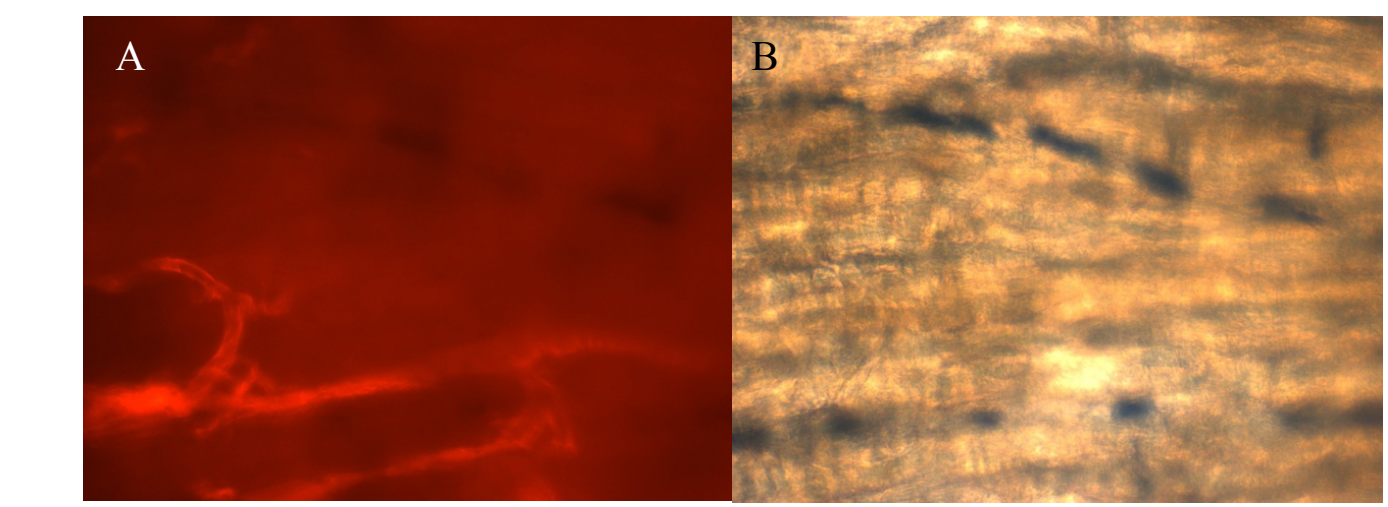

$\mathrm{N}=5$ Anterior Gracilis Collateral Control A) Alpha-Smooth Muscle Actin B) Microfil

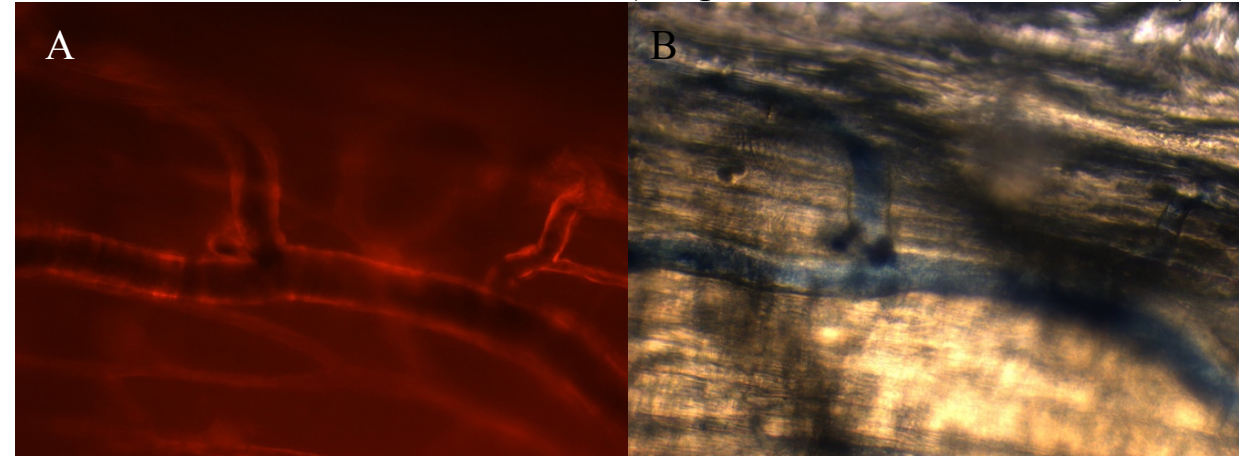

$\mathrm{N}=6$ Anterior Gracilis Collateral Day-7 Post-Femoral Artery Ligation A) Alpha-Smooth Muscle Actin B) Microfil

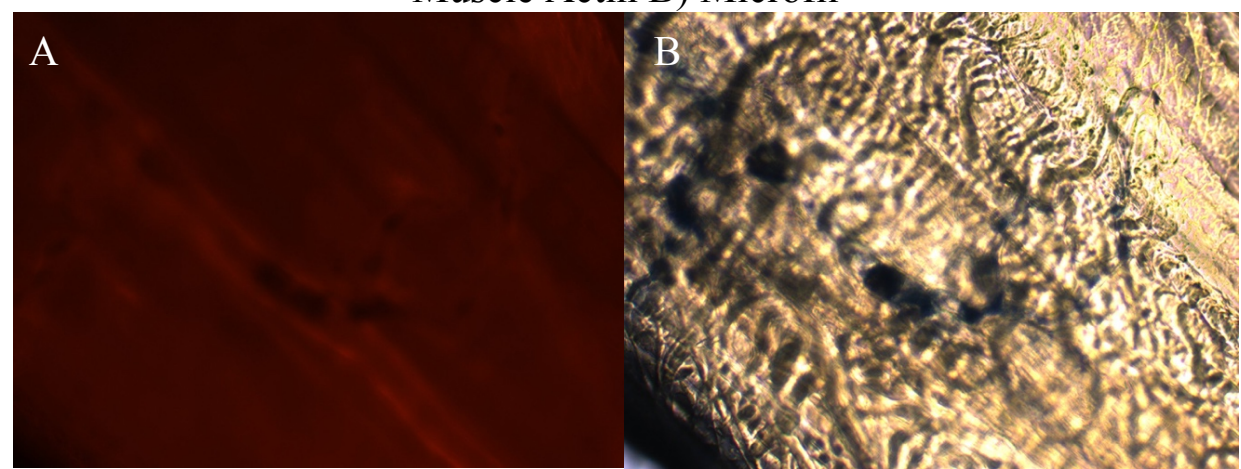

$\mathrm{N}=6$ Anterior Gracilis Collateral Control A) Alpha-Smooth Muscle Actin B) Microfil 


\section{BALB/C Females:}

A

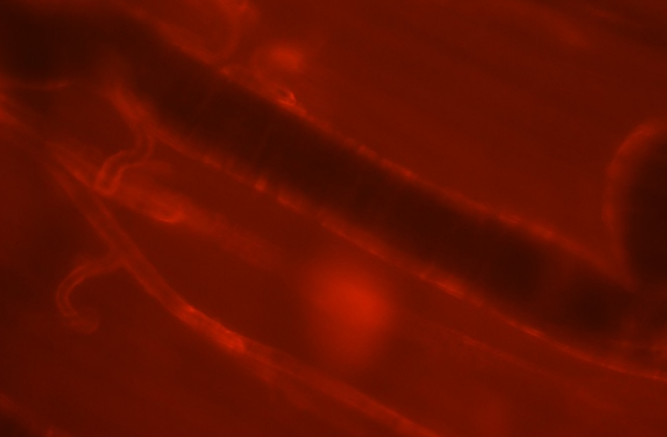

$\mathrm{B}$

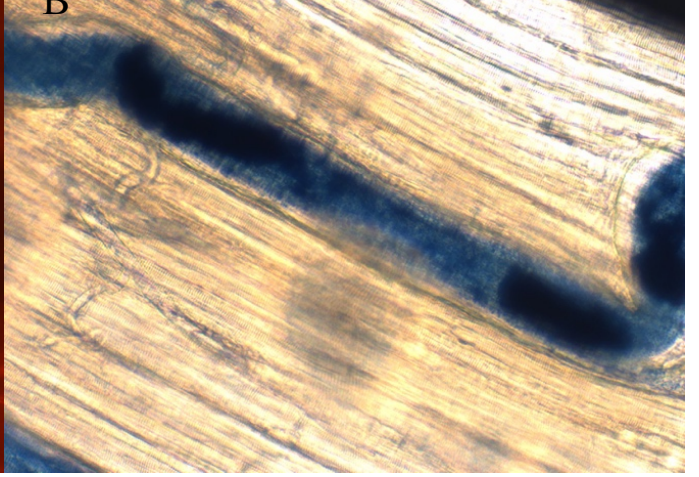

$\mathrm{N}=1$ Anterior Gracilis Collateral Day-7 Post-Femoral Artery Ligation A) Alpha-Smooth Muscle Actin B) Microfil

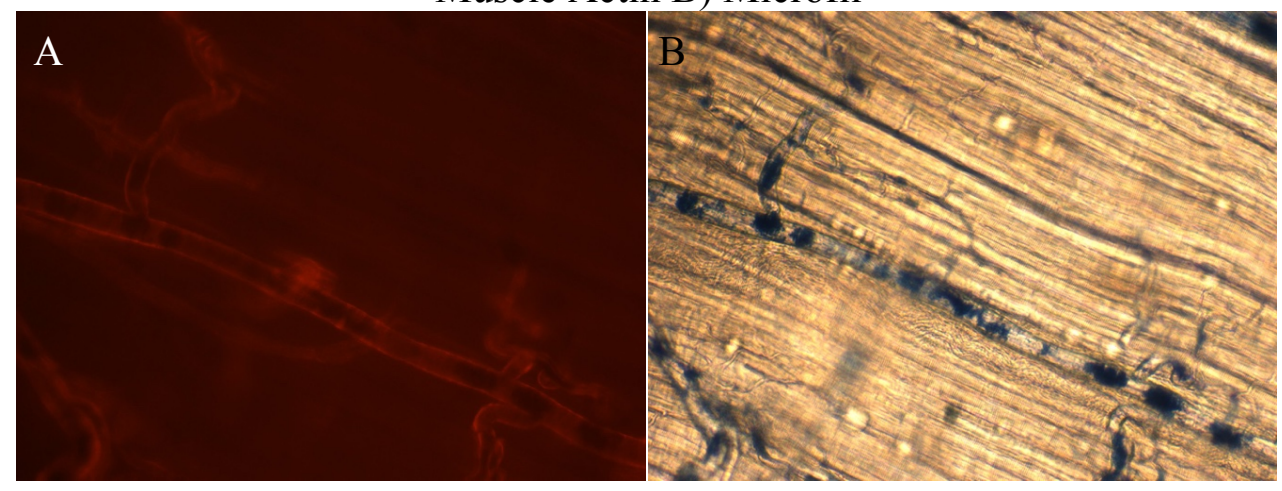

$\mathrm{N}=1$ Anterior Gracilis Collateral Control A) Alpha-Smooth Muscle Actin B) Microfil

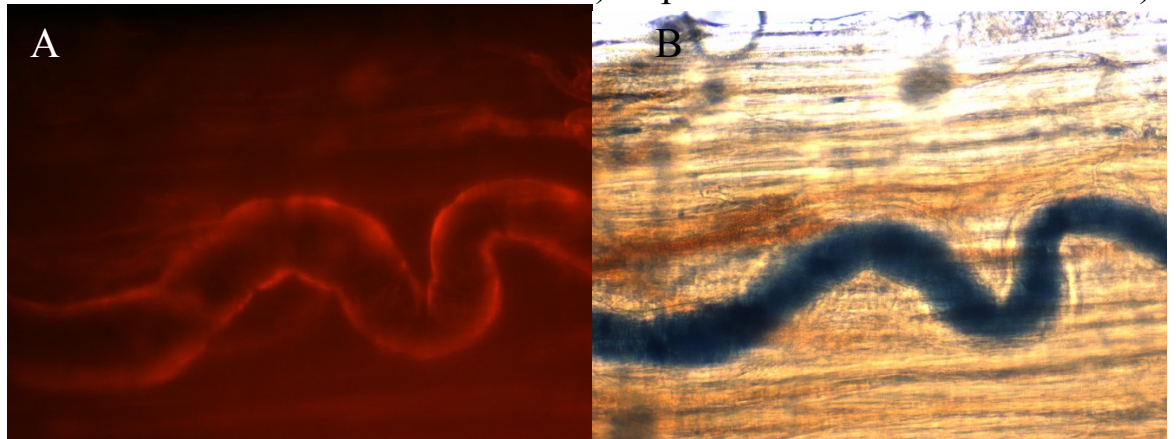

$\mathrm{N}=2$ Anterior Gracilis Collateral Day-7 Post-Femoral Artery Ligation A) Alpha-Smooth Muscle Actin B) Microfil

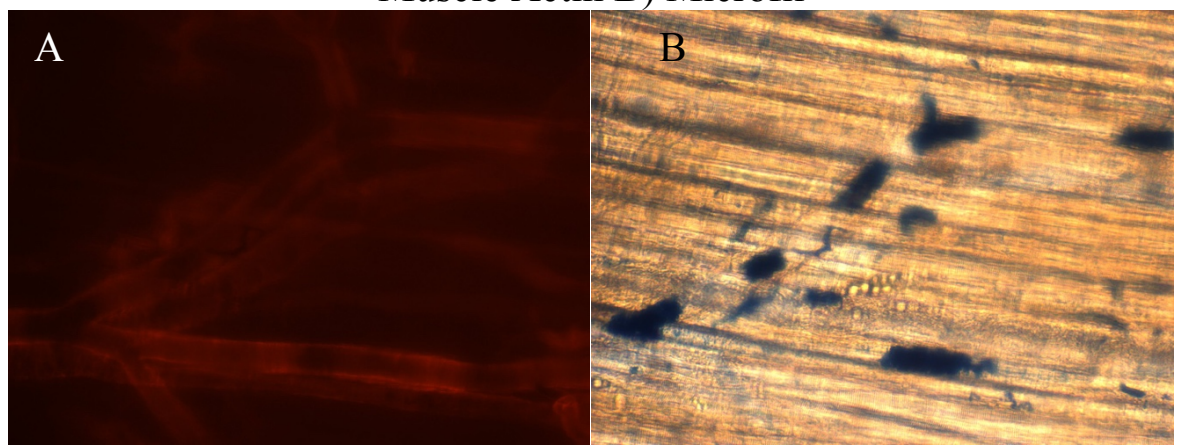

$\mathrm{N}=2$ Anterior Gracilis Collateral Control A) Alpha-Smooth Muscle Actin B) Microfil 


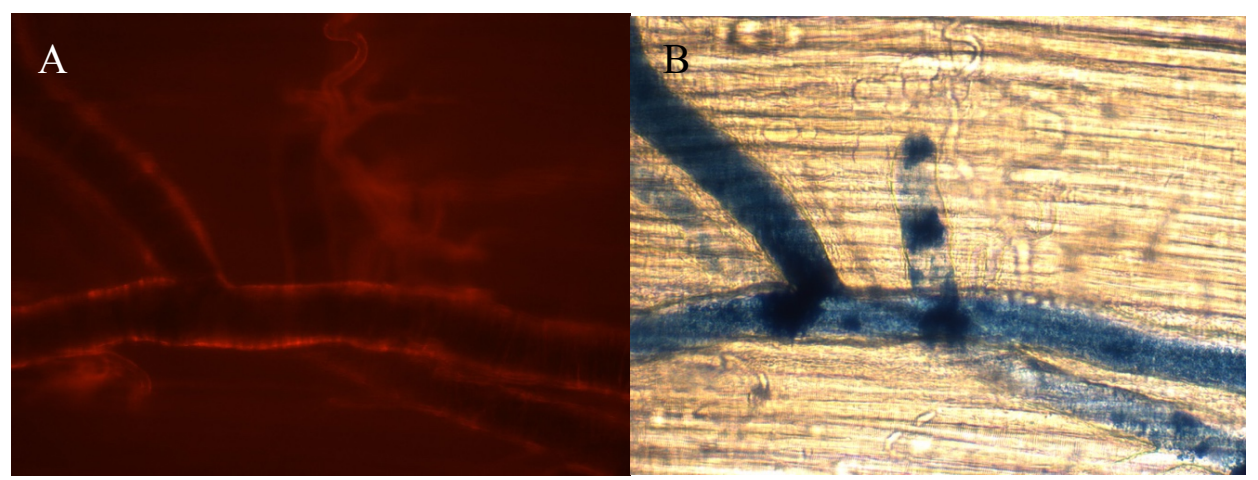

N=3 Anterior Gracilis Collateral Day-7 Post-Femoral Artery Ligation A) Alpha-Smooth Muscle Actin B) Microfil

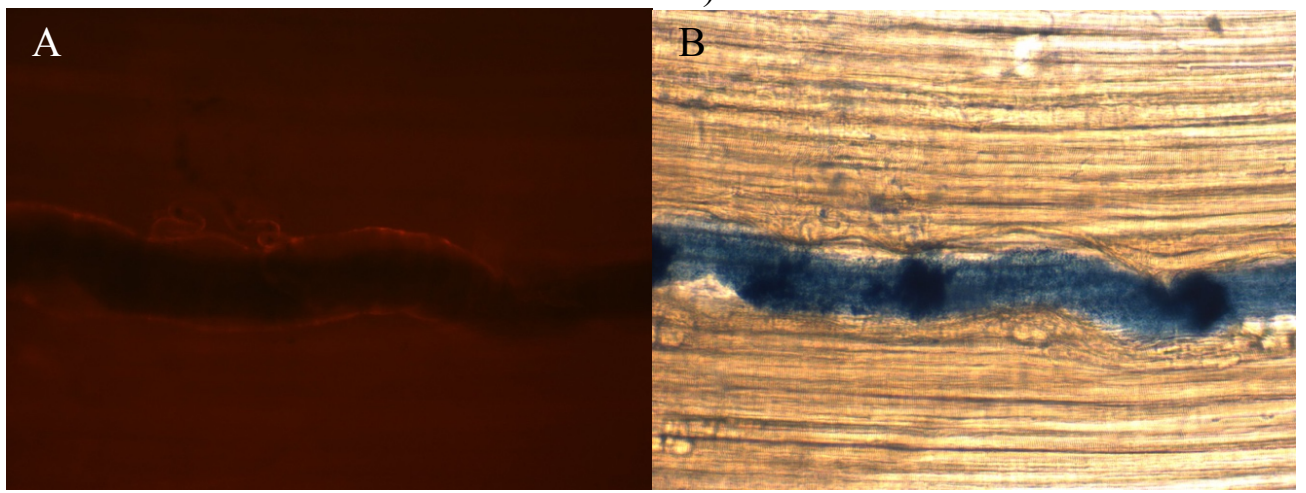

$\mathrm{N}=4$ Anterior Gracilis Collateral Day-7 Post-Femoral Artery Ligation A) Alpha-Smooth Muscle Actin B) Microfil

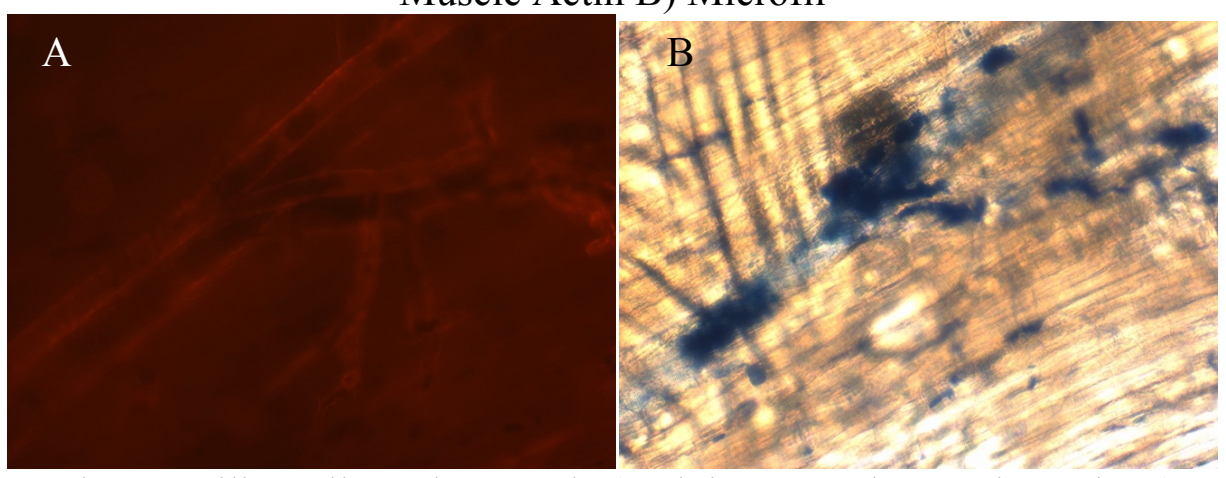

$\mathrm{N}=4$ Anterior Gracilis Collateral Control A) Alpha-Smooth Muscle Actin B) Microfil

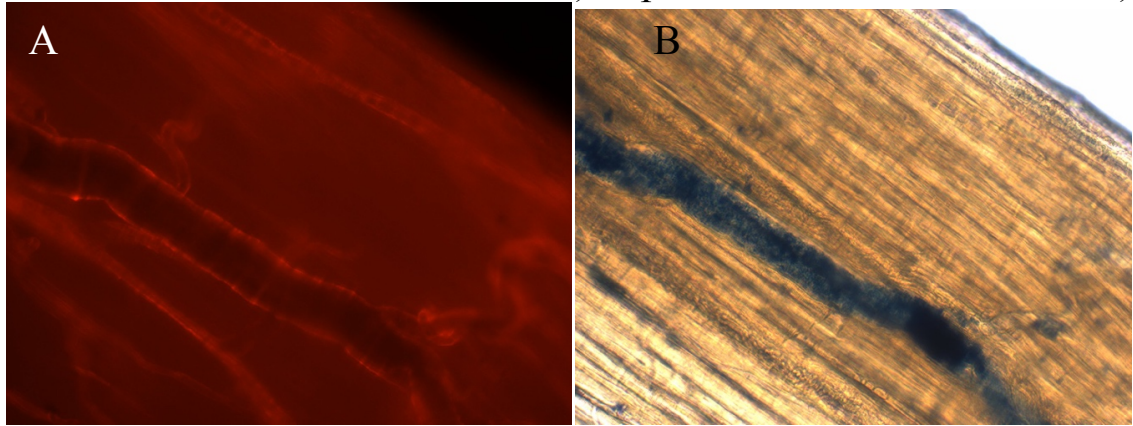

$\mathrm{N}=5$ Anterior Gracilis Collateral Day-7 Post-Femoral Artery Ligation A) Alpha-Smooth Muscle Actin B) Microfil 


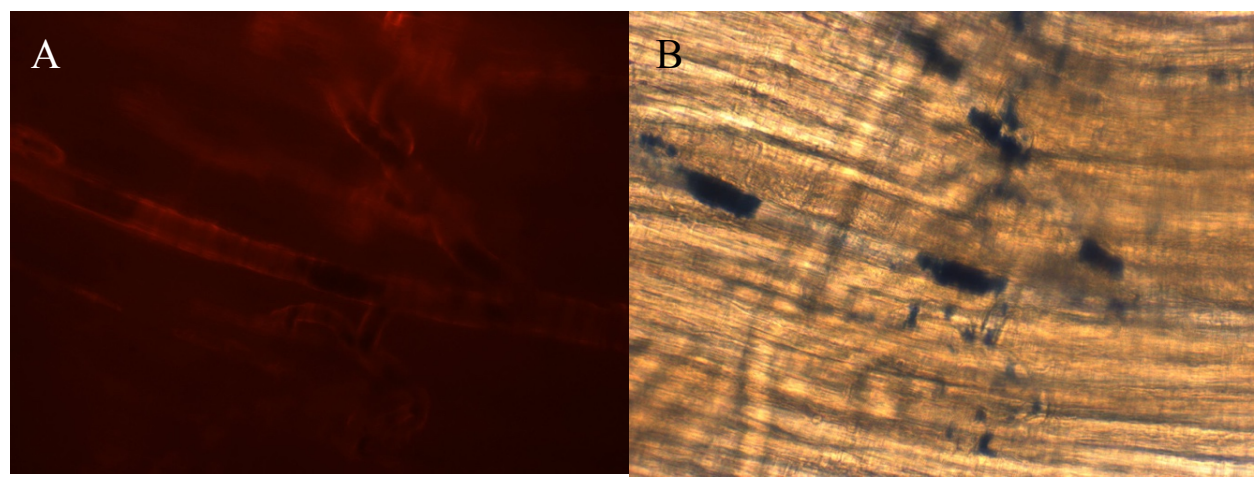

$\mathrm{N}=5$ Anterior Gracilis Collateral Control A) Alpha-Smooth Muscle Actin B) Microfil

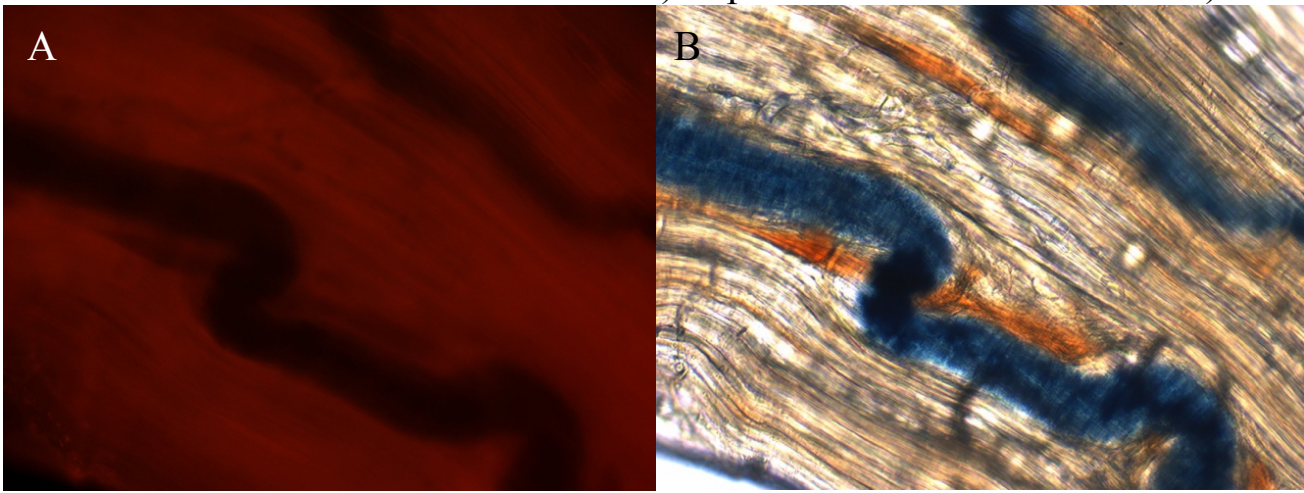

$\mathrm{N}=6$ Anterior Gracilis Collateral Day-7 Post-Femoral Artery Ligation A) Alpha-Smooth Muscle Actin B) Microfil

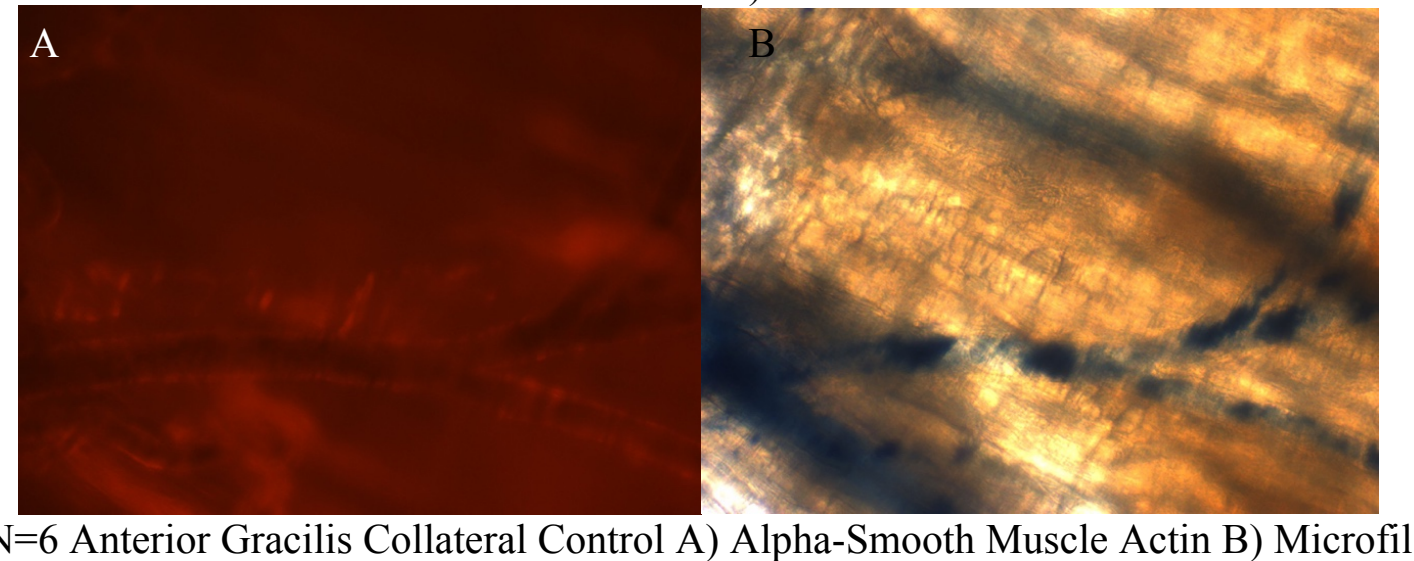




\section{BALB/C Males:}
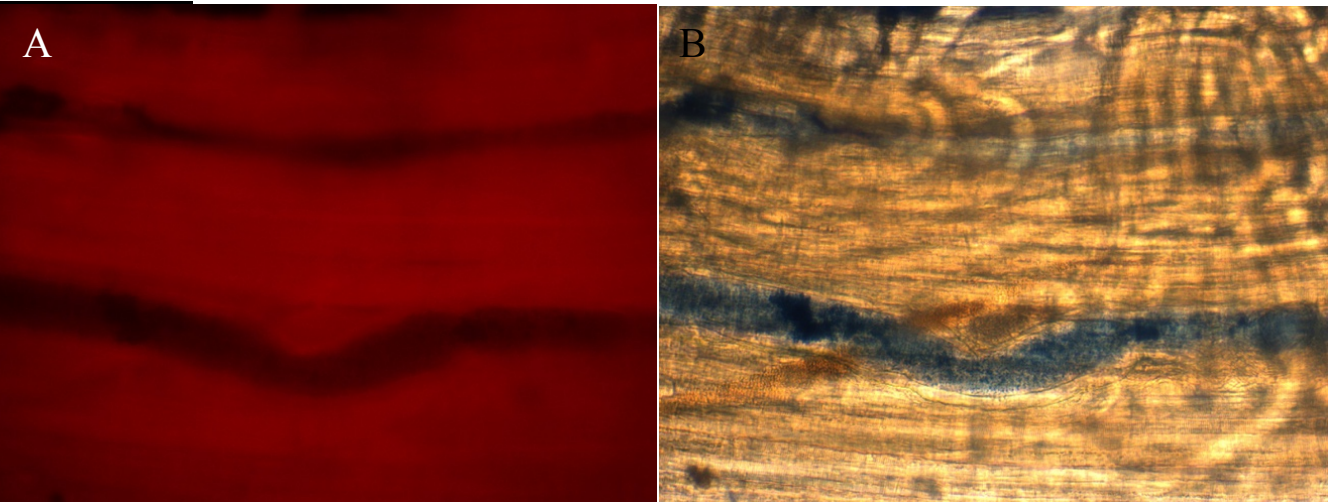

$\mathrm{N}=1$ Anterior Gracilis Collateral Day-7 Post-Femoral Artery Ligation A) Alpha-Smooth Muscle Actin B) Microfil

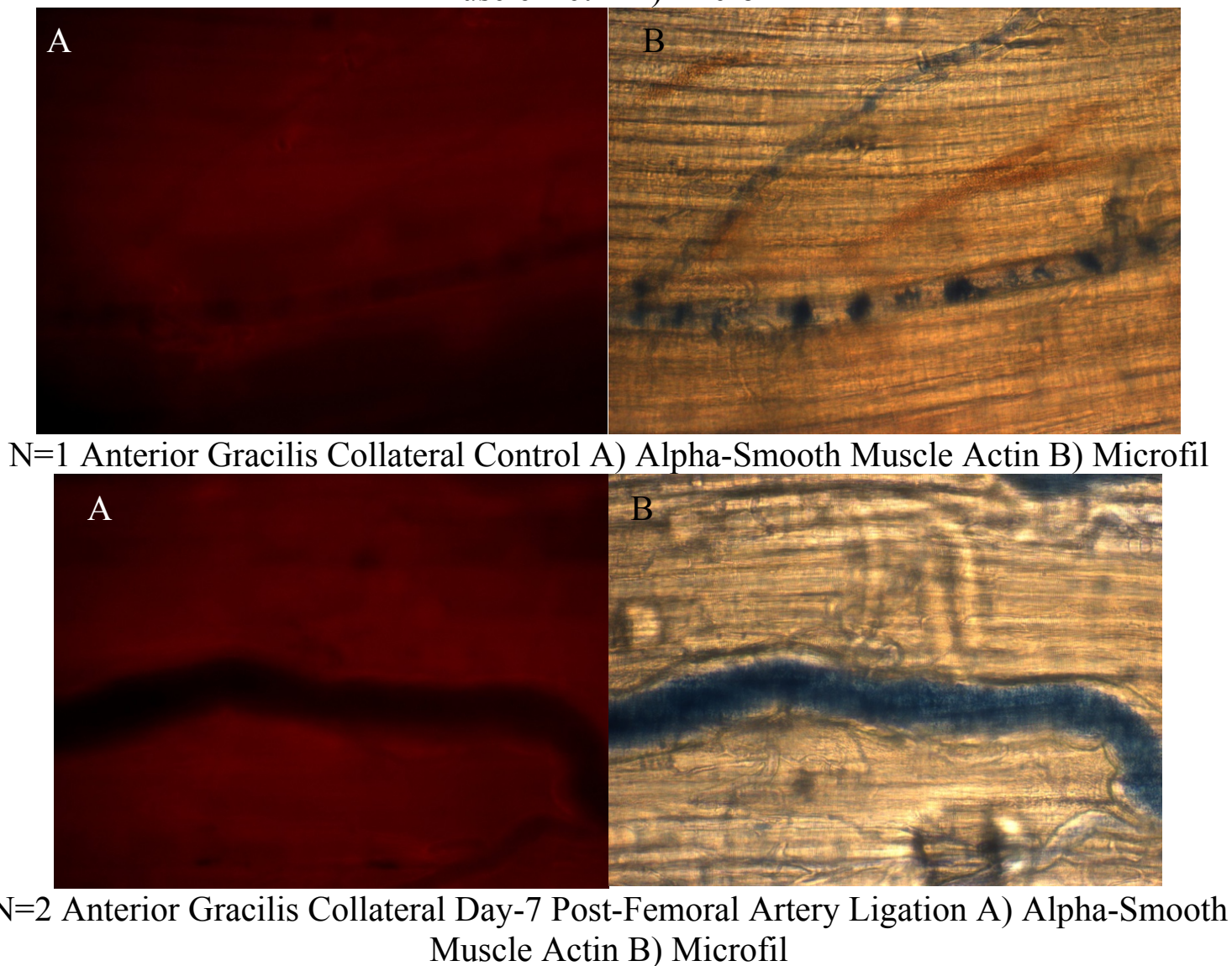




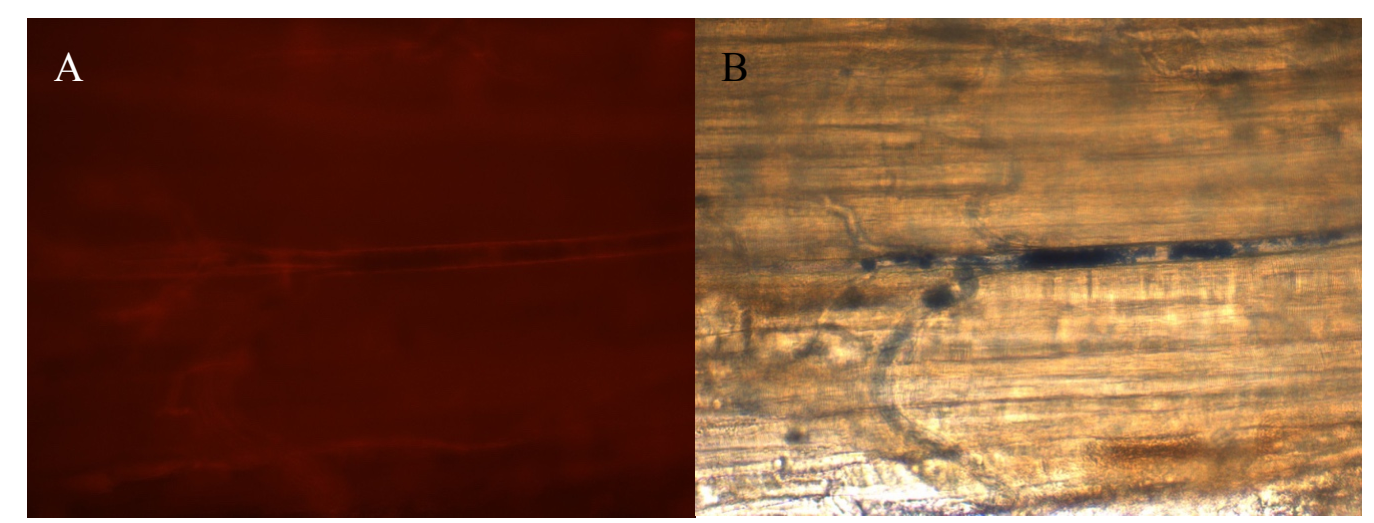

$\mathrm{N}=2$ Anterior Gracilis Collateral Control A) Alpha-Smooth Muscle Actin B) Microfil

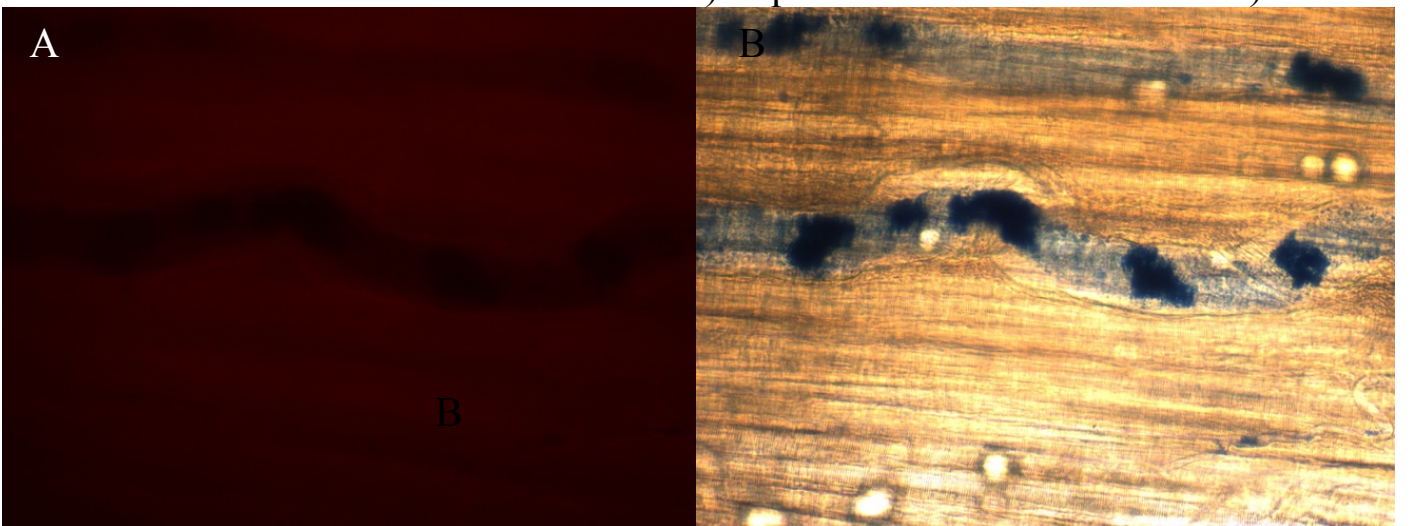

N=3 Anterior Gracilis Collateral Day-7 Post-Femoral Artery Ligation A) Alpha-Smooth Muscle Actin B) Microfil

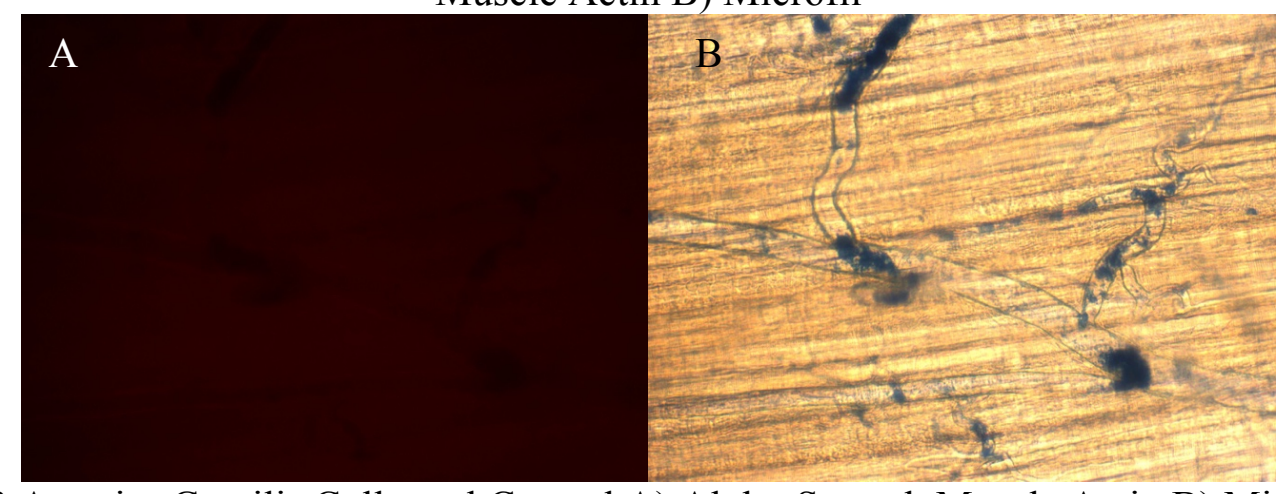

N=3 Anterior Gracilis Collateral Control A) Alpha-Smooth Muscle Actin B) Microfil 


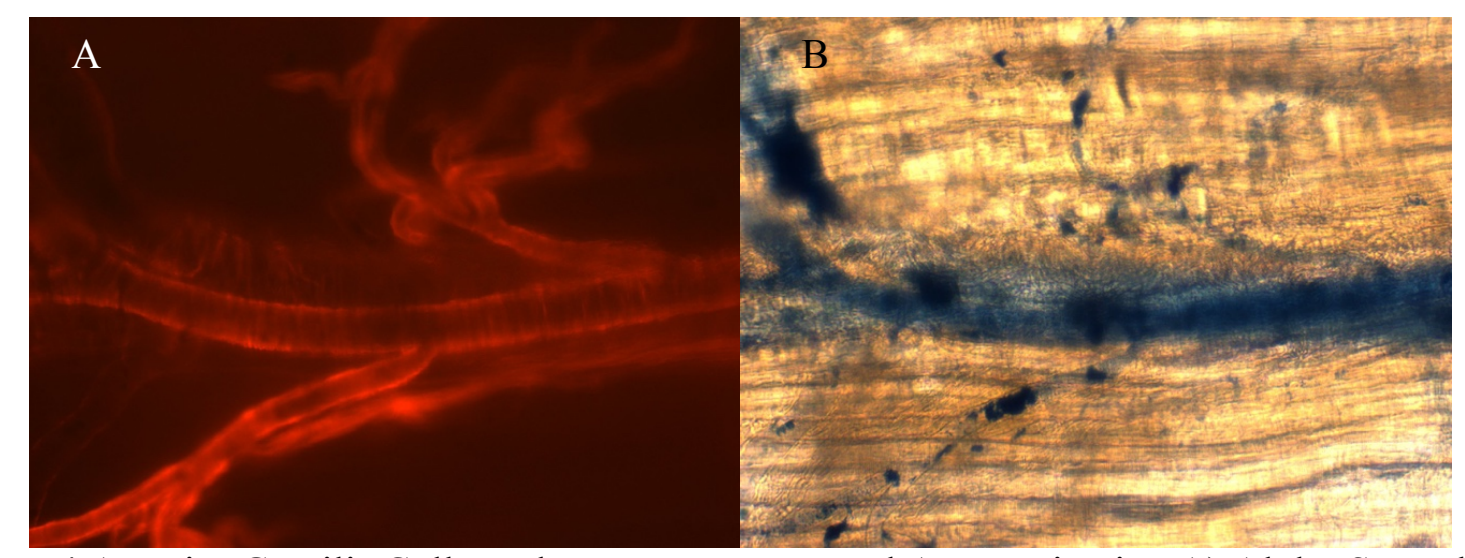

$\mathrm{N}=4$ Anterior Gracilis Collateral Day-7 Post-Femoral Artery Ligation A) Alpha-Smooth Muscle Actin B) Microfil

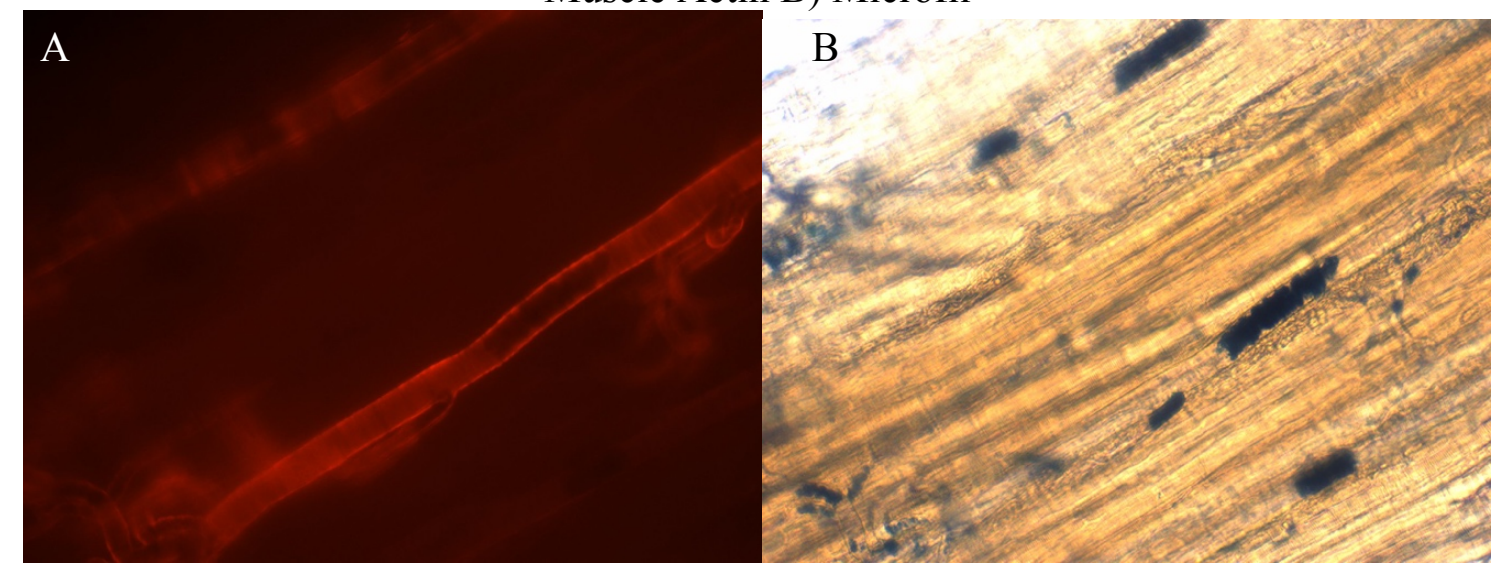

$\mathrm{N}=4$ Anterior Gracilis Collateral Control A) Alpha-Smooth Muscle Actin B) Microfil

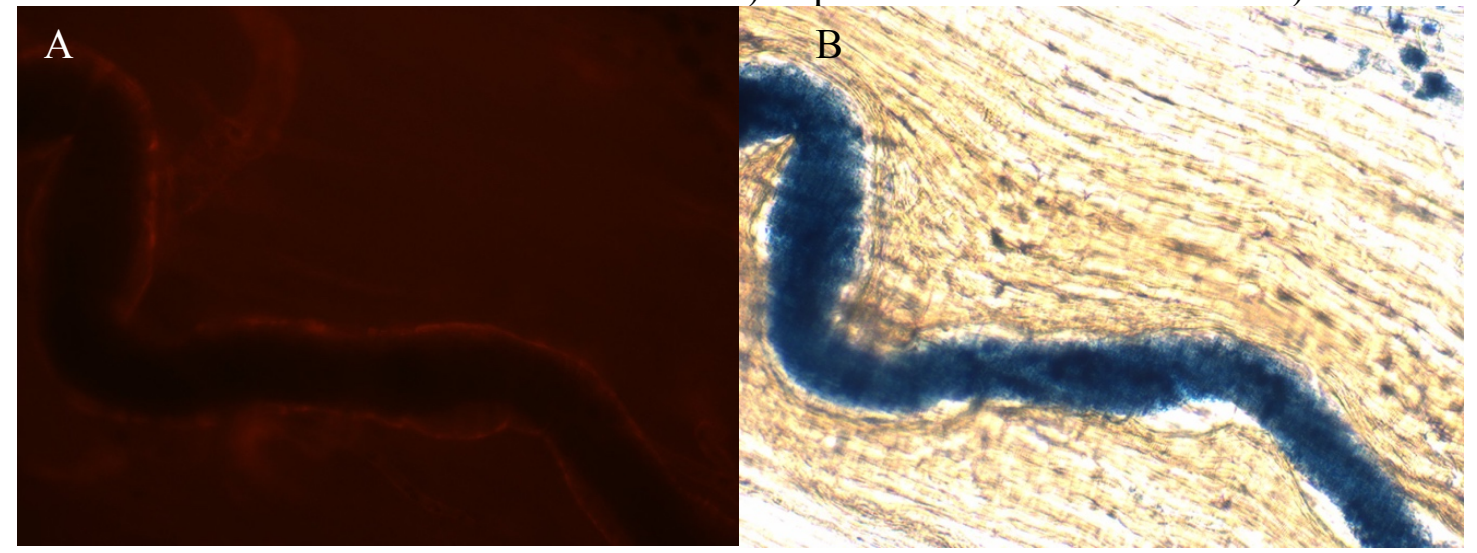

$\mathrm{N}=5$ Anterior Gracilis Collateral Day-7 Post-Femoral Artery Ligation A) Alpha-Smooth Muscle Actin B) Microfil 


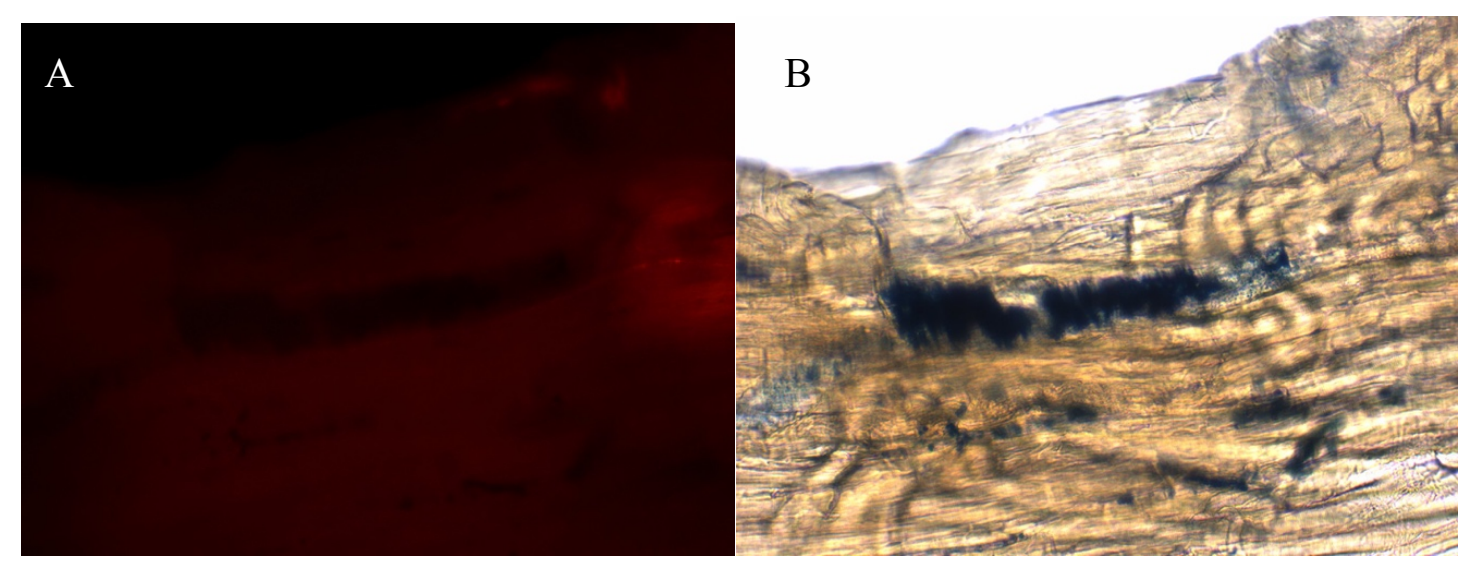

$\mathrm{N}=5$ Anterior Gracilis Collateral Control A) Alpha-Smooth Muscle Actin B) Microfil

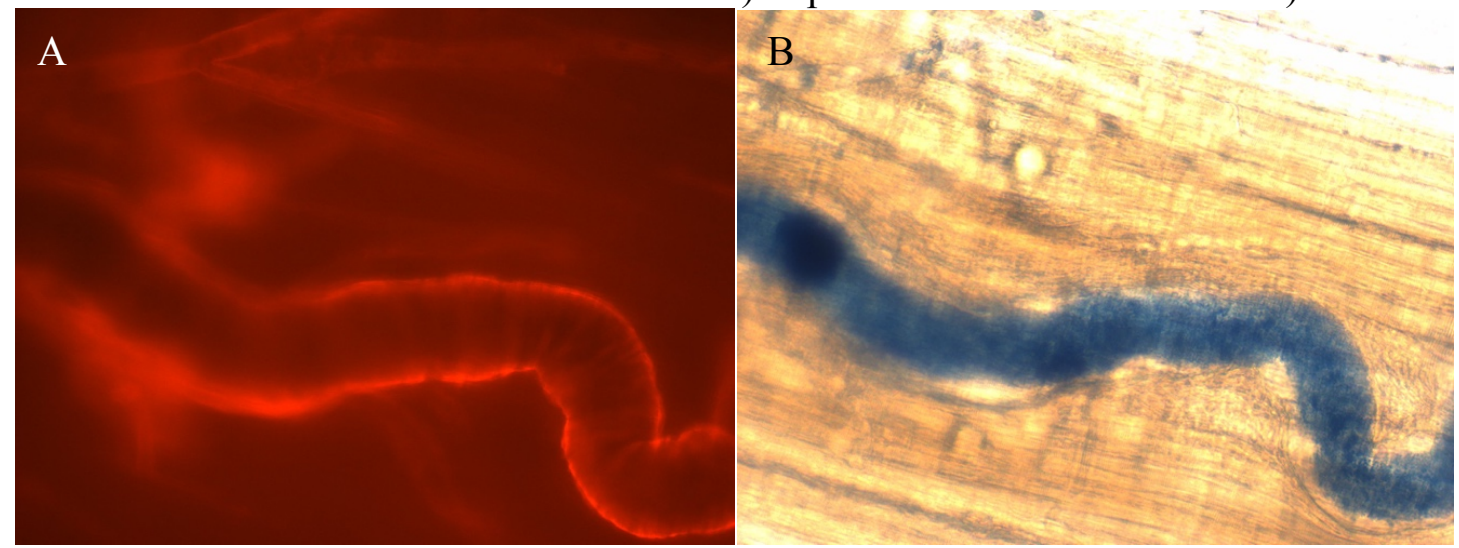

N=6 Anterior Gracilis Collateral Day-7 Post-Femoral Artery Ligation A) Alpha-Smooth Muscle Actin B) Microfil

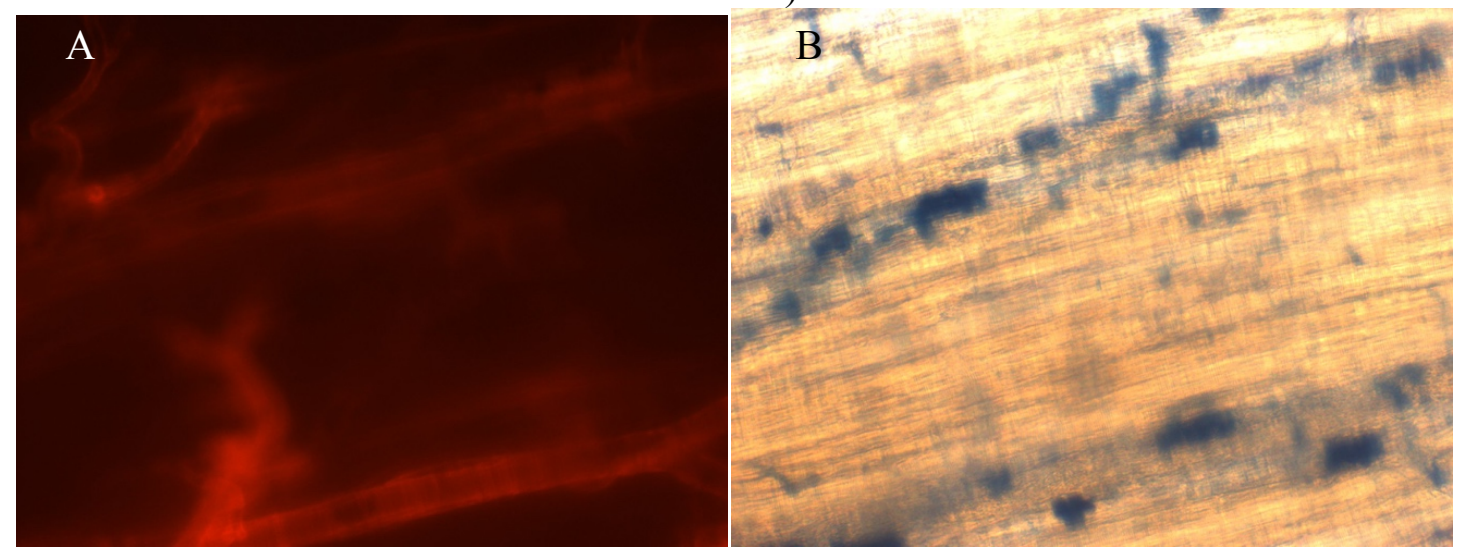

$\mathrm{N}=6$ Anterior Gracilis Collateral Control A) Alpha-Smooth Muscle Actin B) Microfil 
Confocal Images (40x)

\section{C57BI/6 Females:}

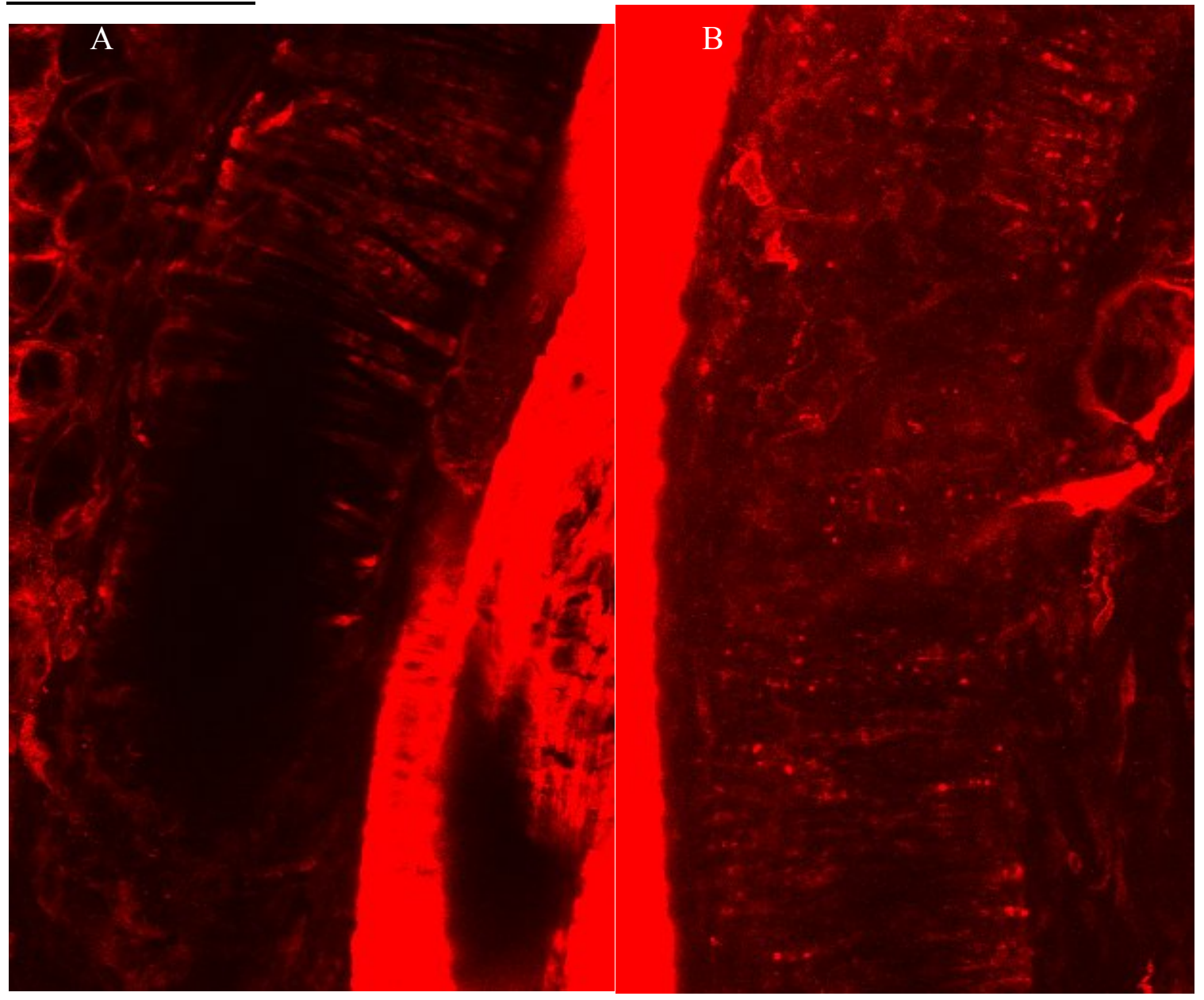

N=1 A) Profunda Femoris Artery Day-7 Post-Ligation B) Profunda Femoris Artery Control 


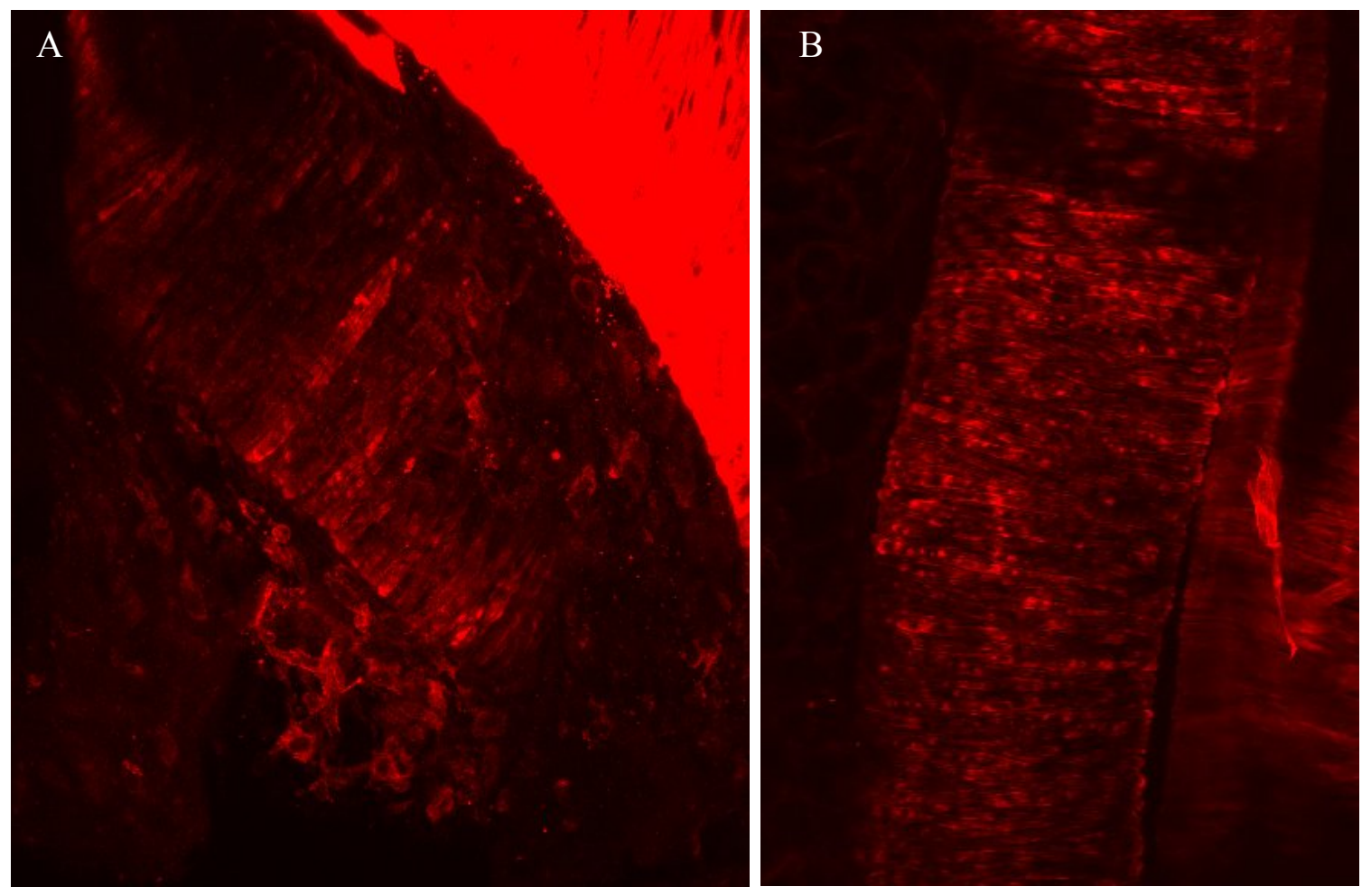

N=2 A) Profunda Femoris Artery Day-7 Post-Ligation B) Profunda Femoris Artery Control

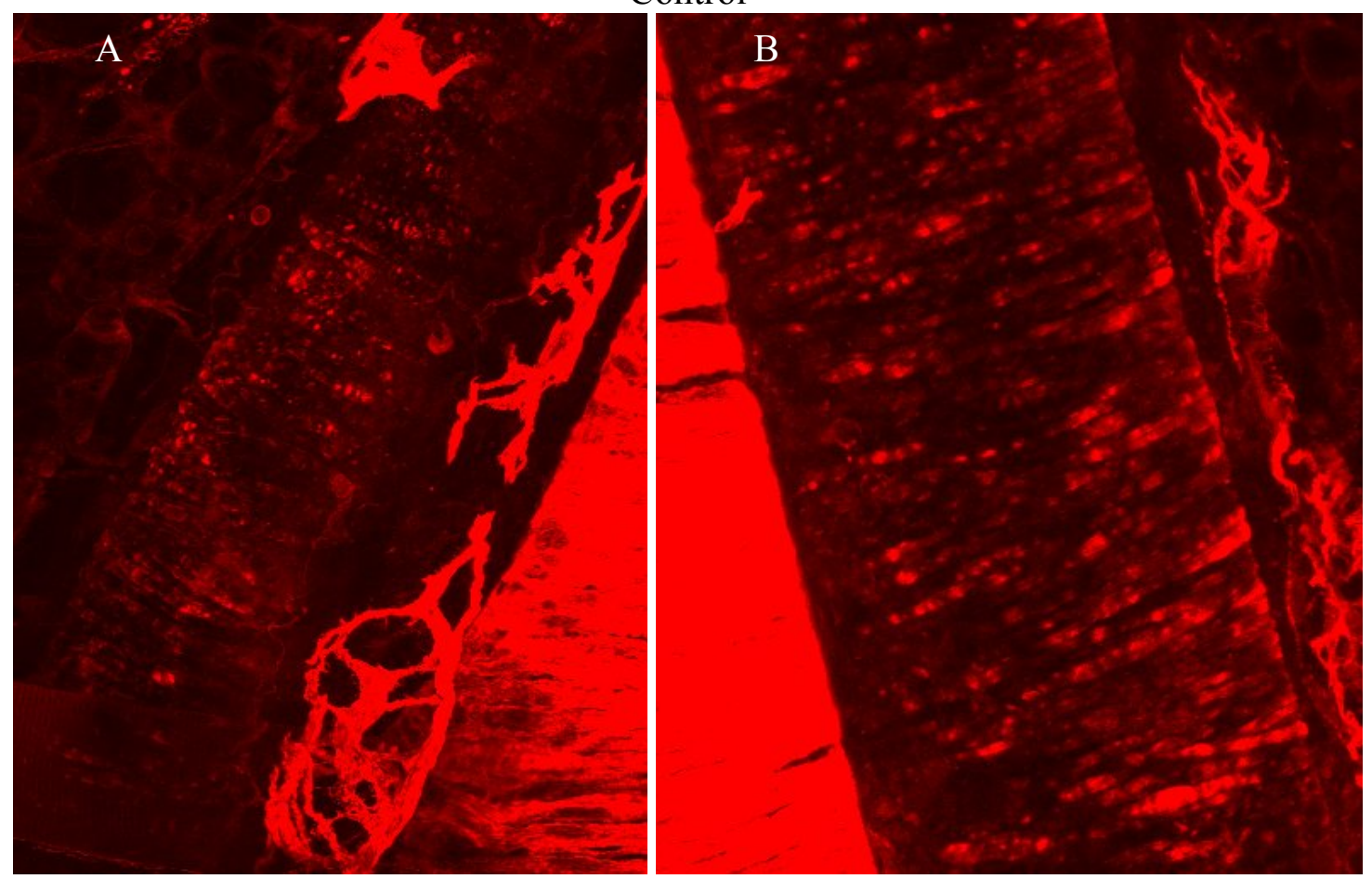

N=3 A) Profunda Femoris Artery Day-7 Post-Ligation B) Profunda Femoris Artery Control 


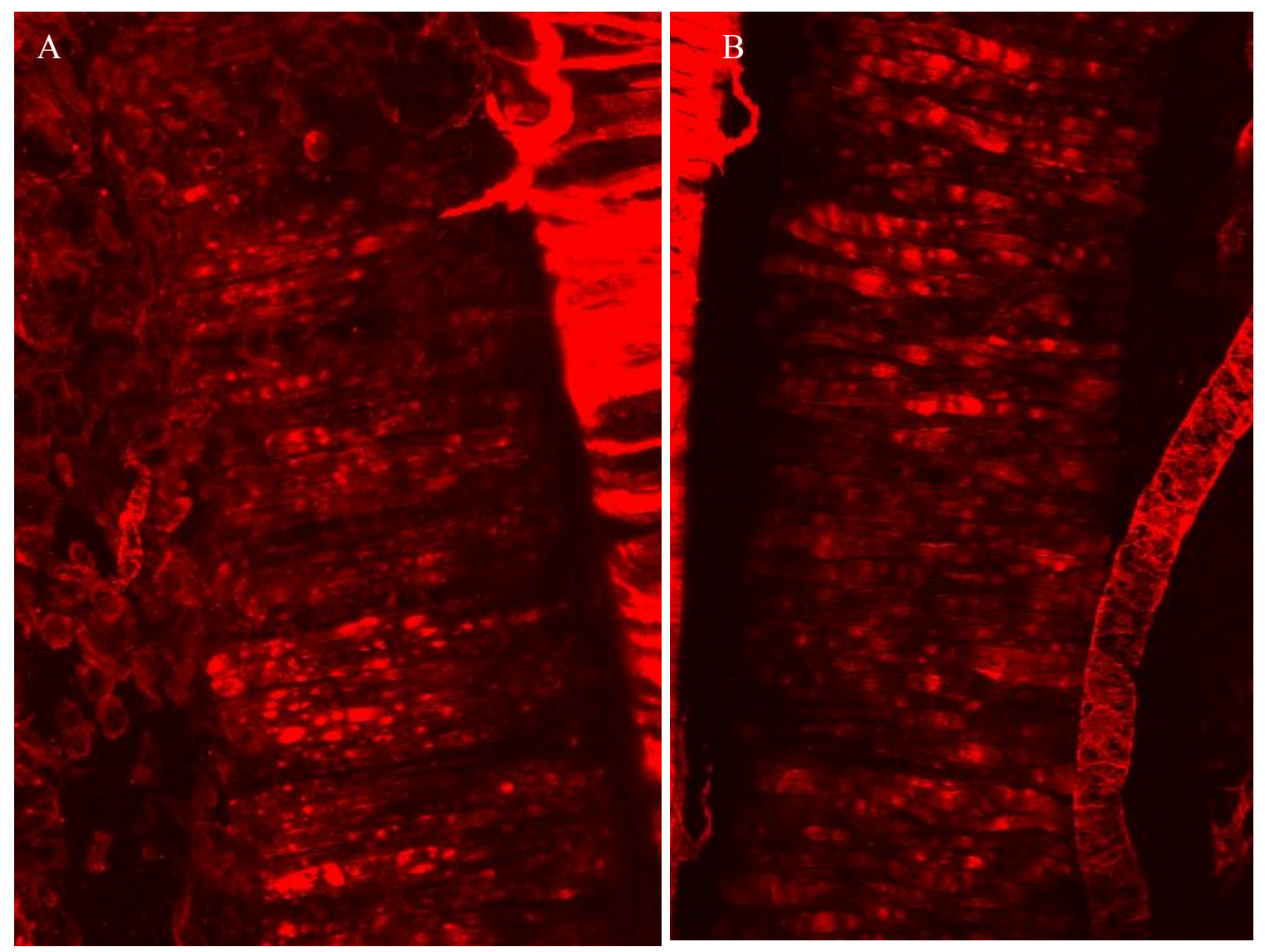

$\mathrm{N}=4$ A) Profunda Femoris Artery Day-7 Post-Ligation B) Profunda Femoris Artery Control 


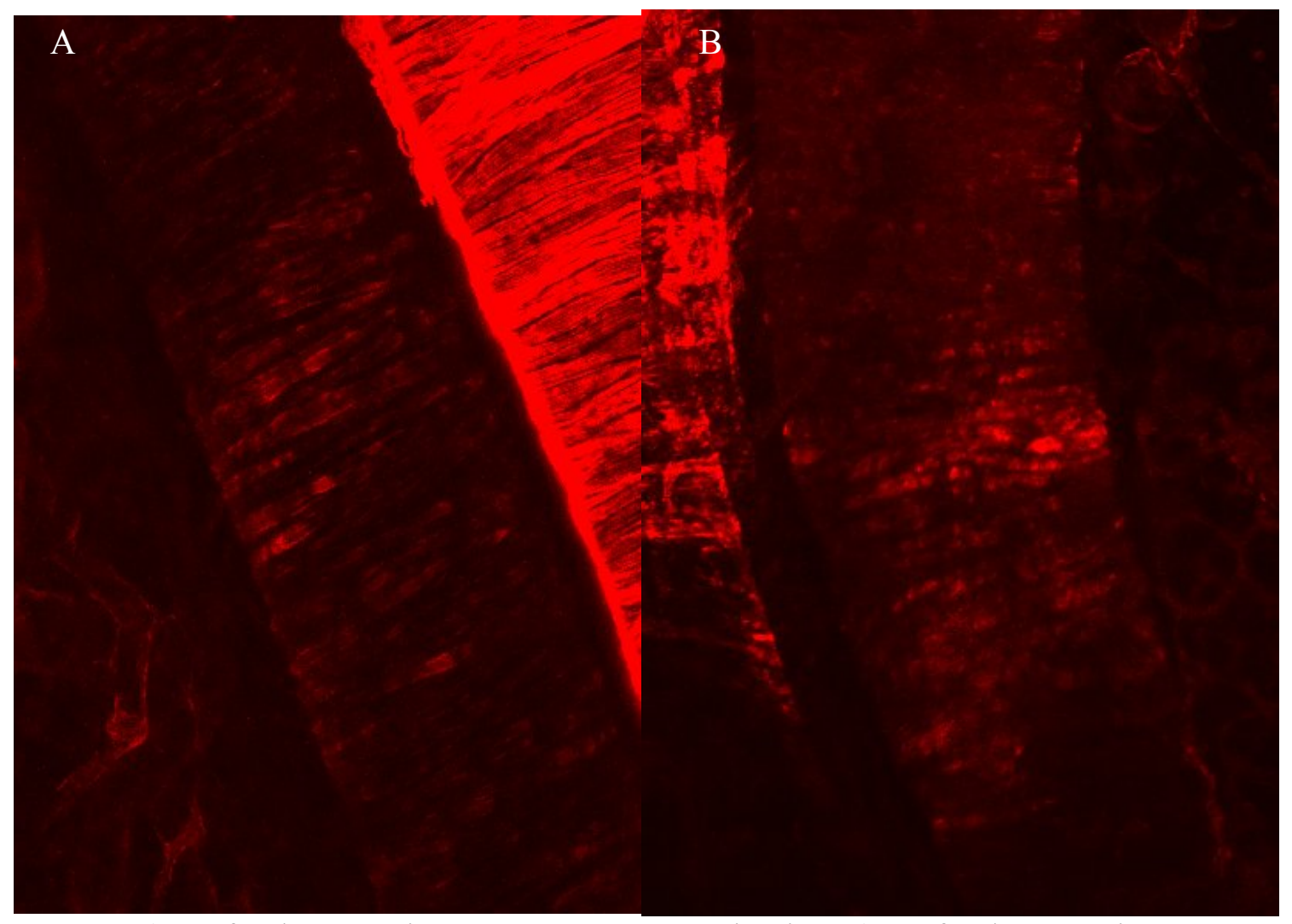

N=5 A) Profunda Femoris Artery Day-7 Post-Ligation B) Profunda Femoris Artery

\section{Control}

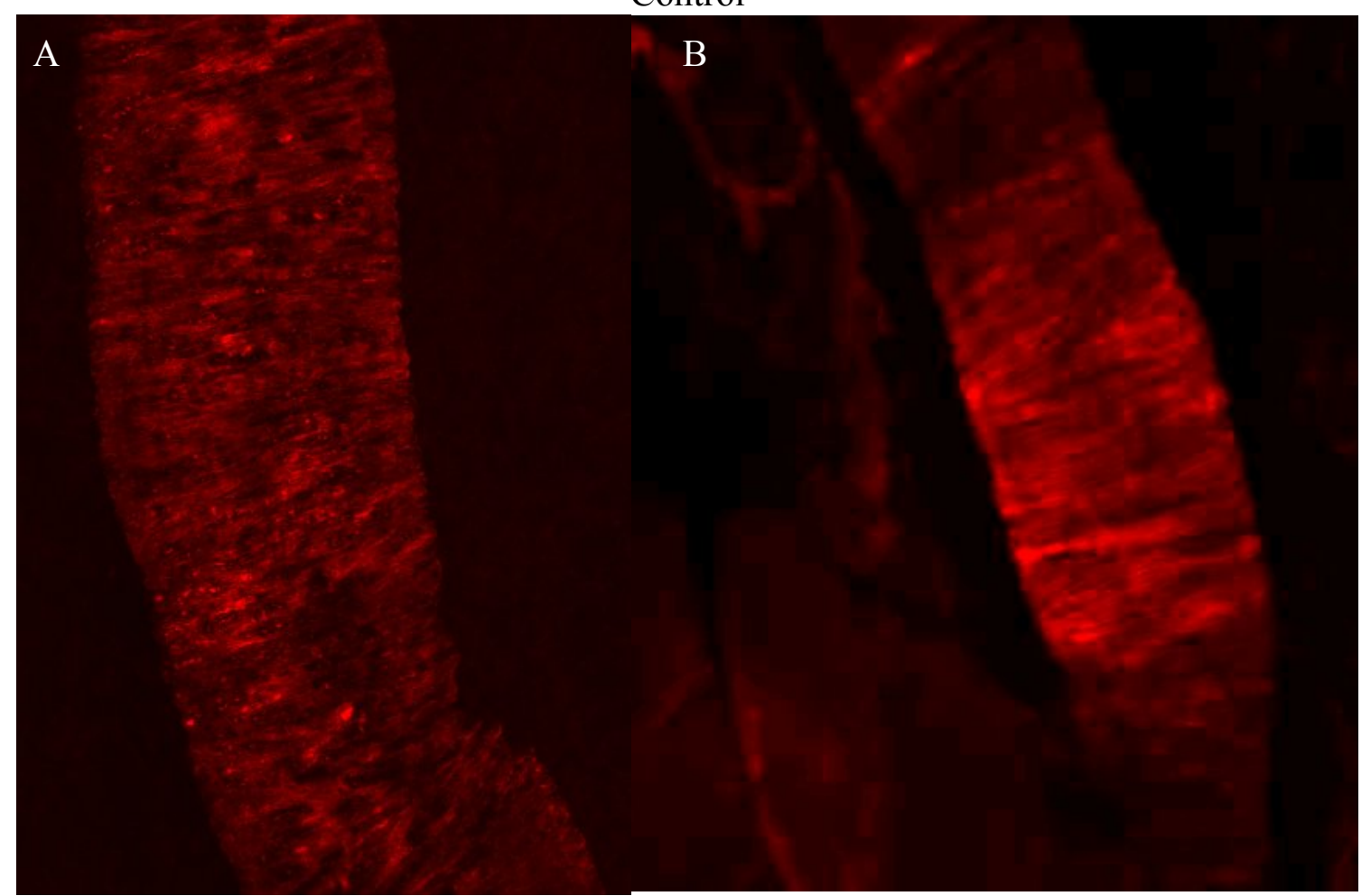

N=6 A) Profunda Femoris Artery Day-7 Post-Ligation B) Profunda Femoris Artery

Control 


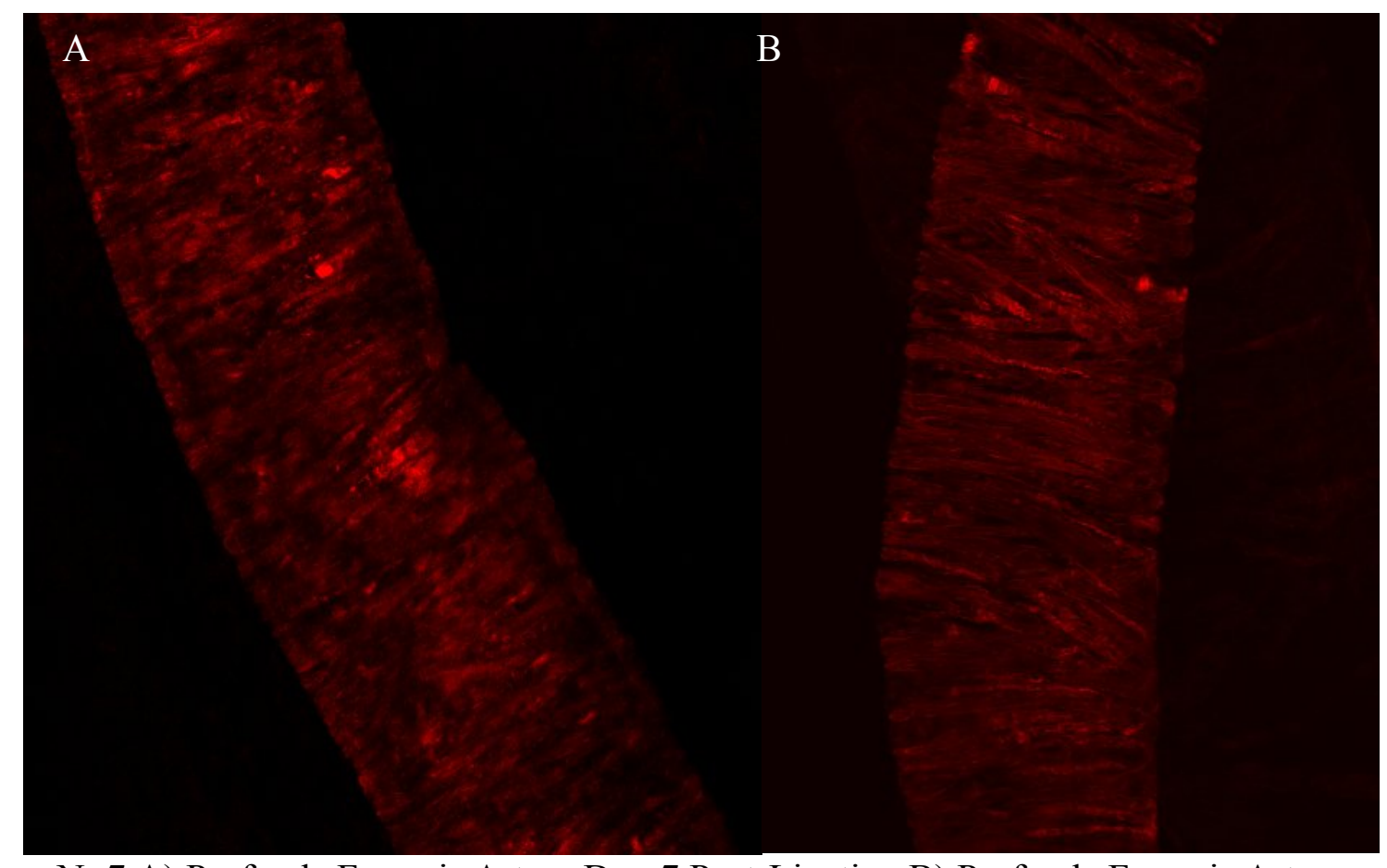

N=7 A) Profunda Femoris Artery Day-7 Post-Ligation B) Profunda Femoris Artery Control

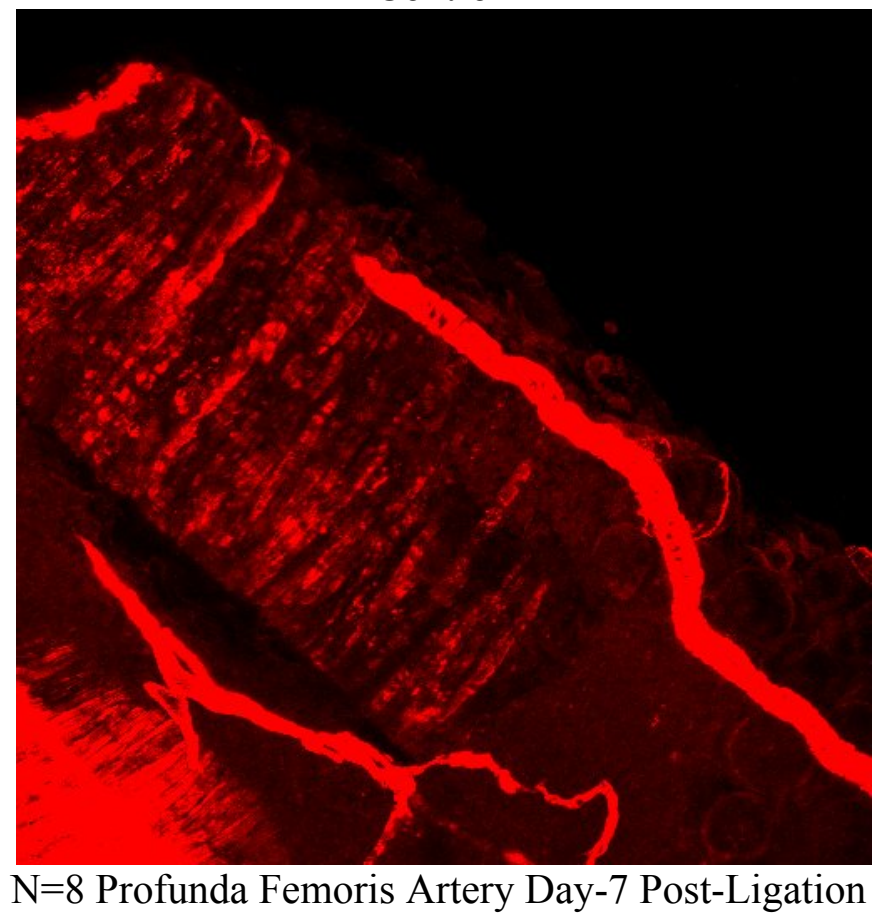




\section{C57Bl/6 Males:}

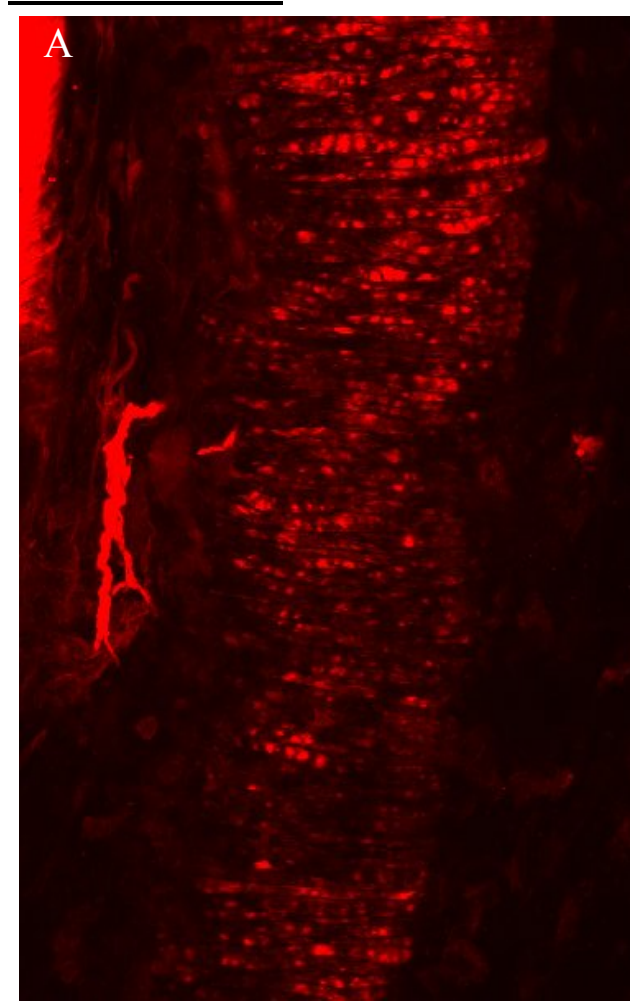

B

N=1 A) Profunda Femoris Artery Day-7 Post-Ligation B) Profunda Femoris Artery

Control

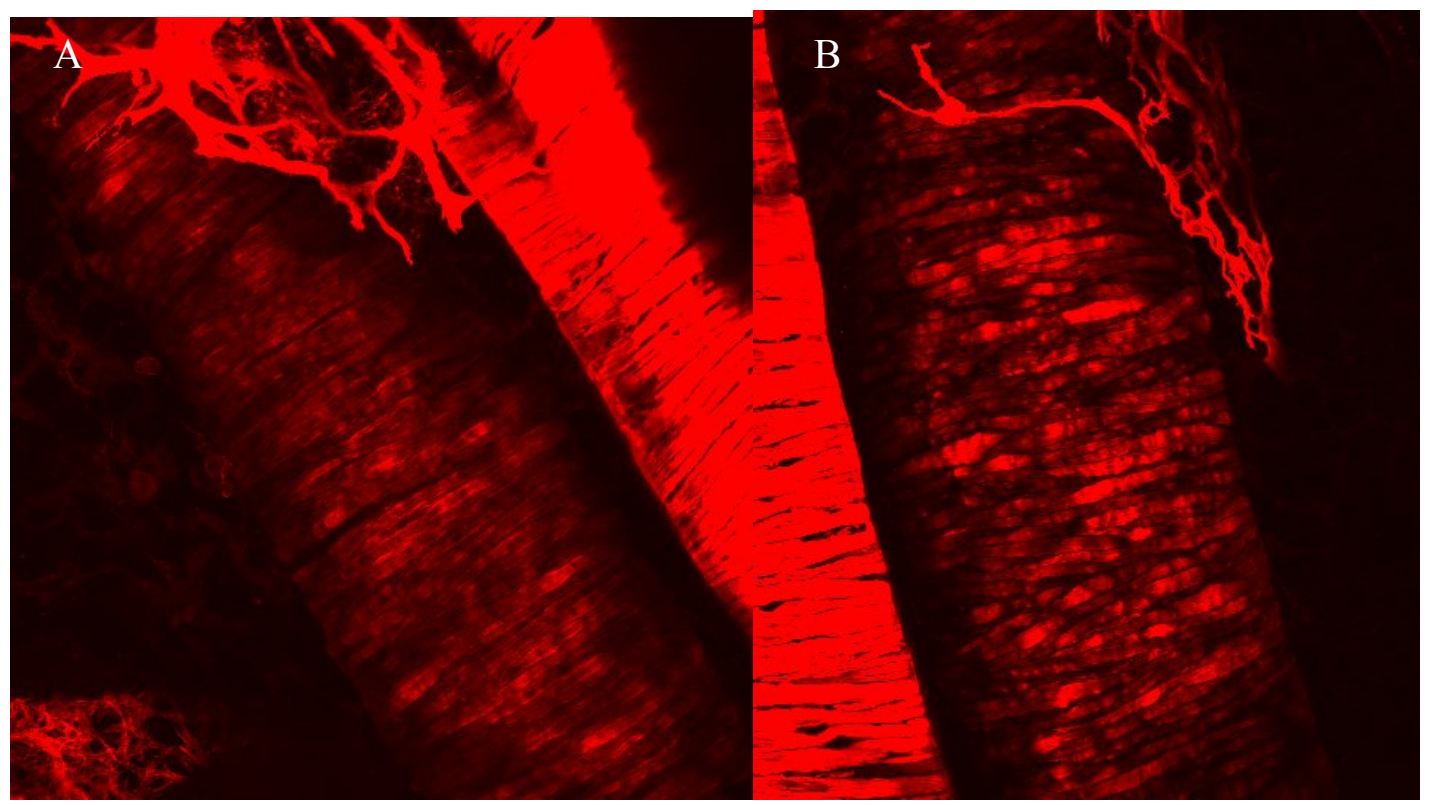

N=2 A) Profunda Femoris Artery Day-7 Post-Ligation B) Profunda Femoris Artery

Control 


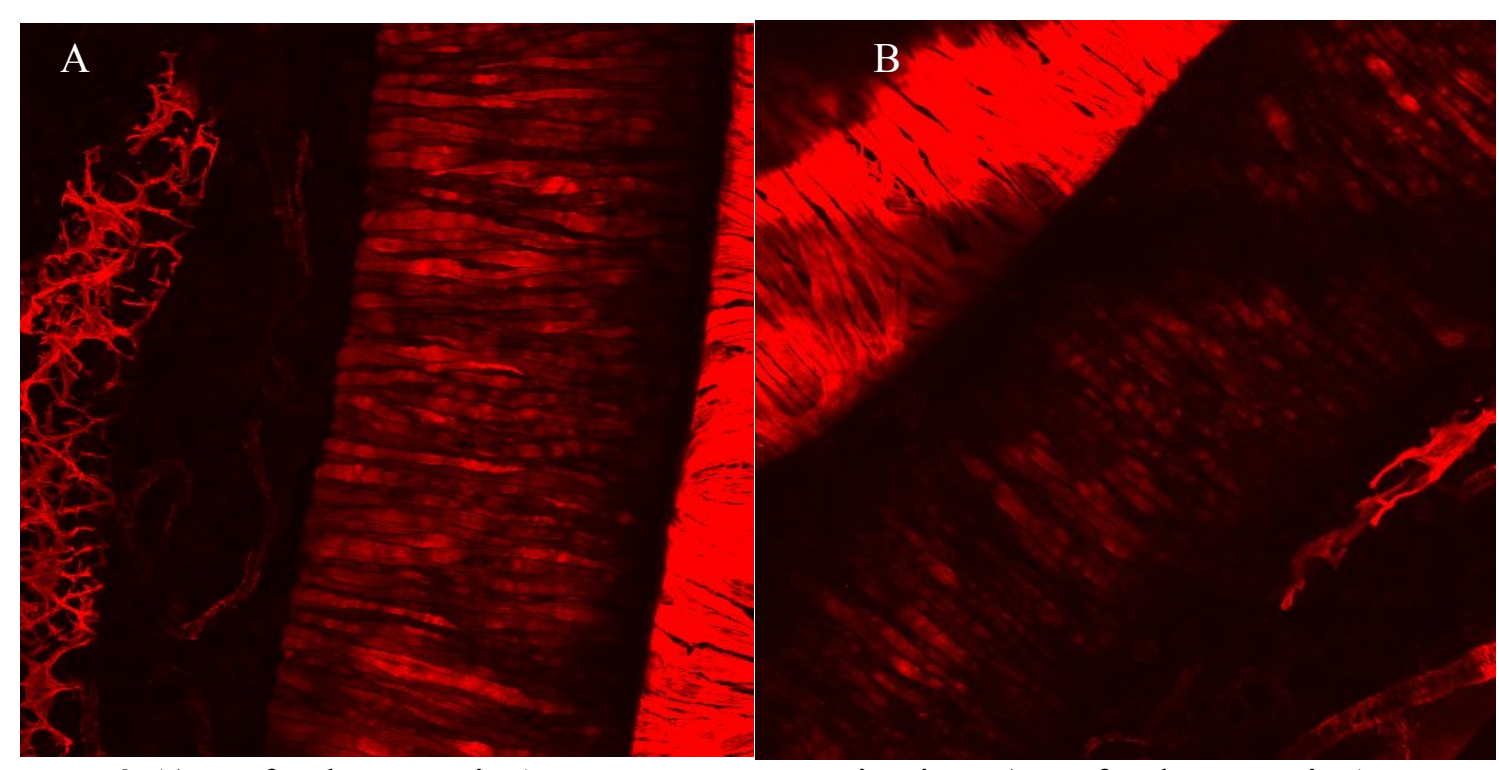

$\mathrm{N}=3$ A) Profunda Femoris Artery Day-7 Post-Ligation B) Profunda Femoris Artery Control

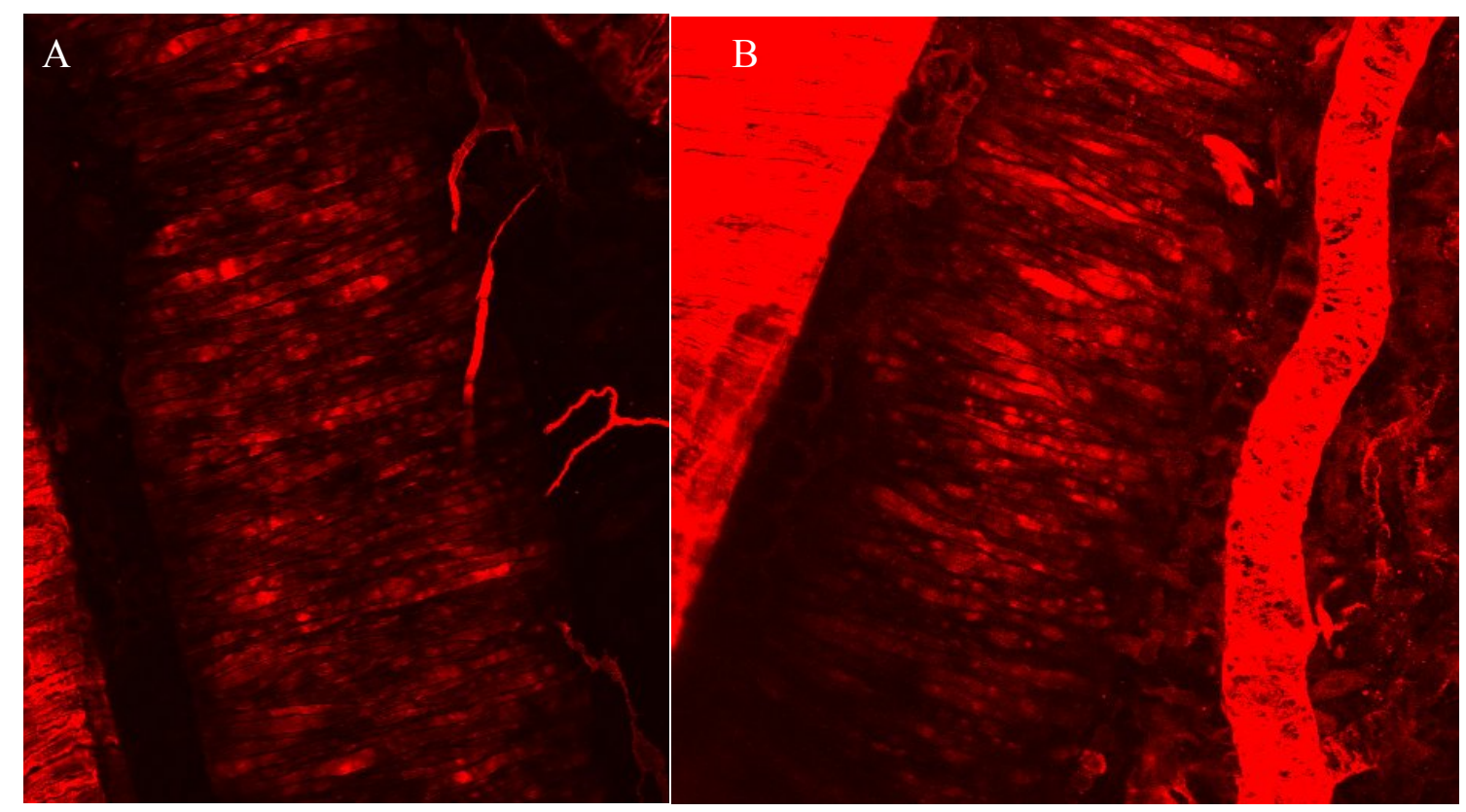

N=4 A) Profunda Femoris Artery Day-7 Post-Ligation B) Profunda Femoris Artery

Control 


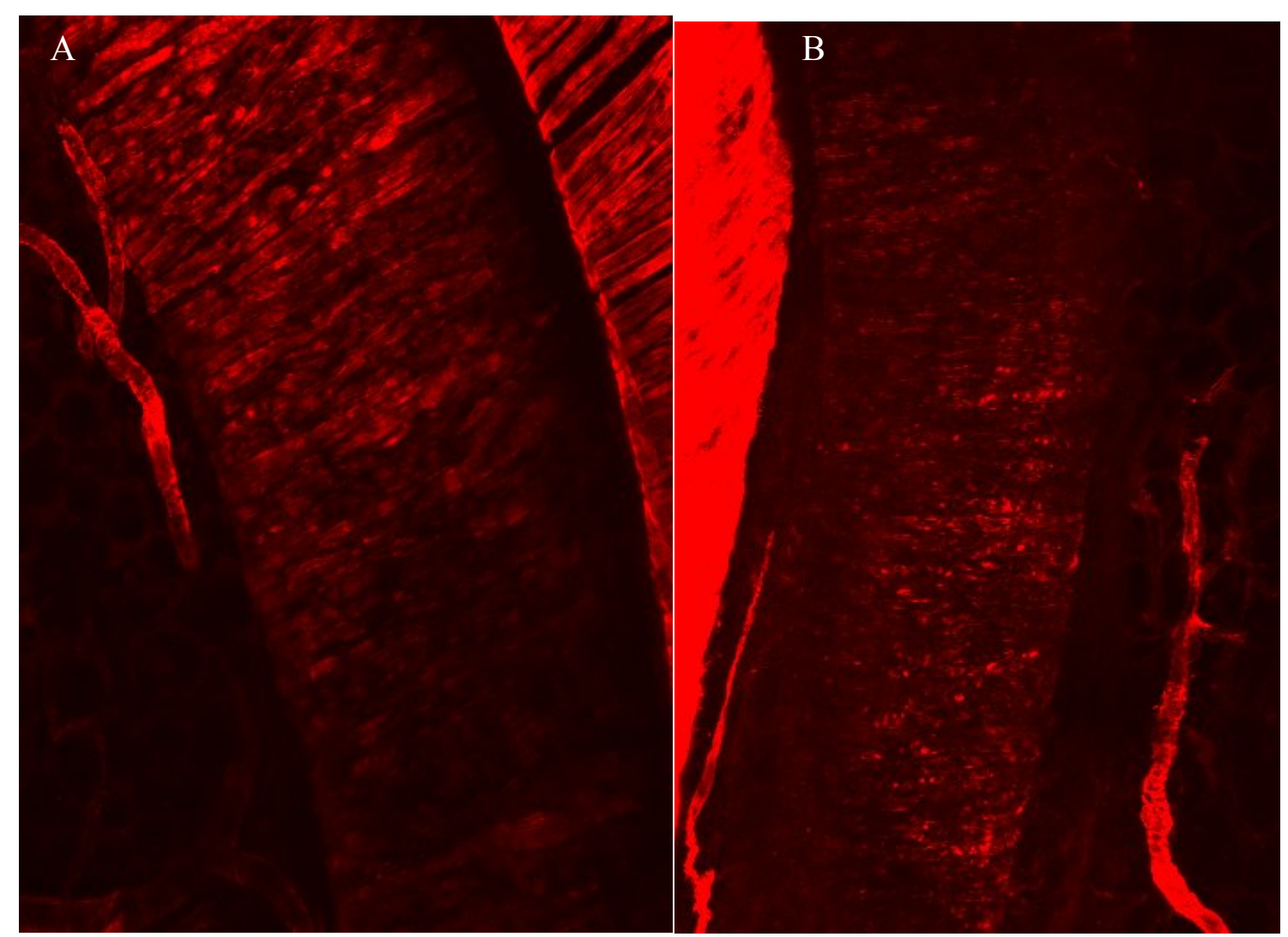

N=5 A) Profunda Femoris Artery Day-7 Post-Ligation B) Profunda Femoris Artery Control

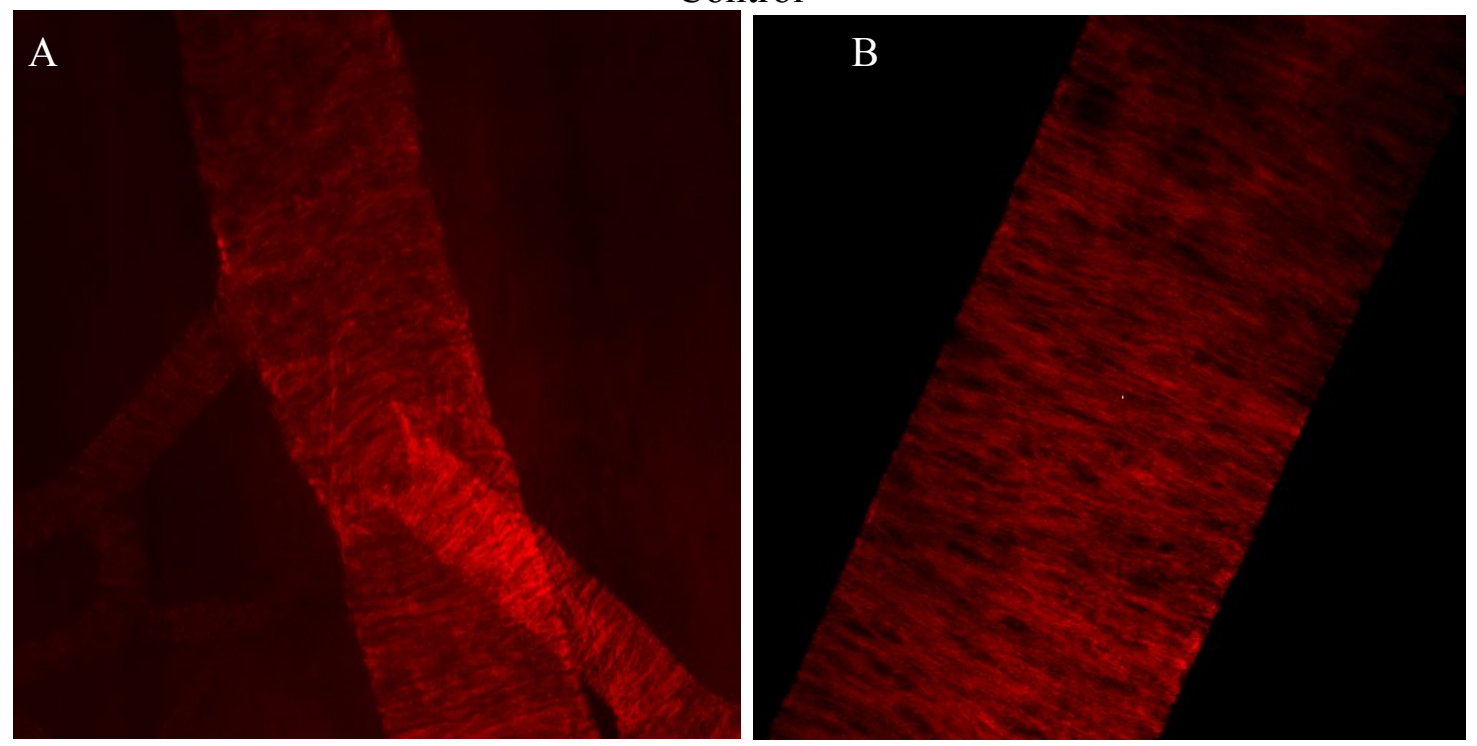

N=6 A) Profunda Femoris Artery Day-7 Post-Ligation B) Profunda Femoris Artery Control 



\section{BALB/C Females:}

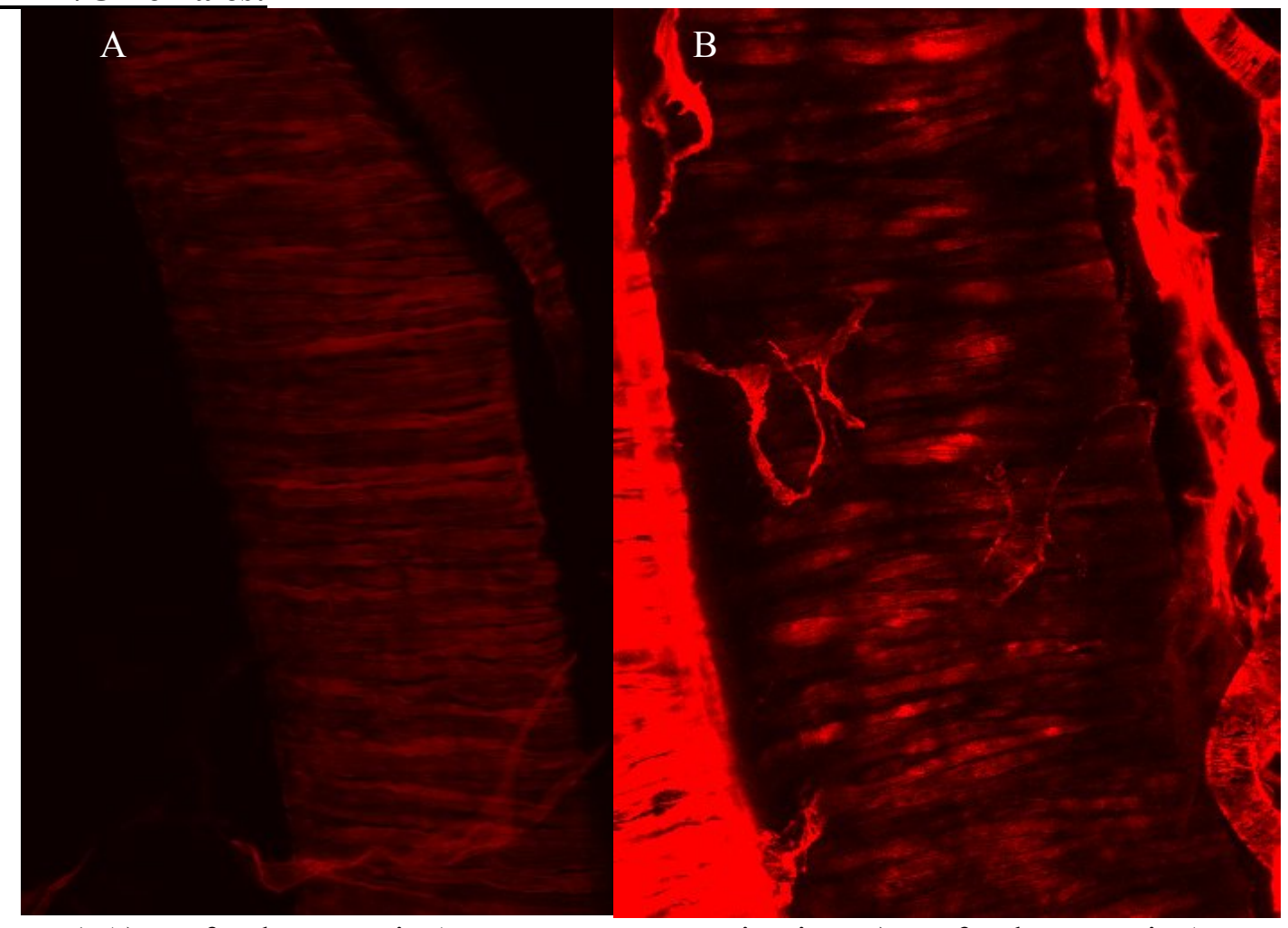

$\mathrm{N}=1$ A) Profunda Femoris Artery Day-7 Post-Ligation B) Profunda Femoris Artery Control

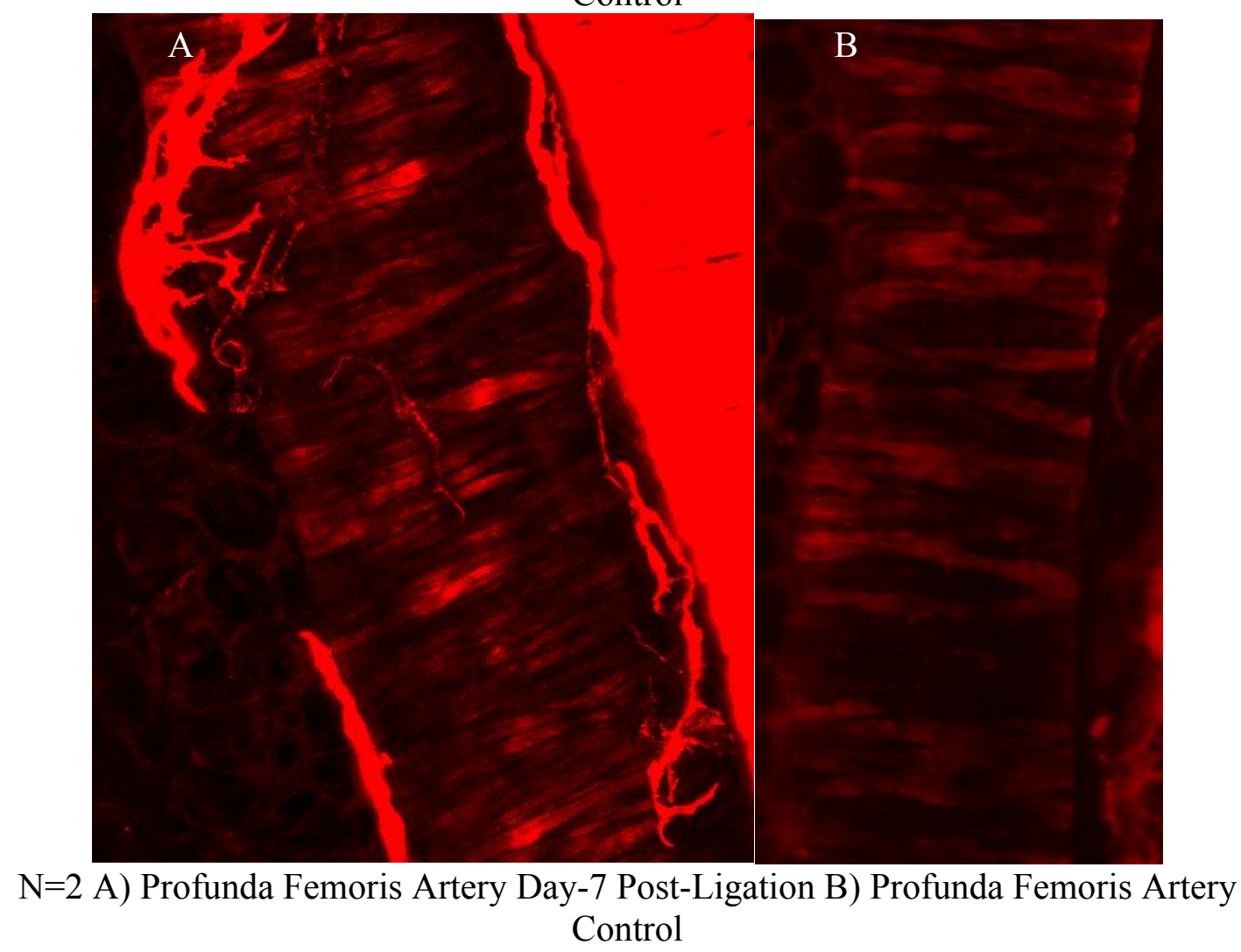




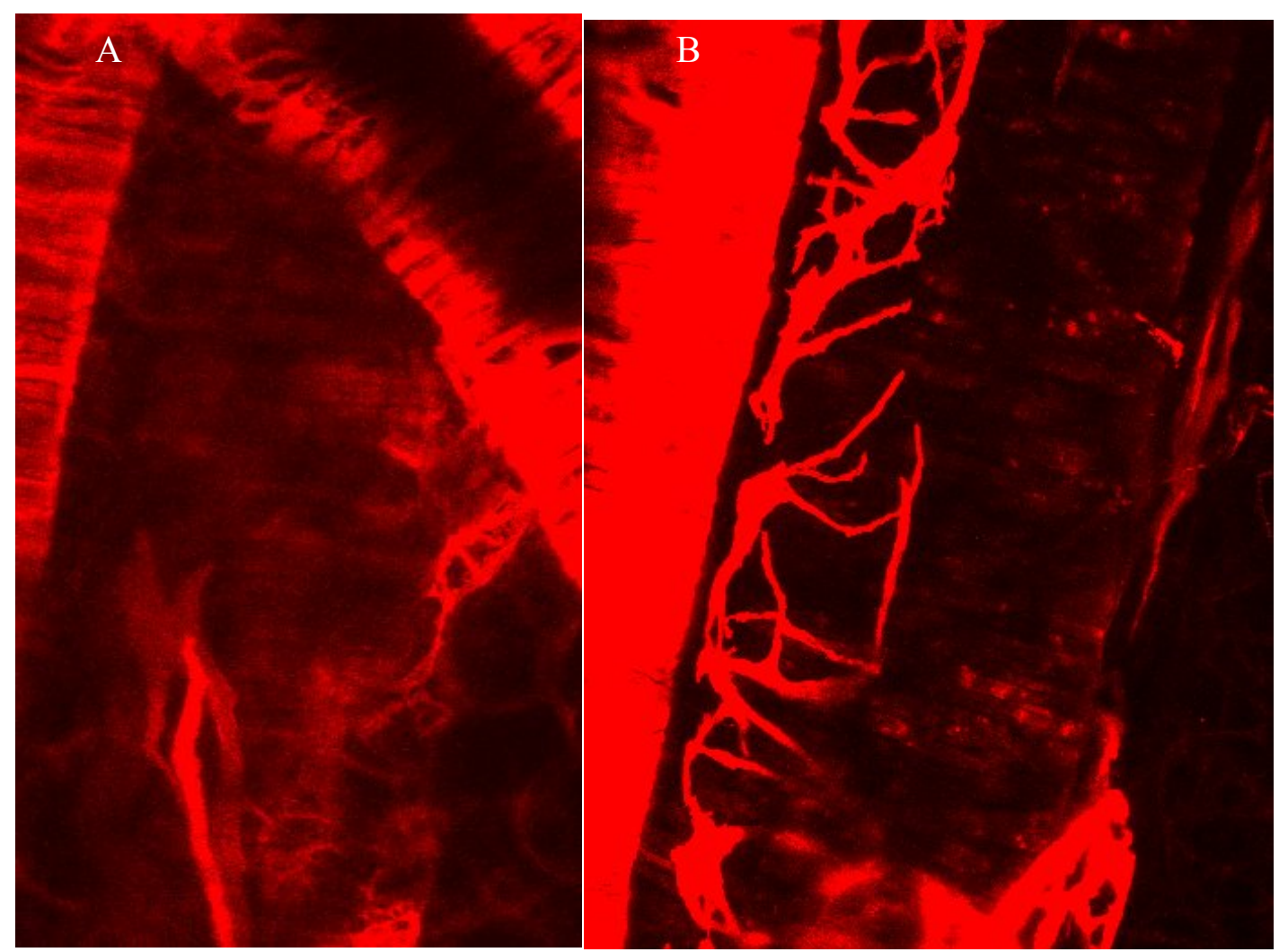

N=3 A) Profunda Femoris Artery Day-7 Post-Ligation (Did not use) B) Profunda Femoris Artery Control

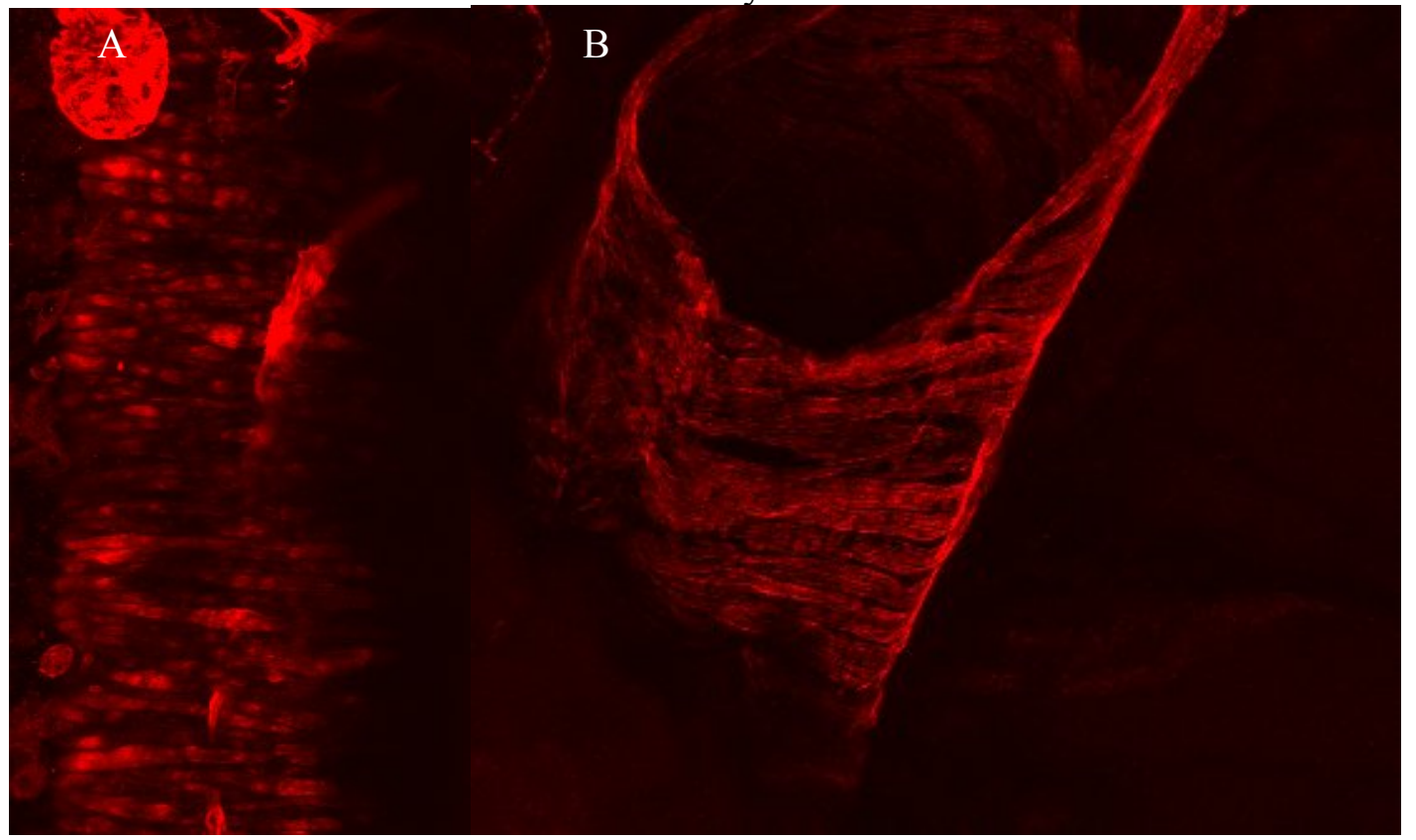

N=4 A) Profunda Femoris Artery Day-7 Post-Ligation B) Profunda Femoris Artery

Control 


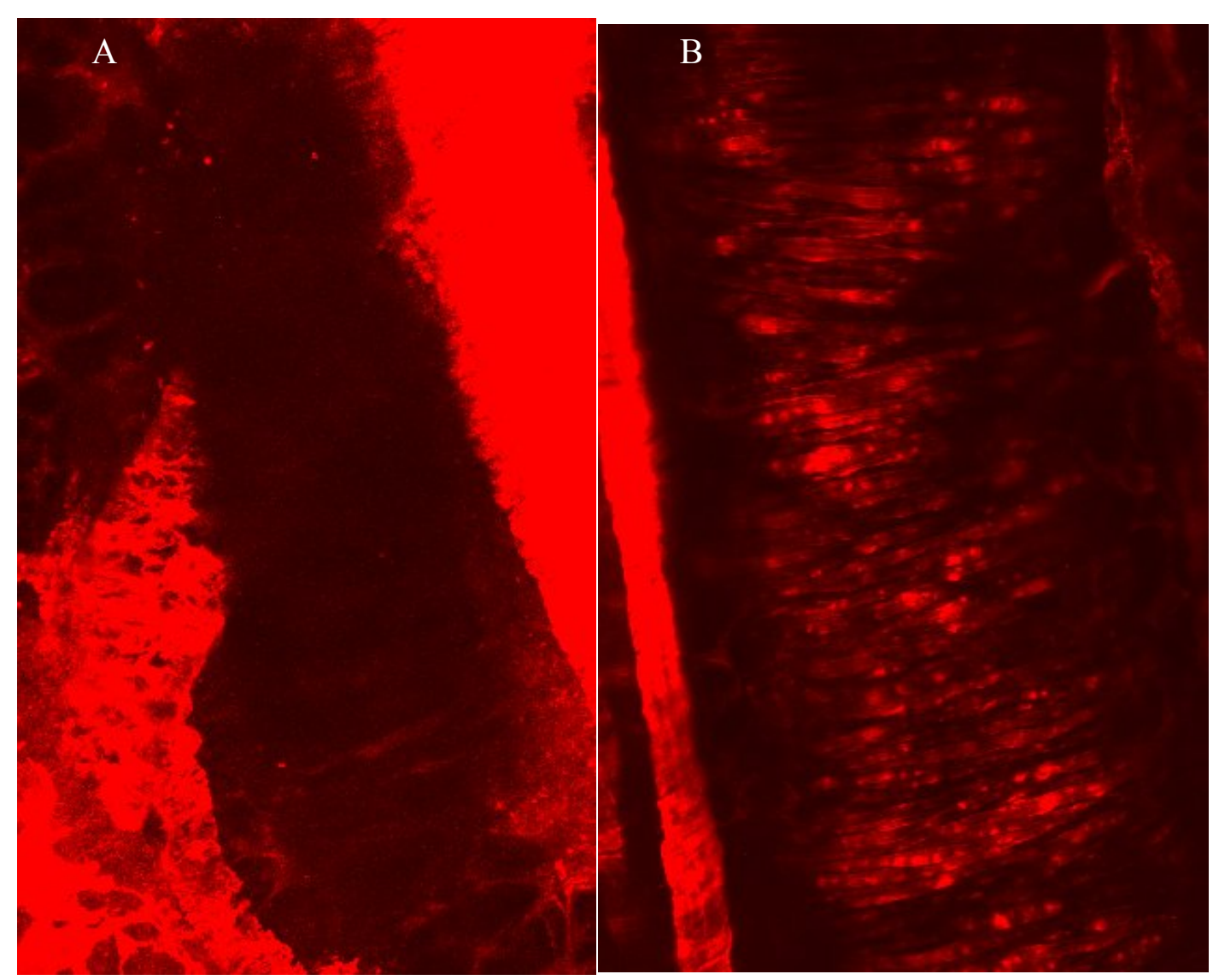

N=5 A) Profunda Femoris Artery Day-7 Post-Ligation B) Profunda Femoris Artery Control

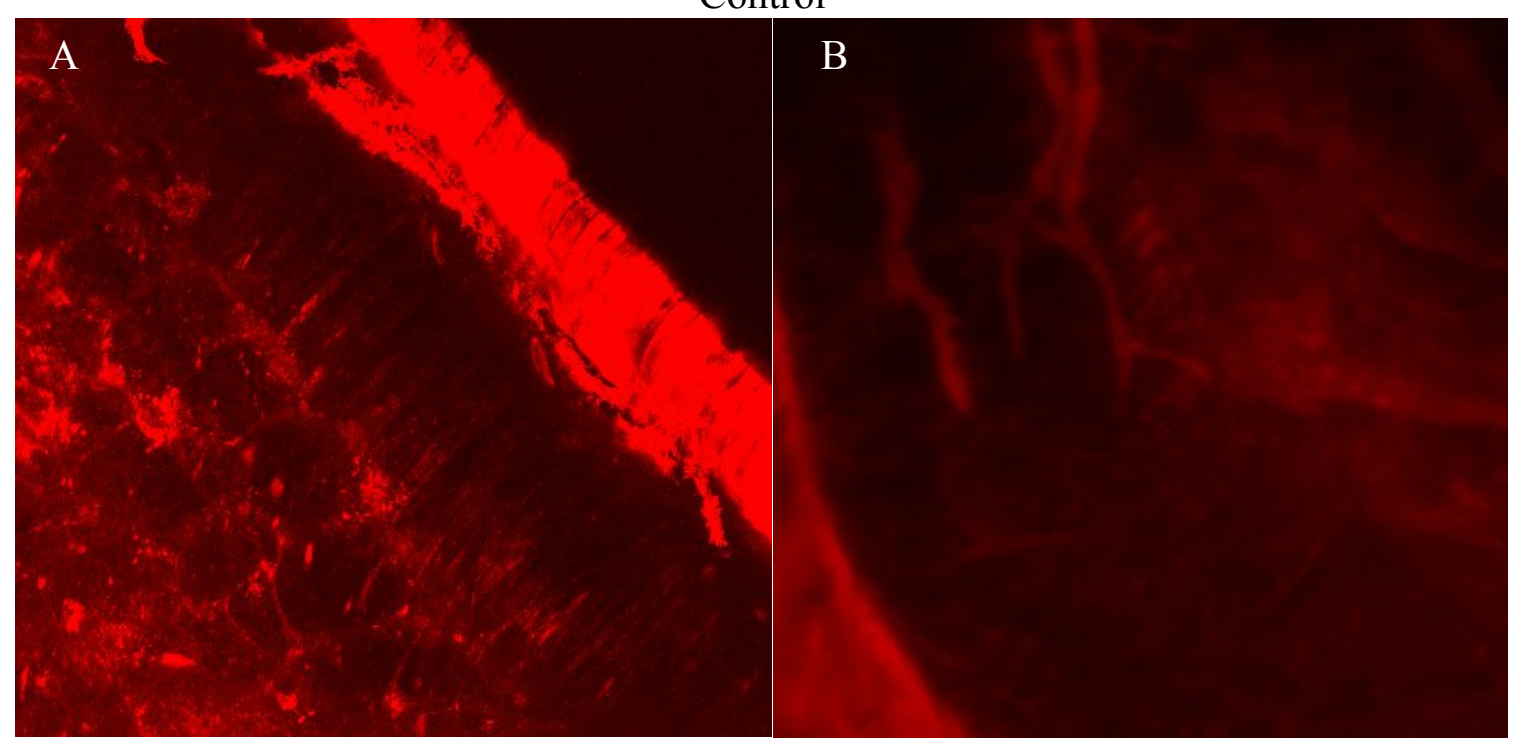

N=6 A) Profunda Femoris Artery Day-7 Post-Ligation B) Profunda Femoris Artery Control (Did not use) 
BALB/C Males:

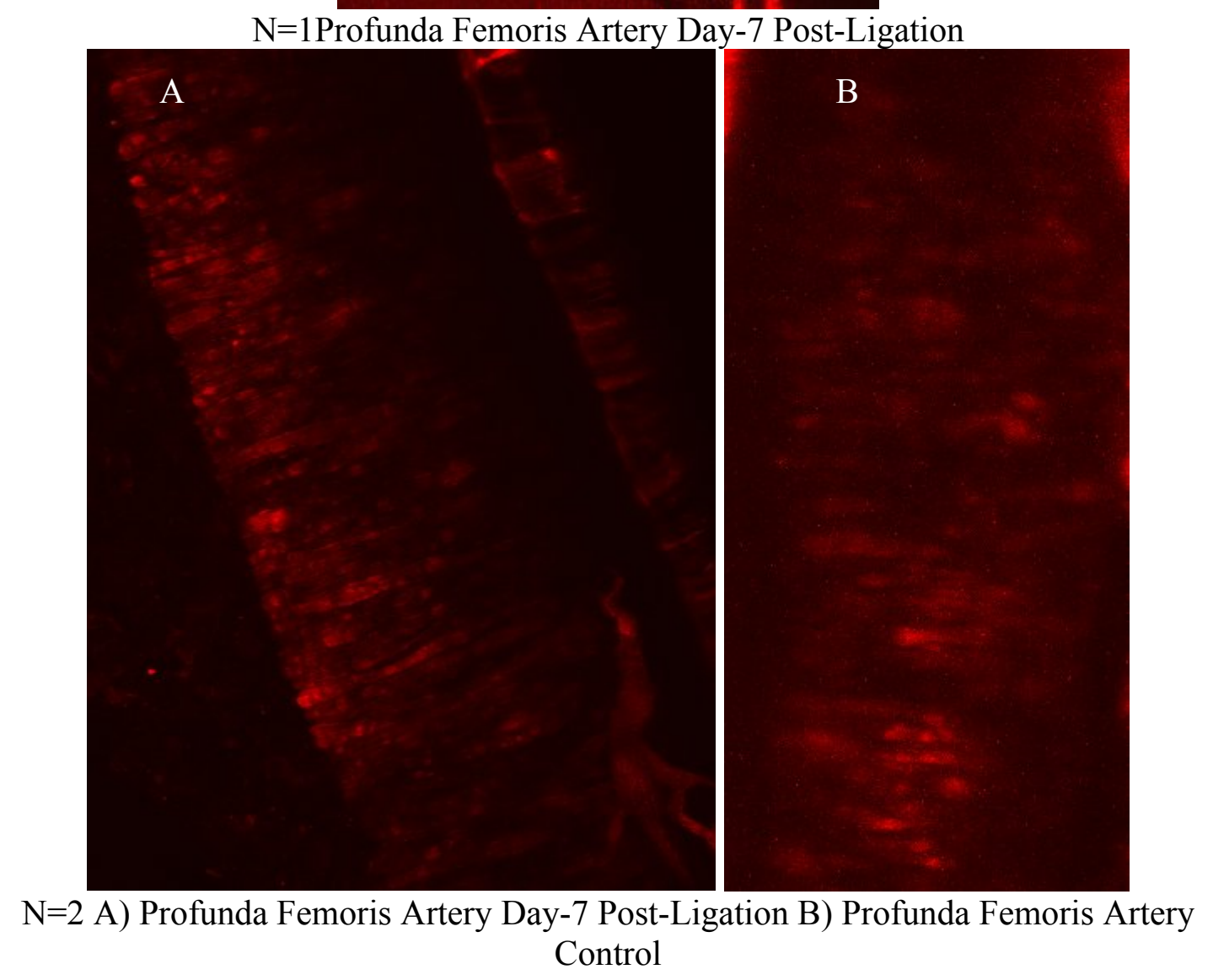




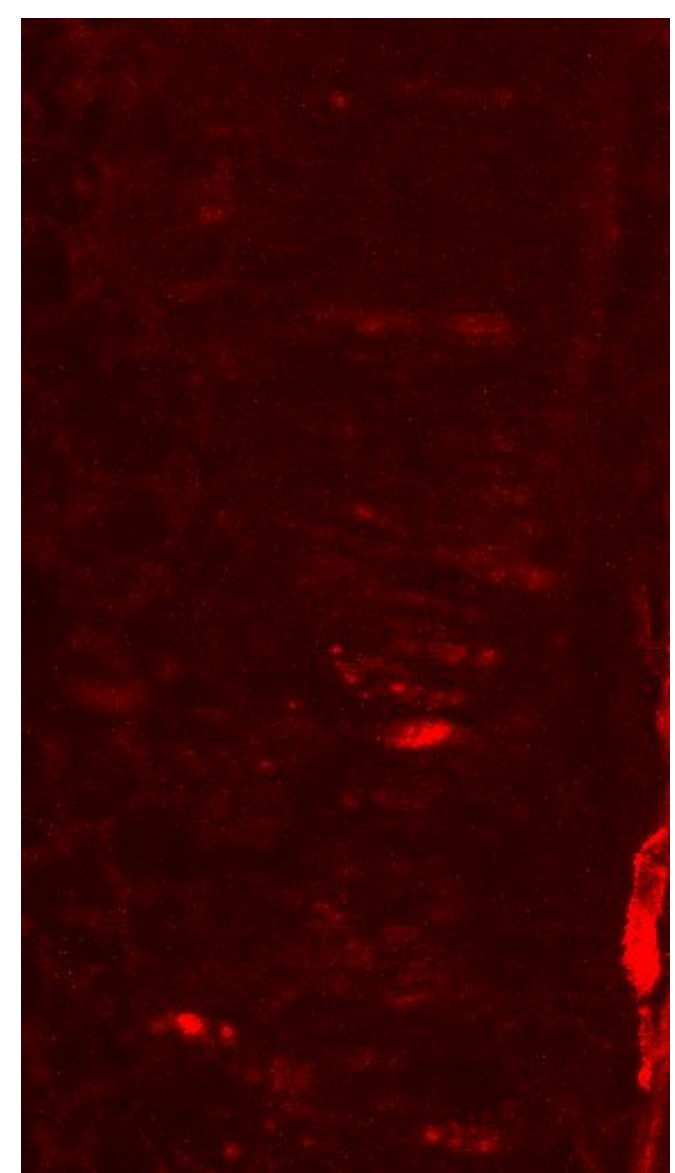

$\mathrm{N}=3$ Profunda Femoris Artery Control

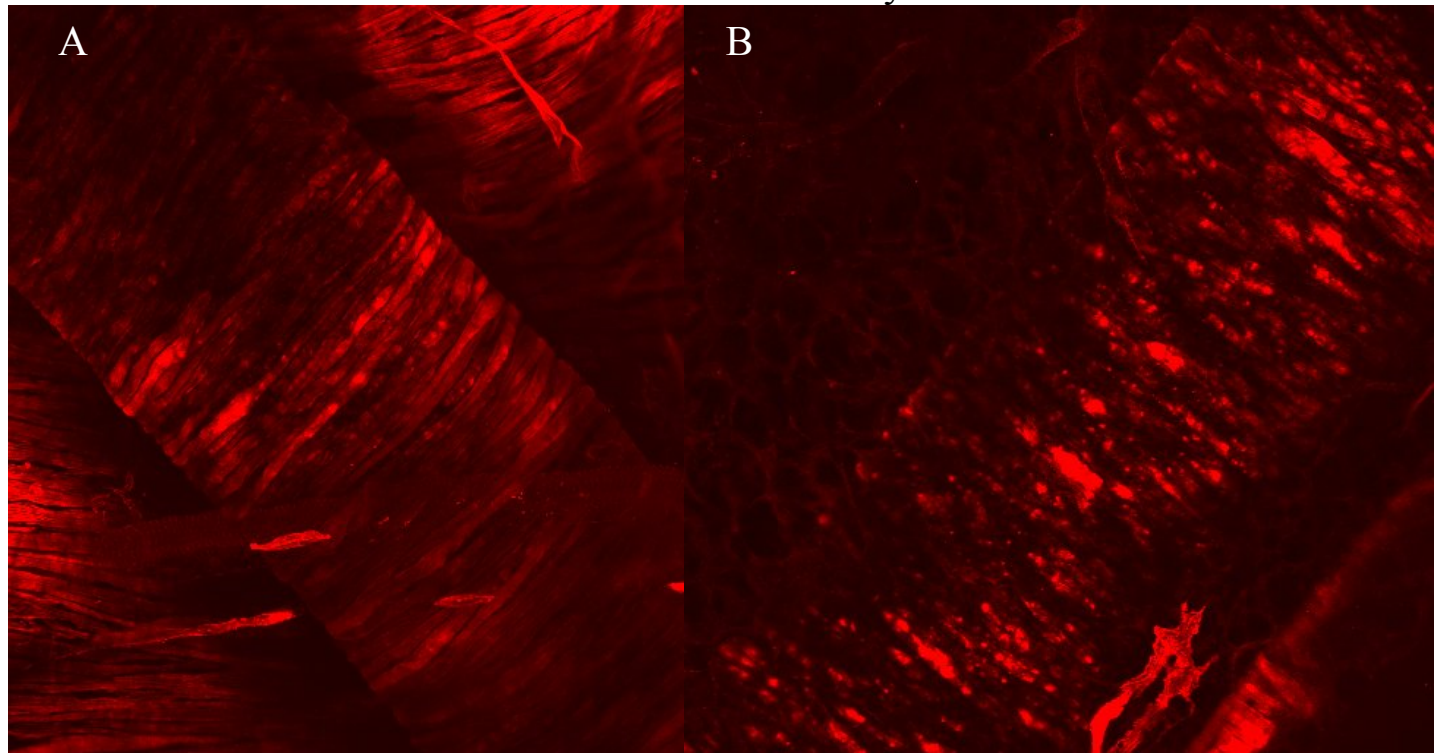

$\mathrm{N}=4$ A) Profunda Femoris Artery Day-7 Post-Ligation B) Profunda Femoris Artery Control 


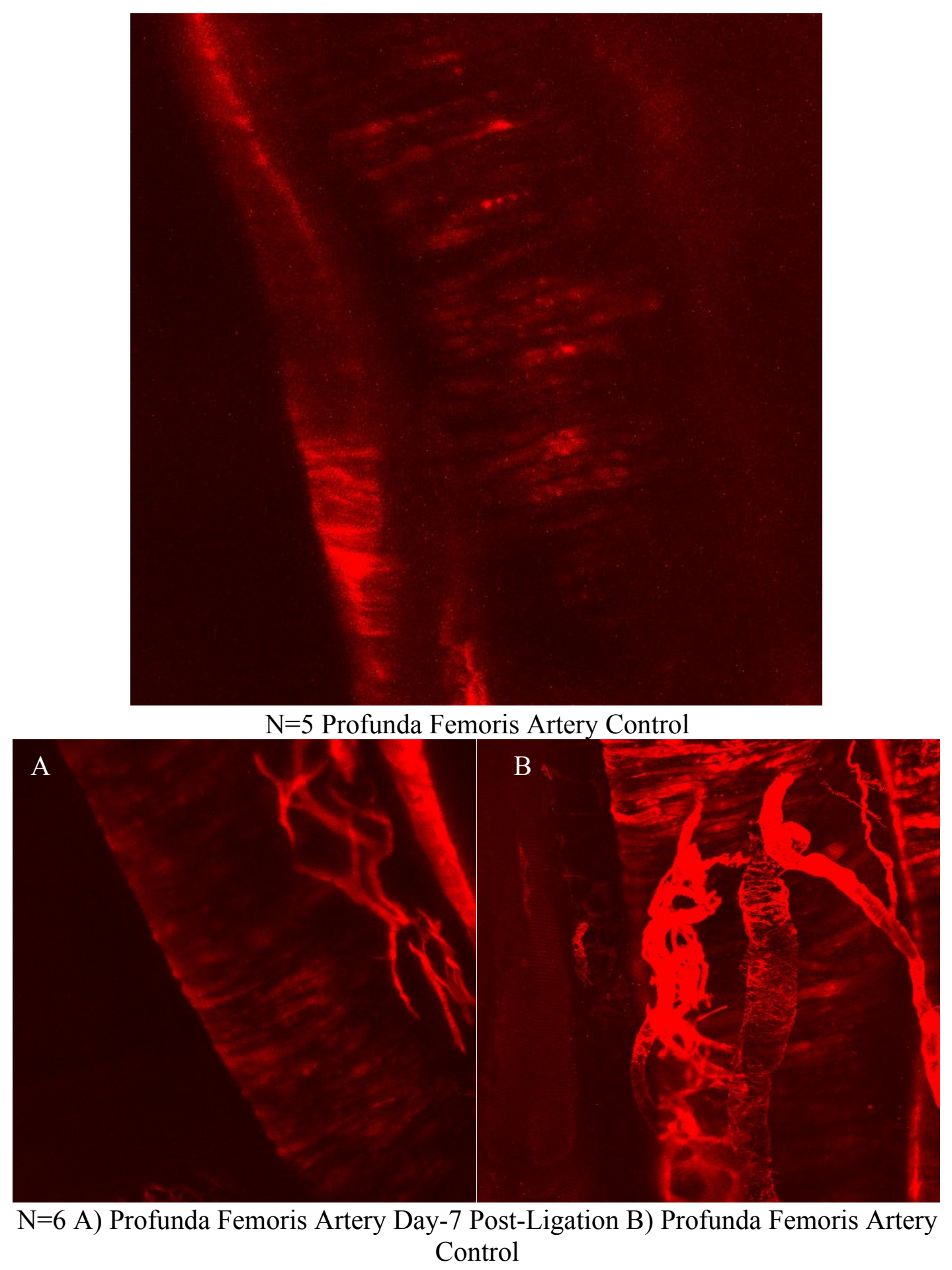




\section{Appendix B: Tables}

Table I. Days to Normal Ambulation Post-Femoral Artery Ligation in C57BI/6 and BALB/c Mice

\begin{tabular}{|c|c|c|c|}
\hline & Sex & $\mathbf{n}$ & Days to Normal Ambulation $\pm \mathrm{SE}$ \\
\hline \multirow{2}{*}{$\mathrm{C} 57 \mathrm{Bl} / 6$} & Males & 13 & $3.9 \pm 0.4$ \\
\hline & Females & 13 & $3.9 \pm 0.4$ \\
\hline \multirow{2}{*}{$B A L B / c$} & Males & 6 & $5.8 \pm 0.2$ \\
\hline & Females & 6 & $6.0 \pm 0.0$ \\
\hline
\end{tabular}

Table II. Daily Ambulation Scoring in C57BI/6 and BALB/c Mice

\begin{tabular}{|c|c|c|c|c|c|c|c|c|}
\hline & Sex & $\mathbf{n}$ & $\begin{array}{c}\text { Day } 1 \text { Post- } \\
\text { Ligation } \pm \\
\text { SE }\end{array}$ & $\begin{array}{c}\text { Day } 2 \text { Post- } \\
\text { Ligation } \\
\pm \mathrm{SE}\end{array}$ & $\begin{array}{c}\text { Day } 3 \text { Post- } \\
\text { Ligation } \\
\pm \mathrm{SE} \\
\end{array}$ & $\begin{array}{c}\text { Day } 4 \text { Post- } \\
\text { Ligation } \\
\pm \mathrm{SE}\end{array}$ & $\begin{array}{c}\text { Day } 5 \text { Post- } \\
\text { Ligation } \\
\pm \text { SE }\end{array}$ & $\begin{array}{c}\text { Day } 6 \text { Post- } \\
\text { Ligation } \\
\pm \mathrm{SE}\end{array}$ \\
\hline \multirow{2}{*}{$C 57 B l / 6$} & Males & 13 & $1.6 \pm 0.2$ & $0.8 \pm 0.1$ & $0.5 \pm 0.2$ & $0.4 \pm 0.2$ & $0.3 \pm 0.1$ & $0.0 \pm 0.0$ \\
\hline & Females & 13 & $1.4 \pm 0.2$ & $1.0 \pm 0$ & $0.1 \pm 0.1$ & $0.1 \pm 0.1$ & $0.0 \pm 0.0$ & $0.3 \pm 0.2$ \\
\hline \multirow{2}{*}{$B A L B / c$} & Males & 6 & $3.0 \pm 0$ & $2.0 \pm 0.0$ & $2.4 \pm 0.2$ & $1.8 \pm 0.3$ & $1.7 \pm 0.3$ & $1.0 \pm 0.3$ \\
\hline & Females & 6 & $2.8 \pm 0.2$ & $1.8 \pm 0.4$ & $2.3 \pm 0.2$ & $1.7 \pm 0.2$ & $1.3 \pm 0.2$ & $1.7 \pm 0.2$ \\
\hline
\end{tabular}

Table III. Indicators of Mechanoadaptation in C57BI/6 and BALB/c Mice

\begin{tabular}{|c|c|c|c|c|c|}
\hline & Sex & Limb & $\mathbf{n}$ & $\begin{array}{c}\text { VSMC Length }(\mu \mathrm{m}) \\
\pm \mathrm{SE}\end{array}$ & $\begin{array}{c}\text { Overlap }(\mu \mathrm{m}) \\
\pm \mathrm{SE}\end{array}$ \\
\hline \multirow{4}{*}{$\mathrm{C} 57 \mathrm{Bl} / 6$} & \multirow{2}{*}{ Males } & $\begin{array}{c}\text { Day-7 } \\
\text { Post-Ligation }\end{array}$ & 6 & $329 \pm 19$ & $19 \pm 2$ \\
\hline & & Control & 7 & $273 \pm 15$ & $27 \pm 2$ \\
\hline & \multirow{2}{*}{ Females } & $\begin{array}{c}\text { Day-7 } \\
\text { Post-Ligation }\end{array}$ & 8 & $288 \pm 13$ & $16 \pm 1$ \\
\hline & & Control & 7 & $235 \pm 19$ & $26 \pm 2$ \\
\hline \multirow{4}{*}{$B A L B / c$} & \multirow{2}{*}{ Males } & $\begin{array}{c}\text { Day-7 } \\
\text { Post-Ligation }\end{array}$ & 4 & $325 \pm 9$ & $24 \pm 2$ \\
\hline & & Control & 5 & $280 \pm 10$ & $29 \pm 1$ \\
\hline & \multirow{2}{*}{ Females } & $\begin{array}{c}\text { Day-7 } \\
\text { Post-Ligation }\end{array}$ & 4 & $327 \pm 10$ & $22 \pm 2$ \\
\hline & & Control & 5 & $297 \pm 11$ & $35 \pm 2$ \\
\hline
\end{tabular}


Table IV. Anterior Gracilis Collateral Remodeling in C57BI/6 and BALB/c Mice.

\begin{tabular}{|c|c|c|c|c|c|c|}
\hline & Sex & Limb & $\mathbf{n}$ & $\begin{array}{c}\text { Outer Diameter } \\
(\mu \mathrm{m}) \\
\pm \mathrm{SE}\end{array}$ & $\begin{array}{c}\text { Inner Diameter } \\
(\mu \mathrm{m}) \\
\pm \mathrm{SE}\end{array}$ & $\begin{array}{c}\text { Wall Thickness } \\
(\mu \mathrm{m}) \\
\pm \mathrm{SE}\end{array}$ \\
\hline \multirow{4}{*}{$\mathrm{C} 57 \mathrm{Bl} / 6$} & \multirow{2}{*}{ Males } & $\begin{array}{c}\text { Day-7 } \\
\text { Post-Ligation }\end{array}$ & 4 & $93 \pm 9$ & $70 \pm 7$ & $12 \pm 1$ \\
\hline & & Control & 5 & $50 \pm 5$ & $38 \pm 4$ & $6 \pm 1$ \\
\hline & \multirow{2}{*}{ Females } & $\begin{array}{c}\text { Day-7 } \\
\text { Post-Ligation }\end{array}$ & 4 & $95 \pm 12$ & $62 \pm 7$ & $17 \pm 6$ \\
\hline & & Control & 5 & $46 \pm 5$ & $29 \pm 3$ & $8 \pm 1$ \\
\hline \multirow{4}{*}{$B A L B / c$} & \multirow{2}{*}{ Males } & $\begin{array}{c}\text { Day-7 } \\
\text { Post-Ligation }\end{array}$ & 6 & $103 \pm 9$ & $67 \pm 7$ & $18 \pm 2$ \\
\hline & & Control & 6 & $50 \pm 7$ & $37 \pm 4$ & $7 \pm 3$ \\
\hline & \multirow{2}{*}{ Females } & $\begin{array}{c}\text { Day-7 } \\
\text { Post-Ligation }\end{array}$ & 6 & $100 \pm 7$ & $70 \pm 6$ & $17 \pm 1$ \\
\hline & & Control & 5 & $46 \pm 3$ & $35 \pm 3$ & $6 \pm 1$ \\
\hline
\end{tabular}




\section{Appendix C: Femoral Artery Ligation Protocol}

Date

Mouse Information

DOB:

Sex:

Tag:

Genotype/strain:

Cage:

Materials

Sterilize- autoclave or flash autoclave

1. forceps (2)

fine forceps (2)

ultrafine forceps (1)

fine scissors (1)

microscissors spring loaded (1)

Pre-sterilize in autoclave

$\begin{array}{ll}\text { 6. } & \text { cotton gauze (2) } \\ \text { 7. } & \text { cotton swabs (12) } \\ \text { 8. } & 6.0 \text { silk suture }(2 \times 1 \text {-inch) } \\ \text { 9. } & \text { needle holder (1) }\end{array}$

Obtained in surgery suite

10. sterile Petri dish w/ sterile saline

11. sterile gloves

12. sterile 7.0 prolene suture

13. heat-cautery

14. FST heat pad w/ rectal probe

15. heat pad

16. recovery bin \& weigh boat

17. depilatory cream

18. non-sterile cotton swabs

19. non-sterile cotton gauze

20. isolation mask \& cap

21. analgesic (Buprenorphine)

\section{Surgery preparation}

22. Spray surgery area with Nolvasan

23. Weigh animal in weight boat

24. Place animal in anesthesia box

25. Open the oxygen cylinder and set anesthesia-machine flow meter to $\sim 31 \cdot \mathrm{min}^{-1}$

26. Anesthetize animal w/ $5 \%$ isoflurane

27. Affix non-rebreathing circuit to bench-top with tape

28. Reduce flow rate to $0.5-1.01 \mathrm{~min}^{-1}$ and the isoflurane to $1-3 \%$

29. Apply ear tag high on left ear

30. Lay animal supine with nose in nose-cone

31. Shave hair on the right hindlimb \& lower abdomen with clippers

32. Remove excess hair with depilatory cream

33. Spray right hindlimb with Nolvagan

34. Return animal to anesthesia box
Initials

35. Apply $4 \times 4$ gauze sponge to heat pad to protect animal from excessive heat

36. Affix non-rebreathing circuit to surgery table w/ chemistry clamp

37. Lay animal supine on circulating heat pad $\mathrm{w} /$ nose in nose-cone

38. Insert rectal probe and set thermo-controller to $37^{\circ} \mathrm{C}$

39. Apply veterinary ointment to eyes to avoid drying during procedure

40. Apply veterinary ointment to anus and place rectal probe $\sim \mathrm{lcm}$ into anus to monitor corebody temperature

Surgery

41. Make a small incision on the middle, medial aspect of the left thigh

42. Extend the incision up to the abdominal wall

43. Blunt dissect the subcutaneous connective tissue to maximize surgical exposure

44. Use cautery to remove fat pad overlying femoral a-v pair \& cauterize epigastric axpair

45. Blunt dissect the femoral artery from the neurovascular bundle just downstream from the deep femoral branch

46. Tie off the femoral artery \& vein with 6.0 silk suture, just downstream to the deep femoral branch

47. Use 6.0 polypropylene suture to close the skin

48. Make a small incision on the middle, medial aspect of the right thing

49. Extend the incision up to the abdominal wall

50. Blunt dissect the subcutaneous connective tissue to maximize surgical exposure

51. Use 6.0 polypropylene suture to close the skin

Post-Surgical

52. Give the animal an subcutaneous injection of buprenorphine $(0.075 \mathrm{mg} / \mathrm{kg})$

53. Place the animal in the recovery bin, on a blue bench cover, above a heat pad and allow to recover

54. Tum flow meter down to 0 , turn off isoflurane, and cloge the oxygen cylinder

55. Indicate surgery on cage card

Notes 


\section{Appendix D: Perfusion Fixation Protocol}

Date

\section{Mouse Information}

DOB:

Sex:

Tag:

Genotype/strain:

Cage:

Weight(g):

\section{Materials}

Non-Sterilize Dissection Instruments

1. Forceps (1)

2. Fine forceps (2)

3. Bone scissors (1)

4. Curved Iris scissors (1)

5. Microdissection scissors (1)

6. Vascular clamp (1)

7. Castroviejos

Obtained in surgery suite

8. Tape

9. $20 \mathrm{~mL}$ syringes (2)

10. $5 \mathrm{~mL}$ syringe (1)

11. Syringe pump

12. Petri-dish

13. Bench cover

14. Depilatory cream

15. Clippers

16. Veterinary ointment

17. Heating pad

18. Catheter

19. Non-sterile saline

20. Cotton swabs

21. Gauze sponges

22. Saran wrap

\section{Vasodilator Cocktail Preparation}

23. Turn on water bath to $37^{\circ} \mathrm{C}$

24. $400 \mu \mathrm{L}$ heparin

25. $1 \mathrm{~mL} \mathrm{SNP(orange)}$

26. $600 \mu \mathrm{L}$ Adenosine(clear)

27. $38 \mathrm{~mL}$ PBS solution

28. $5 \mathrm{~mL} \mathrm{4 \%} \mathrm{Paraformaldehyde} \mathrm{(PFA)}$

29. Thaw SNP, Adenosine and PFA

30. Add heparin, SNP, Adenosine, and PBS solution together in a $50 \mathrm{~mL}$ conical

31. Place vasodilator cocktail in water bath

\section{Procedure Preparation}

32. Obtain saline filled petri-dish, cotton swab, and instruments
Perfusion Fixation

Initials

Fixation

33. Remove hair on both legs by shaving \& depilation

34. Tape animal in supine position to $4 \mathrm{X} 4$ gauze sponge over heating pad

35. Expose muscles of interest and blunt dissect to aid in removal post-fixation, then cover with saran wrap

36. Fill $20 \mathrm{~mL}$ syringe with $20 \mathrm{~mL}$ warm Vaso D, load into syringe pump and attach catheter

37. Flow liquid through the catheter to the tip to prevent air from being injected into circulatory system

38. Lift skin from muscle in abdominal region and cut a window over the sternum

39. Lift sternum and cut connective tissue under

40. Use bone scissors in hole to quickly cut through the ribs to the armpit on both sides

41. Clamp sternum with castroviejos and reflect towards mouse's head

42. Cut diaphragm with curved iris scissors to open chest cavity

43. Cut away excess tissue around the heart

44. Make a small incision in the apex of the heart

45. Insert catheter and clamp with vascular clamp and cut right atrium

46. Inject Vaso D solution into animal approximately $20 \mathrm{~mL} \mathrm{X} 2(5 \mathrm{~mL} / \mathrm{min})$, soaking up excess blood and fluids with gauze sponges

47. Inject $5 \mathrm{~mL} \mathrm{PFA} \mathrm{(} 4 \mathrm{~mL} / \mathrm{min})$

48. Dissect out muscles of interest using fine forceps and microdissection scissors

49. Turn off water bath, cover scope, turn off oxygen, turn off isofluorane, and clean instruments

Notes 


\section{Microfil casting and dissection protocol}

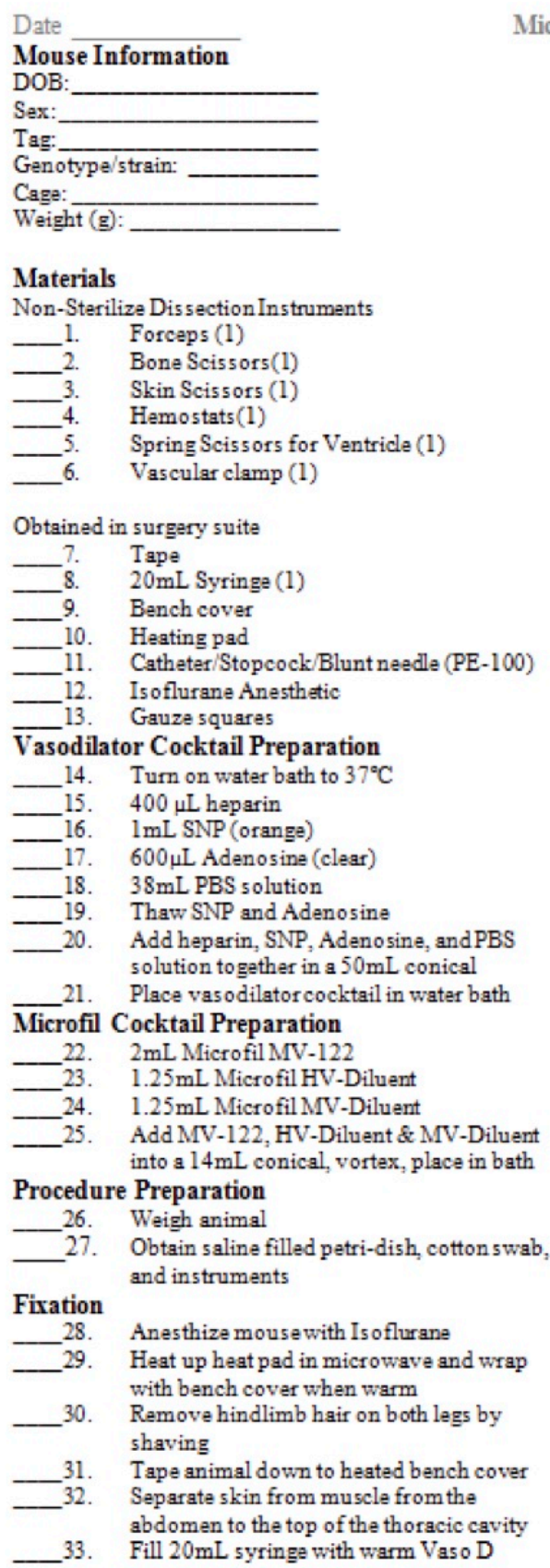

Initials

34. Cut through abdomen close to diaphragm

35. Quickly cut through the ribs and diaphragm to open chest cavity and clamp back with hemostats

36. Cut away excess tis sue around the heart

37. Make a small incision in the apex of the heart

38. Insert catheter and clamp with vascular clamp and cut right atria

39. Inject Vaso D solution into animal approximately $20 \mathrm{~mL}$ at $5 \mathrm{~mL} / \min \times 2$

40. Add $2 \mathrm{~mL}$ of curing agent to Microfil

41. Inject $1 \mathrm{~mL}$ of Microfil Cocktail (.5mL/min)

42. Pause microfilm and ligate both ankles with sill suture once Microfil has passed the knee. Resume Microfil.

43. Repeat step 41 until satis fied with fill.

44. Remove mouse from heat pad and take out catheter (keep heart clamped)

45. Place mouse in bag (cover open wounds with saran wrap) and let sit overnight at room temp

46. Cover scope, turn off water bath, turn off oxygen, turn off Is oflurane, clean instruments

Dissection Date:

Non-Sterilized Dis section Instruments

47. Fine Forceps (2)

-48. Forceps (1)

49. Iris Scissors (1)

50. Dissection scissors (1)

Obtained in surgery suite

51. Non-sterile saline

52. Cotton swab

53. Bench cover

-54. Tape

55. Petri Dishes (2)

56. Cover Slips (2)

57. Disposable pipettes (1)

58. $25 \%$ ethanol

59. Dis sect chosen muscles and place on cover slip and then in labeled petri dish of $25 \%$ ethanol

60. Cover scope and clean instruments

Notes:

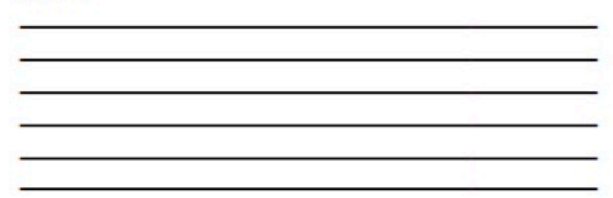




\section{Appendix F: ASMA Staining Protocol}

\section{Materials}

24-well culture plates (Cat\#: 3738, Corning Incorporated) PBS

$0.1 \%$ Saponin (Cat\#: 47036, Sigma-Aldrich)

2\% Bovine Serum Albumin (Cat\# B6917, Sigma Aldrich)

Monoclonal Anti-Alpha Smooth Muscle Actin, Cy3 Conjugate (Cat\#: C6198, Sigma-Aldrich)

Slides

Coverslips

Parafilm

Aluminum foil

\section{Staining}

1. Using forceps, remove muscle from PBS (stored in microcentrifuge tube at $4^{\circ} \mathrm{C}$ ) and place in a single well of a 24-well culture plate.

2. Prepare antibody solution containing 1:200 1A4 clone (alpha-smooth muscle actin, $\mathrm{Cy} 3$ conjugate) in $0.1 \%$ saponin (reconstituted in PBS), $2 \%$ BSA (reconstituted in PBS) in PBS, using $0.3 \mathrm{~mL}$ of solution per muscle.

3. Incubate muscle in antibody solution for 3 nights ( 72 hours) at $4^{\circ} \mathrm{C}$ ). (Note: Critical step-3 nights crucial for bright staining) by gently pipetting solution over muscle.)

4. Wash in $0.1 \%$ saponin in PBS $3 \mathrm{x}$ for 20 minutes at room temperature. Cover plate with foil during each wash.

5. Wash in plain PBS for 30 minutes. Cover with foil during each wash.

6. Place 1-2 drops of 50/50 PBS and Glycerol onto slide.

7. Remove muscle from well using forceps and place on a slide.

8. Add 1-2 drops of 50/50 PBS and Glycerol to the top of the muscle and place cover slips over the muscle.

9. Paint edges of coverslip with clear nail polish to create a seal and prevent tissue desiccation.

10. Store slides at $4^{\circ} \mathrm{C}$ wrapped in foil or an opaque container between imaging.

\section{Imaging}

11. Image using a standard fluorescent microscope. (Cy3 excitation: $550 \mathrm{~nm}$, emission: $570 \mathrm{~nm}$ ) 


\section{Appendix G: Confocal Protocol}

Date

Initials

Materials

1. Depression slide

2. Coverglass (.08-.13mm thick)

3. Clear nail polish

4. 50/50 PBS-glycerol

5. Slide box

6. Forceps (1)

\section{Slide Preparation}

7. Using forceps, gently place the sample into the well on the depression slide with the anterior of the sample facing up

8. Drop 50/50 glycerol onto the sample

9. Place ceverglass on top of sample and use nail polish to seal the edges

\section{Confocal Microscope Setup and Imaging}

10. Turn on the confocal microscope by switching the seven power buttons starting from top to bottom going from left to right (at the one with the keys, wait for the steady green light to move on)

11. Log into the log book

12. Log on to computer: password: fluoxiew

13. Open Eluoxiexx Program

14. Choose "Load Acquisition" to pull up parameters of an old file

15. Place a single drop of oil onto the $40 \mathrm{x}$ objective (this will be the viewing objective)

16. Turn off the light before removing sample from slide box

17. Place the sample onto the stage with the coverslip facing downward, toward the objective

18. Carefully bring the objective closer to the sample using the coarse adjustment until the slide contacts the oil

19. Open the shutter on the tube as well as the stage to let the fluorescent light in

20. Turn on the fluorescent light via the icon on the program that has a diamond on top of a circle

21. Locate the desired location of the vessel for imaging through the eye piece using the coarse and fine objective adjustments located on the bottom of the microscope near to the left and right of the stage

22. Press XY Repeat on Fluoview program to bring image onto computer

23. Adjust the power (do not increase the power above 20) to see the clearest image of the sample, making sure that image is not saturated

24. Find the top of the vessel by altering the Z-plane, moving the fine adjustment clockwise to move to the surface of the sample and counterclockwise to go deeper into the sample

25. Once the top is determined, click the "Set" button on the bottom left of the program

26. Next find the end of the Z-stack desired by going deeper into the vessel and set this as the end point

27. Set the step size to $1 \mu \mathrm{m}$

28. Click the Z-stack "XYZ" button to take the Z-stack

29. Save the file as an oib onto the computer and export it as a tiff

\section{Microscope Clean Up}

30. Turn off the microscope in the opposite way it was turned on, from right to left, bottom to top

31. Make sure to close the shutters

32. Log out in the log book

33. Fold a lens sheet and drip isopropyl alcohol (IPA) onto it then make a single swipe over the objective to clean the oil from it, repeat until the lens is clear using several lens sheets, use a cotton tip applicator with IPA to clean the area around the lens on the objective

34. Cover confocal microscope

Notes 


\section{Appendix H: Inadequate Methods}

There were several methods that did provide an adequate assessment of the data. These methods are outlined below, along with suggestions for possible mitigation of challenges.

\section{Transilluminator}

To attempt to visualize the red blood cell column to measure inner diameter in the gracilis collateral midzone, a transilluminator was used. A transilluminator is a waterresistant probe with a light at the distal end designed to fit behind the dissected anterior gracilis in vivo. The light was placed directly behind the collateral midzone, and images were captured utilizing an Olympic BXFM intravital microscope. However, the method did not provide images with clearly discernable red blood cell columns, so inner diameter measurements were not successfully recorded. Possible reasons for failure are depth of vessels resulting in challenging focusing for microscope, or incorrect microscope settings. Suggestions for possible mitigation include adjustment of light settings or location of probe to result in clearer images, adjustment of imaging variables to result in clearer images, removal of tissue overlying gracilis muscle, and adjustment of postprocessing of images. A sample image is seen below.

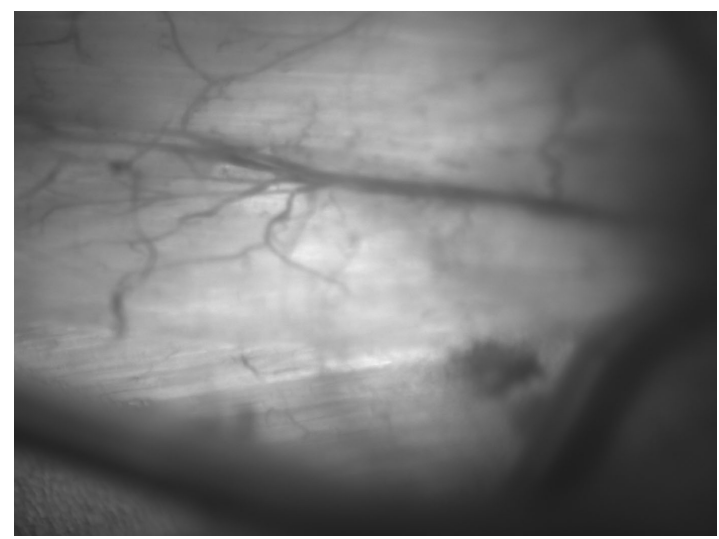

In vivo gracilis collateral midzone visualization utilizing transilluminator.

\section{Endothelial Lectin Stain}

To attempt to visualize endothelial cells to measure inner diameter in the gracilis collateral midzone, a lectin stain was used. Lectin specifically binds to glycoproteins located in the basal membrane of endothelial cells [91], and can be visualized using widefield fluorescent microscopy. This protocol can be seen in Appendix I. In addition to the recommended incubation time and concentration in the protocol, I also performed 1:40 4 hour, 1:20 2 hour, 1:20 4 hour, and 1:20 overnight incubation. However, upon imaging there was only nonspecific activation of cells, not allowing clear visualization of the endothelium. As lectin depends on diffusion through tissue, it is possible that the gracilis collateral is too deep in the anterior gracilis muscle for the molecule to bind to the endothelium. Suggestions for possible mitigation include adjustment of antibody 
concentrations, incubation times, and permeabilizing agents to allow for binding to the collateral endothelium, adjustment of widefield fluorescent filters, and adjustment of post-processing of images. A sample image of a lectin stained image overlaid to an alphasmooth muscle actin image is seen below, with no clear visualization of the endothelium.

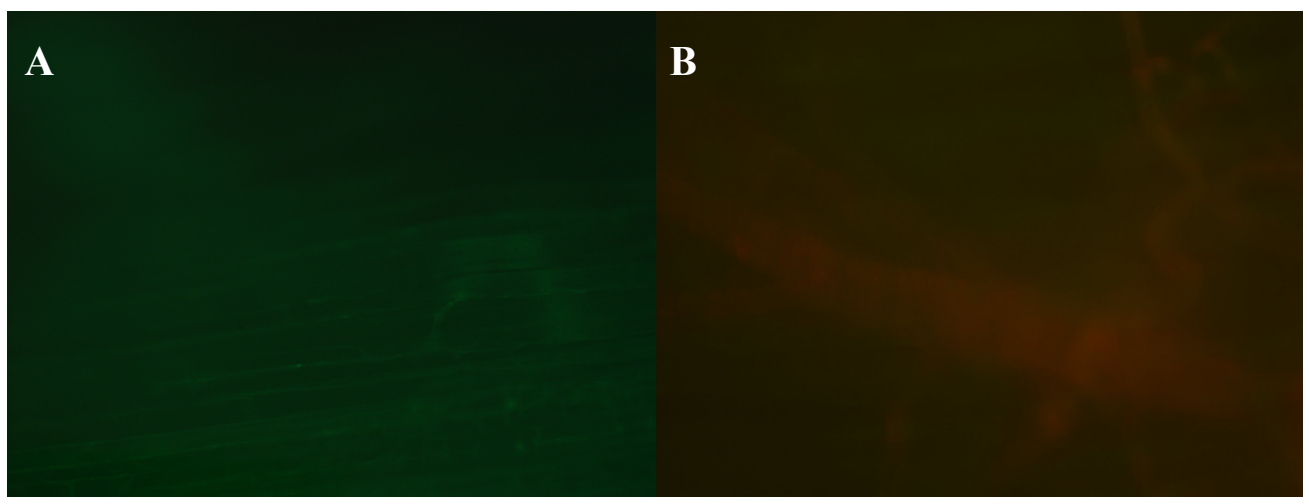

Lectin stain. (A) Lectin positive image of 1:20 dilution incubated for 4 hours. (B) Lectin positive image (green) overlaid with alpha-smooth muscle actin positive (red).

\section{Evans Blue Dye}

To visualize inner diameter of the gracilis collateral midzone, Evans Blue Dye was utilized. Evan's blue dye binds to serum albumin, resulting in luminal staining of vessels, allowing visualization upon microscopy [92]. It is injected into the ventral artery in the tail. However, upon intravital microscopy using a transilluminator, clear visualization of the inner diameter was not obtained. This may be due to diffusion of the dye to other tissues, as the myofibers also turned blue, as well as challenges previously discussed with transillumination. Potential mitigation includes adjustment of transillumination technique, concentration of dye or volume injected, a different method of injection such as intracardiac following perfusion fixation, adjustment of widefield microscopy brightlight settings, or adjustment of post-processing of images.

\section{Estrous Cycle Determination}

To assign where a female mouse was in the murine estrous cycle on day-7 post ligation, vaginal visualization was utilized, as outlined in a prior study [93]. Images were captured using a hand-held digital camera of the vaginal area, and then compared to the reference images in the publication. However, as there were no personnel in the lab trained in this subjective method, there was no way to confirm the correct assignment of the estrous cycle. To mitigate this moving forward, collaboration with the group who created this method would be ideal to ensure proper training and success in assignment.

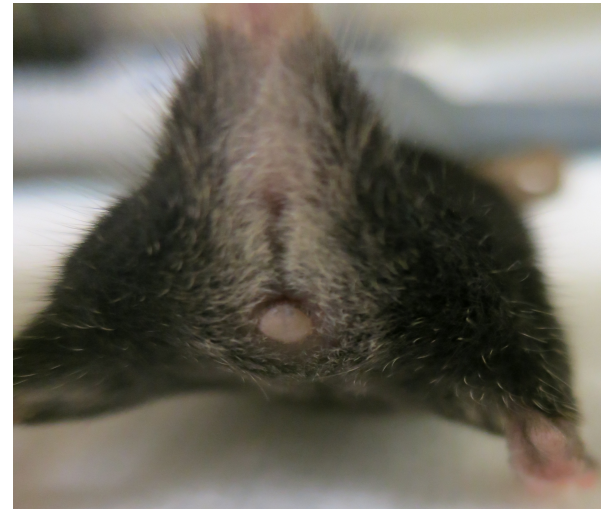

Example image for vaginal visualization. 


\section{Length Density and Volume Fraction}

To determine vessel density in the anterior gracilis muscle along the stem, midzone and reentry portions, length density and volume fraction calculations were utilized following alpha-smooth muscle actin staining as described in Appendix I, and imaged using widefield microscopy. Images were taken at the stem, midzone, and reentry regions of the vessel and imported into Rapid Analysis of Vessel Elements (RAVE) software. Length density is a measure of total arteriole length per unit area of tissue, and volume fraction represents the total length of all vessels divided by total pixel area, with the method outlined in a prior publication [94]. However, because images were not in focus all the way through the depth of collateral location in the muscle, it was difficult to use the software to assign a correct binary to distinguish between vascular and muscular tissue. As the images were taken on the widefield microscope, utilization of the confocal microscope and creation of a z-stack would be ideal for the uniform focus of the vessels necessary for RAVE software utilization.

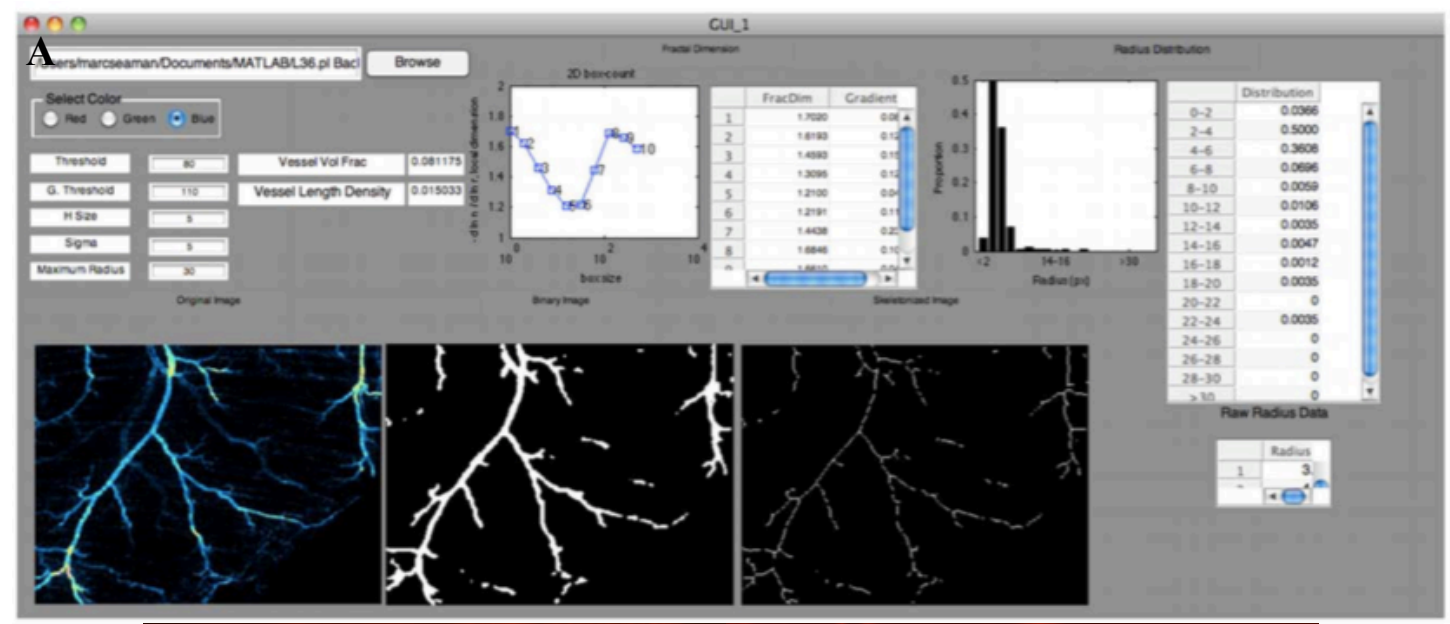

B $\quad$ C

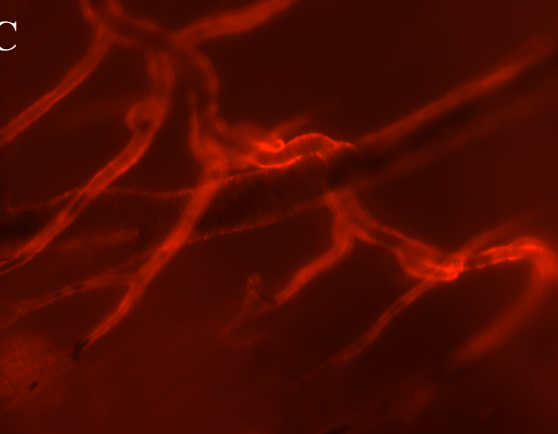

Vessel Density Measurement. (A) Rapid Analysis of Vessel Elements (RAVE) Software GUI. (B,C) Representative alpha-smooth muscle actin positive images that were uploaded for assessment. 


\section{Appendix I: Lectin Stain Protocol}

\section{Staining Protocol for White Gastroc Specimens (Laughlin Work)}

\section{Tissue Harvesting:}

1. Pin-out the desired Gastroc half onto $60 \times 15 \mathrm{~mm}$ pertri dish filled with SLYGARD (silicone elastomer).

2. Immerse tissue in $4 \%$ P-form in PBS for 3 hours in the fridge. Drop petri dish into $150 \mathrm{ml}$ beaker. Add enough P-form solution to ensure immersion of specimen.

3. Un pin specimen and wash with PBS for 30 minutes on rotating plate. Replace the PBS solution every 10-15 minutes. For all washes muscle specimens were placed in a small $10 \mathrm{ml}$ beaker or petri dish.

4. Cut of red section, leaving only the white section.

5. Store white section in PBS/Glycerol overnight. This step mimics the storage/shipping process of the harvested muscles.

\section{Tissue Staining (upon arrival of specimens):}

1. Place each muscle specimen in an individual $10 \mathrm{ml}$ beaker or glass petri dish and wash with PBS for 30 minutes on rotating plate. Replace the PBS solution every 1015 minutes.

2. Incubate white portion in $3 \mathrm{mg} / \mathrm{ml}$ type I collagenase in PBS for 30 minutes. Place muscle specimen in $10 \mathrm{ml}$ beaker and add approximately $2 \mathrm{ml}$ of collagenase solution.

3. Wash with $0.1 \%$ saponin in PBS for 30 minutes on rotating plate. Again, place each muscle specimen in an individual $10 \mathrm{ml}$ beaker or glass petri dish. Replace the $0.1 \%$ saponin in PBS solution every 10-15 minutes.

4. Incubate in 1:200 1A4-CY3 in $0.1 \%$ saponin, $2 \%$ BSA in PBS for 3 nights at $4 \mathrm{deg}$. C. Place muscle specimen in a $10 \mathrm{ml}$ falcon tube. Fill tube with $1.5-2 \mathrm{ml}$ of antibody solution. Ensure that the tissue is immersed in antibody solution.

5. Wash with $0.1 \%$ saponin in PBS for 1 hour on rotating plate. Again, place each muscle specimen in an individual $10 \mathrm{ml}$ beaker or glass petri dish. Replace the $0.1 \%$ saponin in PBS solution every 10-15 minutes.

6. Incubate in 1:20 BSI Lectin FITC in $0.1 \%$ saponin in PBS for 2 hours at $4 \mathrm{deg}$. C. Place muscle specimen in a $10 \mathrm{ml}$ falcon tube. Fill tube with $1.5-2 \mathrm{ml}$ of antibody solution. Ensure that the tissue is immersed in antibody solution.

7. Wash with $0.1 \%$ saponin in PBS for 30 minutes on rotating plate. Again, place each muscle specimen in an individual $10 \mathrm{ml}$ beaker or glass petri dish. Replace the $0.1 \%$ saponin in PBS solution every 10-15 minutes.

8. Store in 50/50 PBS/Glycerol in the freezer. Place muscle specimen in a $10 \mathrm{ml}$ falcon tube. Fill tube with $1.5-2 \mathrm{ml}$ of glycerol solution. Ensure that the tissue is immersed in solution. 